\title{
2 Empirischer Teil
}

\subsection{1 bis 2005 - zweieinhalb Jahrzehnte der Zuwanderung nach Wien}

Zwei grundlegende raumrelevante Tendenzen kennzeichneten die Entwicklung der Zuwanderung nach Wien im Analysezeitraum seit 1981:

- Bestand die Wohnbevölkerung mit Migrationshintergrund 1981 im Wesentlichen noch aus den beiden Gruppen der „klassischen Gastarbeiter“ (Exjugoslawen und Türken), so ist es seitdem zu einer extremen Diversifikation und Heterogenisierung der Immigrantenbevölkerung gekommen, die sich nunmehr aus Zuwanderern aus allen Kontinenten zusammensetzt.

- Das Bewusstsein und die Diskussion um die faktische Existenz ethnischer Segregation und Konzentration hat sich in Wien - zum Unterschied von anderen europäischen Metropolen - erst in den 1990er Jahren herausgebildet. Dies ist vor allem auf das Faktum zurückzuführen, dass ethnische Ghettos im klassischen Sinne nach wie vor fehlen. Wien war trotz Zuwanderung lange Zeit von krassen Segregationsprozessen verschont geblieben. Die Bevölkerung war im Wesentlichen einigermaßen durchmischt.

Die zahlenmäßige Entwicklung der Wohnbevölkerung Wiens war noch in den 1970er Jahren durch Stagnation geprägt. Die Volkszählung 1971 wies eine Bevölkerungszahl von 1,62 Mio. aus. Im Jahr 1981 lebten nur mehr rund 1.528.000 Menschen in der österreichischen Bundeshauptstadt. Szenarien einer quantitativ schrumpfenden, stark überalterten Bevölkerung schienen Anfang der 1980er Jahre realistisch zu sein. Manche Bevölkerungsszenarien prognostizierten sogar einen Rückgang der Wohnbevölkerung in Wien auf 1,2 Mio. nach der Jahrtausendwende. Erst seit 1988 setzte ein deutlicher Umschwung ein, und die Wiener Wohnbevölkerung begann wieder zuzunehmen. Bis 1991 vollzog sich ein Wachstum auf wiederum 1,52 Mio. Einwohner. 2005 hatte Wien 1.651.438 Einwohner, davon waren 309.184 ausländische Staatsbürger (vgl. Abb. 1).

Die Analyse der Entwicklung der ausländischen Wohnbevölkerung dokumentiert, dass der Anteil der Ausländer von bescheidenen 1,45\% im Jahre 1961 auf 7,6\% im Jahr 1981, 13\% 1991 und 18,7\% (2005) angestiegen ist. 1992 hatte sich im Vergleich zu 1980 (110.740) die ausländische Wohnbevölkerung Wiens bereits verdoppelt und betrug 216.875. Besonders stark ausgeprägt war die Zunahme der ausländischen Bevölkerung zwischen 1987 und 1993 (vor allem im Gefolge der Öffnung des Eisernen Vorhanges und einer kurzfristig steigenden Arbeitskräftenachfrage). Ihr Anteil stieg von 7,3\% (1983) auf 14,9\% (1993). Nach einer kurzen Stagnationsphase (1993, 1994), die vor allem auf rigide Zuwanderungsbeschränkungen zurückzuführen war, begannen die Zahl und der Anteil der ausländischen Wohnbevölkerung wiederum anzusteigen. Seit 1997 waren alljährlich Zuwächse zu verzeichnen, die sich seit dem Jahr 2000 stetig vergrößerten. 


\section{Abbildung 1: Die Entwicklung der österreichischen, der ausländischen und der gesamten Bevölkerung in Wien 1980-2005}

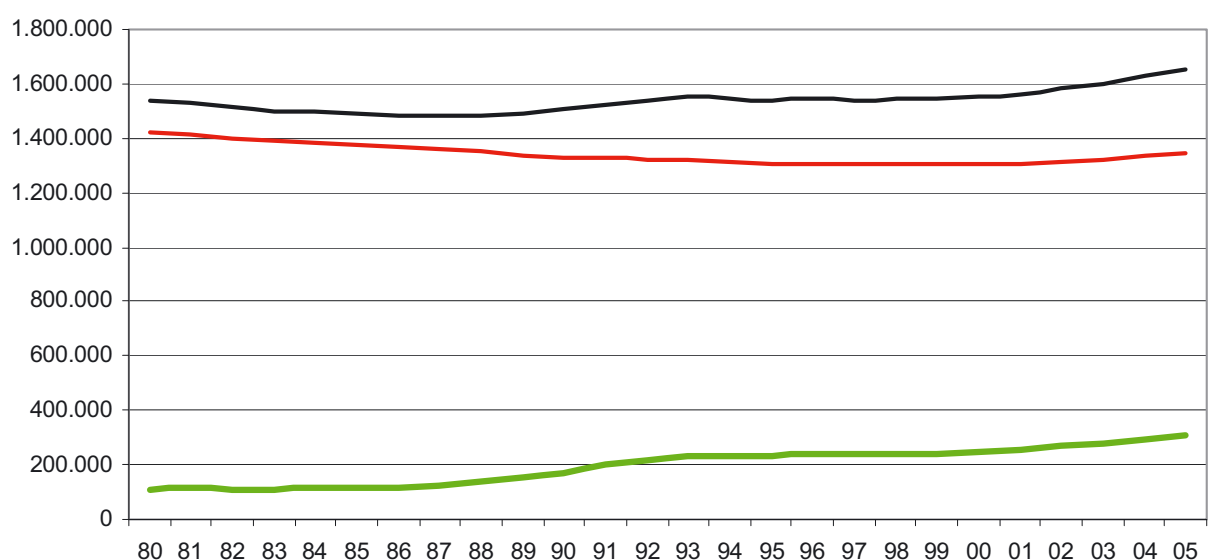

— Österreicher —Wohnbevölkerung insgesamt — Ausländer

Quelle: Statistik Austria - Wohnbevölkerung zum Jahresende gemäß Bevölkerungsfortschreibung; eigener Entwurf.

Das Ausmaß der Zuwanderung wird vor allem durch die Indexwerte veranschaulicht. Mit 1980 als Ausgangsbasis lag der entsprechende Wert 1990 bei 155,3, 2000 bei 223,6 und 2005 bereits bei 279,2. Bezüglich der Entwicklung der Gesamtbevölkerung spiegeln die Indexwerte $(1980=100)$ einen Rückgang bis 1987 mit dem tiefsten Index von 96,7 und sodann einen progressiven Trend wider. 1992 war mit 100,2 bereits wieder eine sogar etwas höhere Bevölkerungszahl als im Ausgangsjahr 1980 erreicht. Die Jahre 1992 bis 2001 brachten einen jeweils geringfügigen Anstieg der Jahresindexwerte, sodann setzte eine Phase stärkeren Wachstums ein, wobei 2005 mit 107,6 der Spitzenwert innerhalb des Analysezeitraums erreicht wurde (vgl. Tab. 2).

2005 lebten in Wien 309.184 Personen, die nicht die österreichische Staatsbürgerschaft besaßen. ${ }^{19}$ Die Zahlen der in Wien lebenden Personen aus dem ehemaligen Jugoslawien und der Türkei bzw. der Angehörigen der so genannten zweiten und dritten Generation sind von 1990 bis 1995 weiter deutlich gestiegen, wobei der Zuwachs bei den Exjugoslawen kontinuierlicher und stärker ausgeprägt war als bei den türkischen Staatsbürgern. Lebten 199187.358 (damals noch) jugoslawische Bürger in Wien, so waren es 2001 bereits 114.811. Abgesehen von einem geringfügigen Rückgang 2002/03 stieg ihre Zahl bis 2005 auf 119.656 an, wobei aber die jährlichen Zuwächse bescheidener als in den 1990er Jahren ausfielen. Mit einem Anteil von 38,7\%

19 Quelle: Meldezettelstatistik der MA 66. 
stellten die Exjugoslawen die größte Immigrantengruppe in der österreichischen Bundeshauptstadt. Unter den Exjugoslawen dominierten Bürger der Bundesrepublik Jugoslawien (Serbien und Montenegro). Ihre Zahl war von 71.662 (2001) auf 76.666 (2005) angewachsen. Die zweitgrößte Gruppe stammte 2005 aus Bosnien und Herzegowina (17.805), knapp gefolgt von den Kroaten (16.915).

Tabelle 2: Die Entwicklung der Wohnbevölkerung Wiens 1980-2005

\begin{tabular}{|c|c|c|c|c|c|c|c|}
\hline & \multirow{2}{*}{\multicolumn{2}{|c|}{$\begin{array}{l}\text { Bevölkerung insg. } \\
\text { abs. } 1980=100\end{array}$}} & \multicolumn{2}{|c|}{ Inländer } & \multicolumn{2}{|c|}{ Ausländer } & \multirow{2}{*}{$\begin{array}{r}\text { Ausländer- } \\
\text { anteil }\end{array}$} \\
\hline & & & abs. & $1980=100$ & abs. & $1980=100$ & \\
\hline 1980 & 1.535 .145 & 100,0 & 1.424 .405 & 100,0 & 110.740 & 100,0 & 7,2 \\
\hline 1981 & 1.528 .631 & 99,6 & 1.412 .376 & 99,2 & 116.255 & 105,0 & 7,6 \\
\hline 1982 & 1.510 .634 & 98,4 & 1.399 .450 & 98,2 & 111.184 & 100,4 & 7,4 \\
\hline 1983 & 1.499 .866 & 97,7 & 1.389 .870 & 97,6 & 109.996 & 99,3 & 7,3 \\
\hline 1984 & 1.494 .874 & 97,4 & 1.381 .875 & 97,0 & 112.999 & 102,0 & 7,6 \\
\hline 1985 & 1.490 .956 & 97,1 & 1.373 .686 & 96,4 & 117.270 & 105,9 & 7,9 \\
\hline 1986 & 1.485 .484 & 96,8 & 1.366 .157 & 95,9 & 119.327 & 107,8 & 8,0 \\
\hline 1987 & 1.484 .258 & 96,7 & 1.359 .760 & 95,5 & 124.498 & 112,4 & 8,4 \\
\hline 1988 & 1.485 .777 & 96,8 & 1.350 .020 & 94,8 & 135.757 & 122,6 & 9,1 \\
\hline 1989 & 1.492 .636 & 97,2 & 1.339 .701 & 94,1 & 152.935 & 138,1 & 10,2 \\
\hline 1990 & 1.502 .772 & 97,9 & 1.330 .837 & 93,4 & 171.935 & 155,3 & 11,4 \\
\hline 1991 & 1.522 .449 & 99,2 & 1.325 .120 & 93,0 & 197.329 & 178,2 & 13,0 \\
\hline 1992 & 1.537 .523 & 100,2 & 1.320 .648 & 92,7 & 216.875 & 195,8 & 14,1 \\
\hline 1993 & 1.549 .436 & 100,9 & 1.319 .152 & 92,6 & 230.284 & 208,0 & 14,9 \\
\hline 1994 & 1.542 .667 & 100,5 & 1.311 .953 & 92,1 & 230.714 & 208,3 & 15,0 \\
\hline 1995 & 1.539 .002 & 100,3 & 1.305 .009 & 91,6 & 233.993 & 211,3 & 15,2 \\
\hline 1996 & 1.542 .191 & 100,5 & 1.305 .758 & 91,7 & 236.433 & 213,5 & 15,3 \\
\hline 1997 & 1.540 .875 & 100,4 & 1.304 .955 & 91,6 & 235.920 & 213,0 & 15,3 \\
\hline 1998 & 1.542 .252 & 100,5 & 1.303 .518 & 91,5 & 238.734 & 215,6 & 15,5 \\
\hline 1999 & 1.548 .537 & 100,9 & 1.305 .870 & 91,7 & 242.667 & 219,1 & 15,7 \\
\hline 2000 & 1.553 .956 & 101,2 & 1.306 .287 & 91,7 & 247.669 & 223,6 & 15,9 \\
\hline 2001 & 1.562 .737 & 101,8 & 1.308 .044 & 91,8 & 254.693 & 230,0 & 16,3 \\
\hline 2002 & 1.583 .814 & 103,2 & 1.314 .932 & 92,3 & 268.882 & 242,8 & 17,0 \\
\hline 2003 & 1.598 .626 & 104,1 & 1.321 .662 & 92,8 & 276.964 & 250,1 & 17,3 \\
\hline 2004 & 1.626 .440 & 105,9 & 1.333 .084 & 93,6 & 293.356 & 264,9 & 18,0 \\
\hline 2005 & 1.651 .438 & 107,6 & 1.342 .254 & 94,2 & 309.184 & 279,2 & 18,7 \\
\hline
\end{tabular}

Quellen: Statistik Austria - Wohnbevölkerung zum Jahresende gemäß

Bevölkerungsfortschreibung; eigene Berechnungen. 
Tabelle 3: Ausländische Wohnbevölkerung in Wien 1981-2005

\begin{tabular}{|c|c|c|c|c|c|c|c|c|}
\hline Staatsangehörigkeit & 1981 & 1991 & 2001 & 2002 & 2003 & 2004 & 2005 & $\begin{array}{r}\text { in } \% \text { der } \\
\text { ausl. WBV } \\
2005 \\
\end{array}$ \\
\hline klassische Gastarbeiter & 78.297 & 131.234 & 153.428 & 157.214 & 155.540 & 157.090 & 159.557 & 51,6 \\
\hline ehem. Jugoslawien & 58.587 & 87.358 & 114.811 & 117.395 & 115.348 & 117.362 & 119.656 & 38,7 \\
\hline Türkei & 19.710 & 43.876 & 38.617 & 39.819 & 40.192 & 39.728 & 39.901 & 12,9 \\
\hline „neue Zuwanderung“ & 5.528 & 21.907 & 31.256 & 34.754 & 38.694 & 46.266 & 52.491 & 17,0 \\
\hline Polen & 2.653 & 11.056 & 13.646 & 14.031 & 14.504 & 18.258 & 21.610 & 7,0 \\
\hline Ungarn & 1.117 & 3.539 & 4.149 & 4.428 & 4.621 & 4.941 & 5.271 & 1,7 \\
\hline Tschechische Rep. ${ }^{1}$ & 753 & 2.619 & 1.839 & 2.012 & 2.114 & 2.224 & 2.362 & 0,8 \\
\hline Slowakei & - & - & 3.300 & 3.927 & 4.448 & 5.427 & 6.360 & 2,1 \\
\hline Rumänien & 350 & 2.532 & 3.809 & 4.882 & 6.109 & 6.961 & 7.796 & 2,5 \\
\hline Russland $^{2}$ & 417 & 1.357 & 2.096 & 2.495 & 3.331 & 4.366 & 4.741 & 1,5 \\
\hline Bulgarien & 238 & 804 & 2.417 & 2.979 & 3.567 & 4.089 & 4.351 & 1,4 \\
\hline$\underline{\text { EU-15 }}$ & - & - & 26.243 & 28.531 & 30.947 & 34.178 & 37.776 & 12,2 \\
\hline Deutschland & 6.374 & 9.017 & 13.398 & 14.759 & 16.014 & 18.094 & 20.417 & 6,6 \\
\hline andere EU-Länder & - & - & 12.845 & 13.772 & 14.933 & 16.084 & 17.359 & 5,6 \\
\hline $\begin{array}{l}\text { ausgew. Länder des Vorde- } \\
\text { ren Orients u. Nordafrikas }\end{array}$ & 3.909 & 7.179 & 8.313 & 8.698 & 8.789 & 8.629 & 8.542 & 2,8 \\
\hline Ägypten & 1.003 & 2.736 & 3.067 & 3.152 & 3.142 & 3.121 & 3.240 & 1,0 \\
\hline Iran & 2.096 & 3.088 & 4.055 & 4.295 & 4.330 & 4.210 & 4.026 & 1,3 \\
\hline Israel & 810 & 1.355 & 1.191 & 1.251 & 1.317 & 1.298 & 1.276 & 0,4 \\
\hline ausgew. asiatische Staaten & 2.770 & 6.694 & 10.129 & 11.778 & 12.914 & 13.623 & 14.463 & 4,7 \\
\hline Indien & 624 & 2.008 & 3.778 & 4.219 & 4.347 & 4.425 & 4.615 & 1,5 \\
\hline Philippinen & 981 & 1.842 & 2.157 & 2.310 & 2.468 & 2.646 & 2.870 & 0,9 \\
\hline Japan & 655 & 1.074 & 1.169 & 1.275 & 1.326 & 1.364 & 1.421 & 0,5 \\
\hline VR China & 510 & 1.770 & 3.025 & 3.974 & 4.773 & 5.188 & 5.557 & 1,8 \\
\hline USA und Kanada & 2.218 & 2.600 & 3.096 & 3.235 & 3.378 & 3.562 & 3.827 & 1,2 \\
\hline sonstige (ungeklärt, staatenlos) & 14.321 & 18.021 & 22.228 & 24.672 & 26.702 & 30.008 & 32.528 & 10,5 \\
\hline Ausländer insgesamt & 113.417 & 196.652 & 254.693 & 268.882 & 276.964 & 293.356 & 309.184 & 100,0 \\
\hline
\end{tabular}

Anmerkungen: 1: 1981 und 1991 Tschechoslowakei; 2: 1981 und 1991 Sowjetunion.

Quelle: 1981 und 1991: Volkszählungen, Statistik Austria; ab 2001: Bevölkerungsregister.

Der Anteil der Türken an der ausländischen Wohnbevölkerung betrug 2005 12,9\%. Ihre Absolutzahl hatte sich von 1991 (43.876) bis 2005 (39.901) deutlich reduziert. Ihr Anteil an allen Ausländern ging seit 1989 zurück, während er bei den 
Exjugoslawen - bedingt durch die Kriegshandlungen auf dem Balkan - ab 1990 angestiegen ist. Diese beiden Gruppen sind mit einem Gesamtanteil von 51,6\% aller in Wien lebenden ausländischen Staatsbürger nach wie vor die zahlenmäßig stärksten Migrantengruppen in Wien (vgl. Tab. 3).

Die politische Trendwende des Jahres 1989 mit dem Fall des Eisernen Vorhanges kennzeichnete auch eine Trendwende in der Migrationsgeschichte Wiens. Zuwanderung aus Tschechien, der Slowakei, Ungarn und Polen war wieder möglich. Grenzüberschreitende Pendelwanderung ebenso wie temporäre und permanente Arbeitsmigration aus den Transformationsstaaten drückten der Wiener „Migrationslandschaft“ erneut ihren Stempel auf. Die Zusammensetzung der ausländischen Wohnbevölkerung begann sich von einer stark binationalen Struktur - dominiert von Exjugoslawen und Türken - in Richtung auf eine heterogenere Zusammensetzung zu verschieben. Zuwanderer aus Ostmitteleuropa stellten 2005 mit einem Anteil von 17\% an allen Ausländern bereits die zweitstärkste geographische Herkunftsgruppe. Nach 1993 stagnierte ihre Zahl und ging wieder zurück, was auf die rigideren Einwanderungsbestimmungen zurückzuführen war. Seit der Jahrtausendwende und vor allem nach der EUErweiterung um die östlichen Mitgliedsstaaten sind die in Wien ansässigen Communities aus den Transformationsstaaten stark angewachsen. Polen haben den Deutschen seit 2004 quantitativ bereits den Rang abgelaufen.

Tabelle 3 dokumentiert weiters, dass Migranten aus Österreichs unmittelbaren Nachbarländern Ungarn, Tschechien und der Slowakei in der Bundeshauptstadt nicht so stark präsent sind wie polnische Staatsbürger. Polen stellt das bei weitem wichtigste Herkunftsland im Rahmen der Ost-West-Wanderung dar: Im Jahr 2005 lebten bereits 21.610 Polen in Wien. 2001 waren es noch 13.646 gewesen. Von 2003 auf 2004 fand ein deutlicher Sprung bezüglich des Stocks der Wiener Polonia statt. 2004 waren um 3.754 polnische Staatsbürger mehr in Wien anässig als im Jahr davor. Die zweitgrößte Herkunftsgruppe aus den neuen EU-Mitgliedsstaaten repräsentieren die Slowaken. 3.300 waren im Jahr 2001 in Wien legal gemeldet. 2005 belief sich ihre Zahl bereits auf nahezu das Doppelte (6.360). Quantitativ an dritter Stelle positionierten sich die Rumänen (2005: 7.796), danach folgten die Ungarn, von denen 20055.271 in der Bundeshauptstadt ansässig waren (Zum Vergleich: 2001 lag ihre Zahl bei 4.149). Mit 2.362 bildeten Migranten aus der Tschechischen Republik nicht nur die zahlenmäßig kleinste Gruppe, sondern verzeichneten zugleich auch den schwächsten Anstieg (um nur 523 Personen im Vergleich zu 2001).

Eine weitere wichtige Gruppe bilden Zuwanderer aus den Mitgliedstaaten der EU15, die 2005 12,2\% der Ausländer stellten. Mit 20.417 in Wien ansässigen Personen nehmen die Deutschen den Rang eins unter den EU-Herkunftsgruppen ein. Der Anstieg der deutschen Zuwanderung war überaus markant. Noch im Jahr 2001 betrug ihre Gesamtzahl in Wien bloß 13.398 Personen. Zu den bedeutenderen Herkunftsländern im Rahmen der EU-Zuwanderung zählen weiters Italien, Frankreich und Großbritannien. 
Analog den EU-Ausländern zur „Elitemigration“ zu zählen sind auch Zuwanderer aus den Vereinigten Staaten (2005: 3.253) und aus Kanada (2005: 574). Viele von ihnen sind nur für einen begrenzten Zeitraum hier, sei es aus geschäftlichen oder beruflichen Gründen oder zum Zwecke des Studiums. Wien hat ja auch eine lange Tradition als Standort internationaler Organisationen (z.B. UNO) aufzuweisen. Die Zuwanderung von Beamten und Managern ist auch als die überschichtende Komponente innerhalb der Gesamtimmigration zu bewerten.

Den Reigen der schwarafrikanischen Herkunftsländer führte Nigeria mit 3.615 Personen für 2005 an. Der Zuwachs war in diesem Fall ebenfalls extrem hoch $(+$ $60,6 \%$ seit 2001). Die Betrachtung der Zuwanderung aus dem arabisch-islamischen Raum zeigt, dass ägyptische (2005: 3.240) und iranische (2005: 4.026) Staatsbürger dominieren. Viele von ihnen kommen auch nach Wien, um hier zu studieren. Eine bereits „klassische“ Berufsdomäne der Ägypter und anderer Nordafrikaner stellen das Zeitungskolporteurswesen und das Taxiunternehmertum dar.

Die Zuwanderung aus fernöstlichen Herkunftsländern ist im Laufe der 1990er Jahre deutlich angestiegen. Pakistani und Bangladeshi sind ebenfalls hauptsächlich als selbständige Zeitungskolporteure tätig. Vor allem Indien verzeichnet als Herkunftsland wachsende Bedeutung (2001: 3.778, 2005: 4.615). Starke Zuwächse hatte auch die Volksrepublik China zu verzeichnen (2001: 3.025, 2005: 5.557). Eine weitere Gruppe von nennenswerter Größe bilden traditionell auch die Filipinos. Frauen von den Philippinen werden bereits seit Jahrzehnten von den Wiener Krankenhäusern als Pflegefachpersonal angeworben. „Chain migration“ hat zur Etablierung einer beträchtlichen philippinischen Community geführt.

\subsection{Ethnische Segregation in Wien: Entwicklung und Veränderungen 1981-2001}

War extreme Wohnsegregation in Wohnheimen und betriebseigenen Gemeinschaftsunterkünften ein Merkmal der Frühphase der Gastarbeitermigration der 1960er Jahre, so schwächte sich diese mit dem Familiennachzug in den 1970er Jahren zunächst erheblich ab, als vor allem der damals noch im großen Ausmaß existierende gründerzeitliche Substandardsektor viele türkische und (ex)jugoslawische Familien absorbierte. Mit dem großflächigen Wegbrechen dieses Teilsegmentes des privaten Mietwohnungsbestandes infolge von Sanierungsmaßnahmen haben sich die Konzentrationstendenzen seit den 1980er Jahren verstärkt. Die ethnische Segregation erhielt eine neue und zusätzliche Dynamik, da die Welle der Zuwanderung auch mit einem Paradigmenwechsel in der Wiener Stadtplanung zusammenfiel. Die Stadterneuerung konzentrierte sich auf die dicht bebauten Bezirke, während nur wenig Stadterweiterung, d.h. Neubau am Stadtrand, erfolgte (vgl. Lichtenberger 1990). Die Teile des Wohnungsmarktes, die vor allem für die Zuwanderer von Bedeutung waren, wurden drastisch reduziert. In dieser Hinsicht ähnelte die Wiener Situation grundsätzlich der in vielen anderen westeuropäischen Städten. 
Eine rezente Entwicklung der räumlichen Verteilung der ausländischen Wohnbevölkerung in Deutschland und in der Schweiz ist in Wien bloß eingeschränkt zu beobachten: Während in deutschen Metropolen Migranten früher vorwiegend in den Innenstädten wohnten, ist dort in den vergangenen Jahren eine verstärkte Abwanderung in die eher peripher gelegenen, dicht bebauten Wohnsiedlungen der 1960er und 1970er Jahre festzustellen. In Wien verteilt sich demgegenüber der Zuzug der Ausländer weiterhin in erster Linie auf die Wohnbezirke entlang des gesamten Süd- und Westgürtels. Diesen Stadtteilen stehen großflächige Gebiete jenseits der Donau sowie in der südlichen und westlichen Peripherie gegenüber, in denen der Anteil der ausländischen Wohnbevölkerung (sieht man von Elitemigranten ab) nur gering ist. Es sind dies hauptsächlich Gebiete, in denen genossenschaftliche und Eigentumswohnkomplexe sowie Gemeindebauten dominieren, bzw. Einfamilienhausgebiete und Wohnquartiere mit großen Altbauwohnungen aus der Hoch- und Spätgründerzeit. ${ }^{20}$ Dies gilt allerdings nicht für alle Immigrantengruppen im selben Ausmaß. Während Türken, Serben, Bosnier und Mazedonier zu erheblichen Anteilen selbst nach der Einbürgerung in den klassischen Gastarbeiterwohnbezirken verharren, verteilen sich Ost-West-Migranten wie Polen, Slowaken oder Russen viel stärker über weite Teile des Stadtraumes. Nordamerikaner, Japaner und EU-Bürger sind überhaupt eher in der südlichen und westlichen Peripherie zu finden als in den altbekannten „Ausländerbezirken“. Südund Ostasiaten haben ihre Wohnsitze ebenfalls über weite Teile Wiens verstreut.

Tabelle 4: Wiener Hauptwohnsitzwohnungen nach Ausstattungskategorien 1981, 1991 und 2001

\begin{tabular}{lrrrr}
\hline & 1981 & 1991 & 2001 & $1981=100$ \\
\hline mit Bad einschl. Duschnische u. Zentralheizung & 248.927 & 513.743 & 680.148 & 273,2 \\
mit Bad einschl. Duschnische & 256.958 & 102.463 & 62.920 & 24,5 \\
mit WC u. Wasserentnahme innerhalb d. Whg. & 77.431 & 47.998 & 11.869 & 15,3 \\
mit Wasserentnahme innerhalb der Wohnung & 85.401 & 52.746 & 13.650 & 16,0 \\
ohne WC u. Wasserentnahme innerhalb d. Whg. & 48.891 & 22.012 & 2.368 & 4,8 \\
insgesamt & $\mathbf{7 1 7 . 6 0 8}$ & $\mathbf{7 3 8 . 9 6 2}$ & $\mathbf{7 7 0 . 9 5 5}$ & $\mathbf{1 0 7 , 4}$ \\
\hline
\end{tabular}

Quelle: Häuser- und Wohnungszählung 1981, 1991, 2001.

Hinsichtlich der Ausstattungsqualität der Wohnungen waren Kategorie-A-Wohnungen mit 248.927 im Jahr 1981 noch eine Minderheit. Bis 1991 hatte sich ihre Zahl allerdings bereits mehr als verdoppelt (513.743). Im selben Zeitraum war eine Reduktion der schlechtesten Ausstattungskategorie auf weniger als die Hälfte der Absolutzahl von 1981 erfolgt (von 48.891 auf 22.012). 2001 wurden bloß noch 2.368 Wohn-

20 Vgl. www.wien.gv.at/stadtentwicklung/wohnenintegration, vom 5. 1. 2006: 3. 
einheiten dieses Substandardsegments gezählt. Auch die standardmäßig schlecht ausgestatteten Wohnungen mit zumindest einer Wasserentnahmemöglichkeit innerhalb der Wohnung hatten eine gravierende Reduktion erfahren. Ihr Bestand war von 85.041 auf 52.748 in der Dekade 1981-1991 zurückgegangen. Bis 2001 erfolgte eine weitere Reduzierung um nahezu drei Viertel auf 13.650 (vgl. Tab. 4).

Besonders illustrativ ist in diesem Zusammenhang eine Analyse der Indexwerte. Während die 680.148 Kategorie-A-Wohnungen des Jahres 2001 einem Indexwert von 273,2 entsprachen, sich diese Kategorie seit 1981 also nahezu verdreifacht hatte, dokumentiert der Wert von 4,8 den drastischen Rückgang des am schlechtesten ausgestatteten Substandardsegments. Die Wohneinheiten mit Wasserentnahme waren gegenüber 1981 auf 16\% ihres Ausgangsbestandes zurückgegangen.

Karte 5: Anteile der ausländischen Wohnbevölkerung auf der Ebene der Zählbezirke 1971

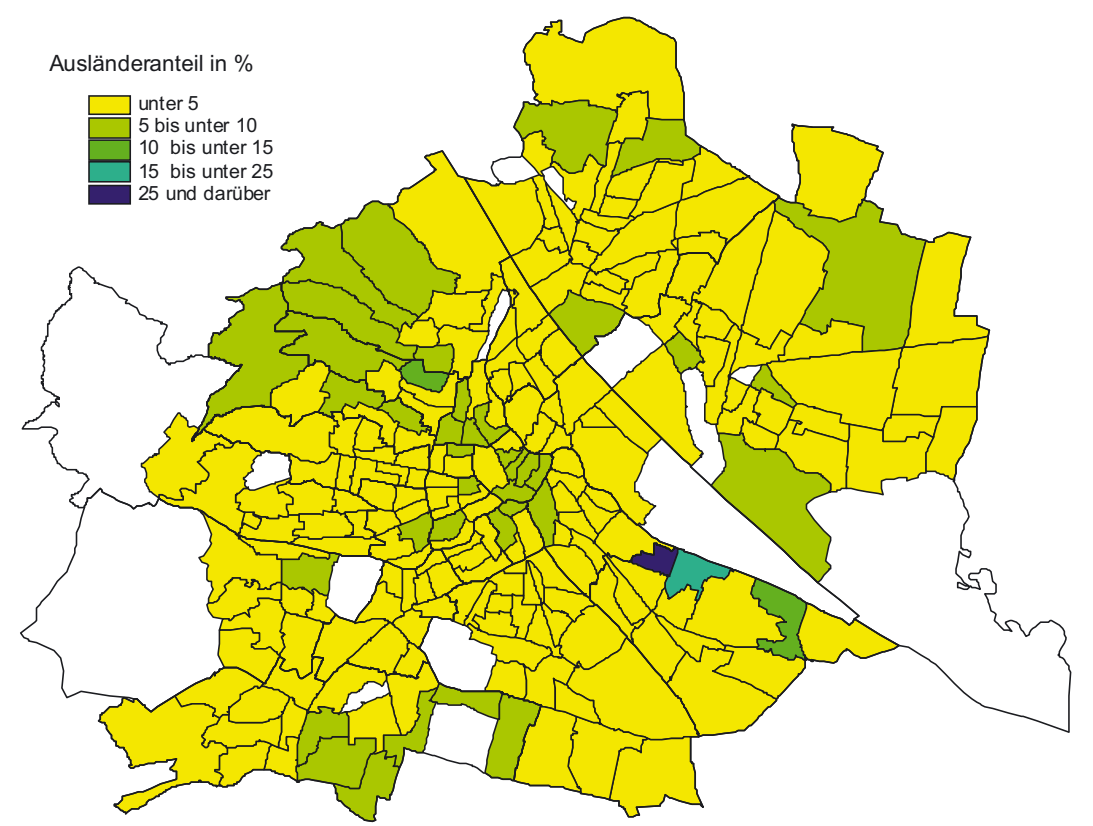

Quelle: Volkszählung 1971, eigene Berechnungen. Kartographie: Ursula Reeger.

Die Entwicklung ethnischer Segregationsprozesse der ausländischen Wohnbevölkerung in Wien auf der Ebene der Zählbezirke im Verlauf der vergangenen 35 Jahre soll im Folgenden kartographisch dokumentiert werden. ${ }^{21}$ Karte 5 weist für 1971 Seg-

21 Die gewählte Darstellungsform mittels durchgehend derselben Schwellenwerte verfolgte den Zweck, die Konzentrationsprozesse zu veranschaulichen. 
regation als ein noch weitgehend inexistentes Phänomen aus. Lediglich in einem Zählbezirk $^{22}$ lag damals der Ausländeranteil bei über $25 \%$, in einem anderen ${ }^{23}$ bei über $15 \%$. Ansonsten traten die Wohnlagen im Wienerwald und in den inneren Bezirken diejenigen mit einem höheren Sozialprestige - als Wohngebiete ausländischer Eliten etwas stärker hervor. Die Gastarbeiterzuwanderung steckte noch in ihren Anfängen. Von den 1,61 Mio. Einwohnern, die Wien 1971 hatte, waren 56.525 ausländische Staatsbürger. Dies entsprach einem Anteil von 3,5\%.

Karte 6: Anteile der ausländischen Wohnbevölkerung auf der Ebene der Zählbezirke 1981

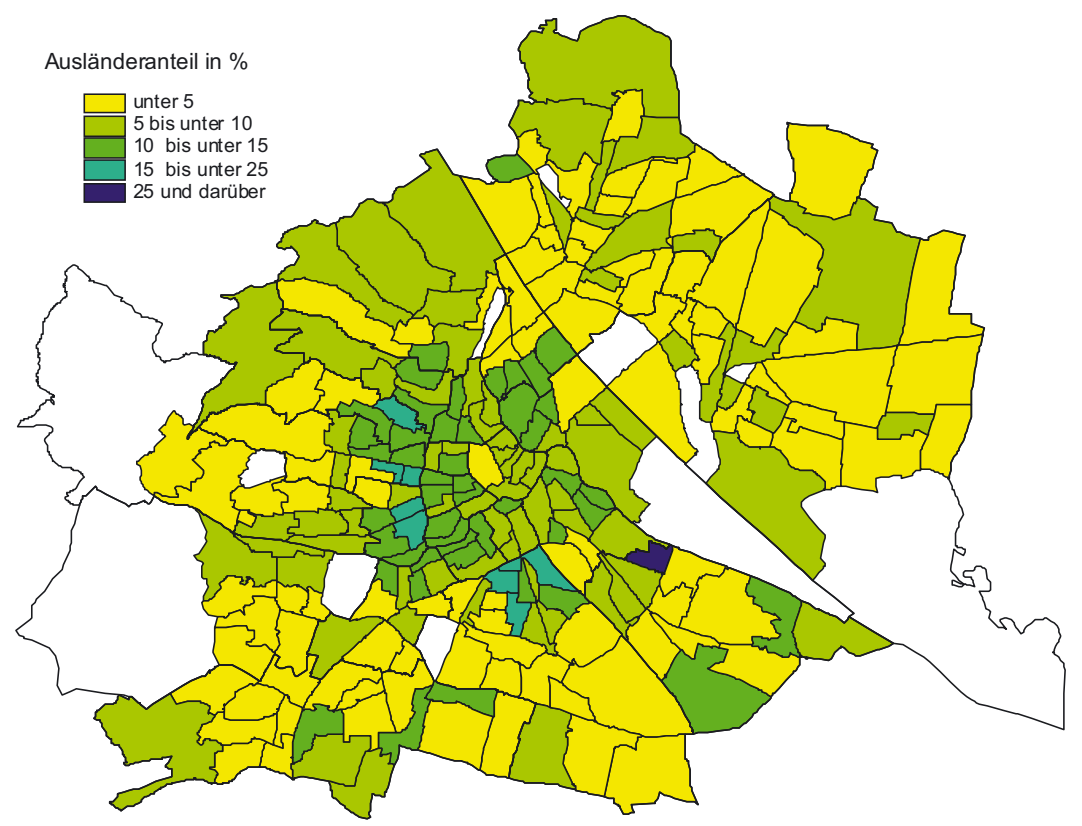

Quelle: Volkszählung 1981, eigene Berechnungen. Kartographie: Ursula Reeger.

Bereits 1981 (vgl. Karte 6) waren beginnende Verdichtungsprozesse der ausländischen Wohnbevölkerung nachweisbar, wobei schon damals die gürtelnahen Zählbezirke zunehmend an Bedeutung gewannen. Die meisten von ihnen wiesen zu diesem Zeitpunkt Ausländeranteile zwischen 10 und 15\% auf. Ausländeranteile zwischen 15 und 25\% entfielen im 10. Bezirk auf die Zählbezirke „Südbahnhof“, „Erlachplatz“ und

22 „Gaswerk Simmering“ mit einer insgesamt geringen Wohnbevölkerung von nur 201 Personen.

23 „E-Werk Simmering“ mit einer Wohnbevölkerung von 145 Personen. 
„Arthaberplatz“, im 15. Bezirk auf „Reithofferplatz“ und „Fünfhaus-Westbahnhof“, im 16. Bezirk auf „Richard-Wagner-Platz“ und „Ludo-Hartmann-Platz“ sowie im 17. Bezirk auf den Zählbezirk „Dornerplatz“.

Karte 7: Anteile der ausländischen Wohnbevölkerung auf der Ebene der Zählbezirke 1991

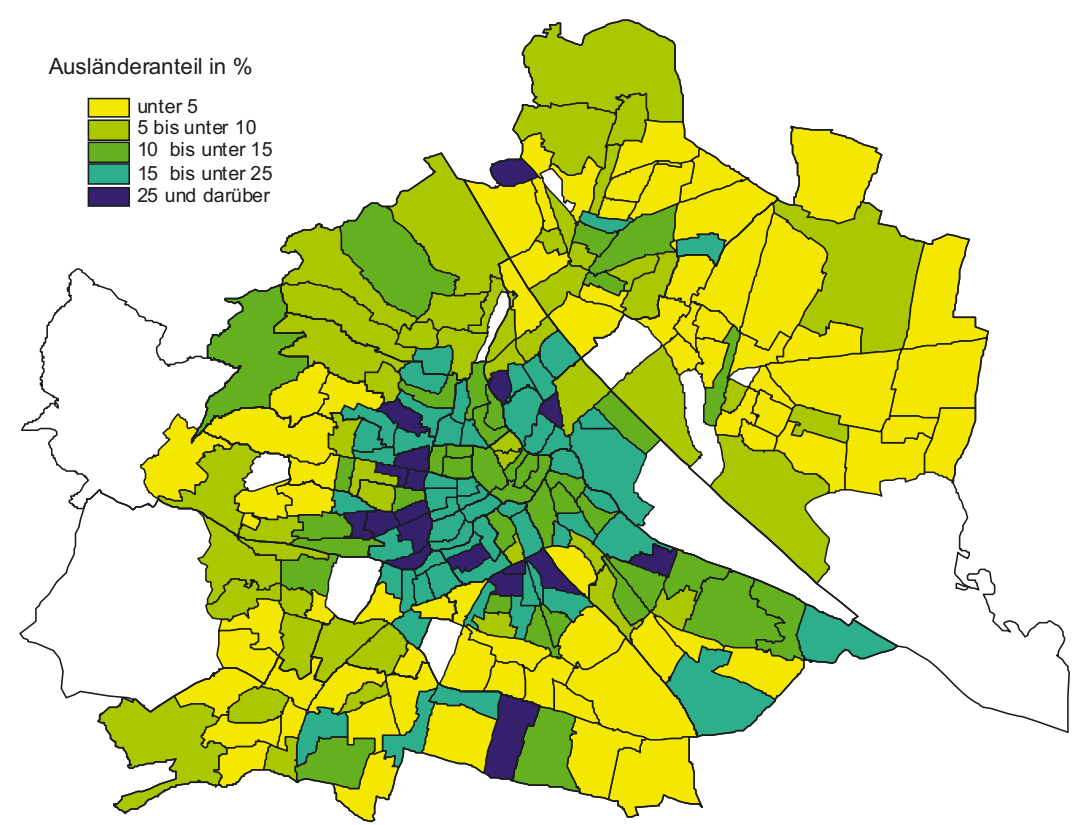

Quelle: Volkszählung 1991, eigene Berechnungen. Kartographie: Ursula Reeger.

1991 hat sich an den Gürtel angelagert bereits ein Dichtemuster von Zählbezirken mit durchgehend über $15 \%$ sowie in den Bezirken 17, 16 und 15 teilweise bei über $25 \%$ liegenden Anteilen ausländischer Wohnbevölkerung gebildet. Innerhalb von nur fünf Jahren haben sich die Konzentrationsprozesse im gründerzeitlichen Baubestand innerhalb und außerhalb des Gürtels weiterhin massiv verstärkt (vgl. Karte 7).

2001 war bereits die überwiegende Mehrzahl der Zählbezirke innerhalb und außerhalb des Gürtels durch Ausländeranteile von zumindest über $15 \%$ und bis $25 \%$ gekennzeichnet (vgl. Karte 8). Die „Gürtelzone“ wies in etlichen Bereichen bereits Konzentrationen von mehr als 25\% auf. Analog hohe Konzentrationswerte wurden auch im 10. und 20. Bezirk erreicht. Relativ wenig hat sich diesbezüglich in den Wienerwaldlagen am westlichen Stadtrand, in den Cottagevierteln Hietzings, Penzings, Währings und Döblings, sowie in den Bezirken jenseits der Donau (21 und 22), aber auch in Teilen des 23. Bezirks verändert. 
Karte 8: Anteile der ausländischen Wohnbevölkerung auf der Ebene der Zählbezirke 2001

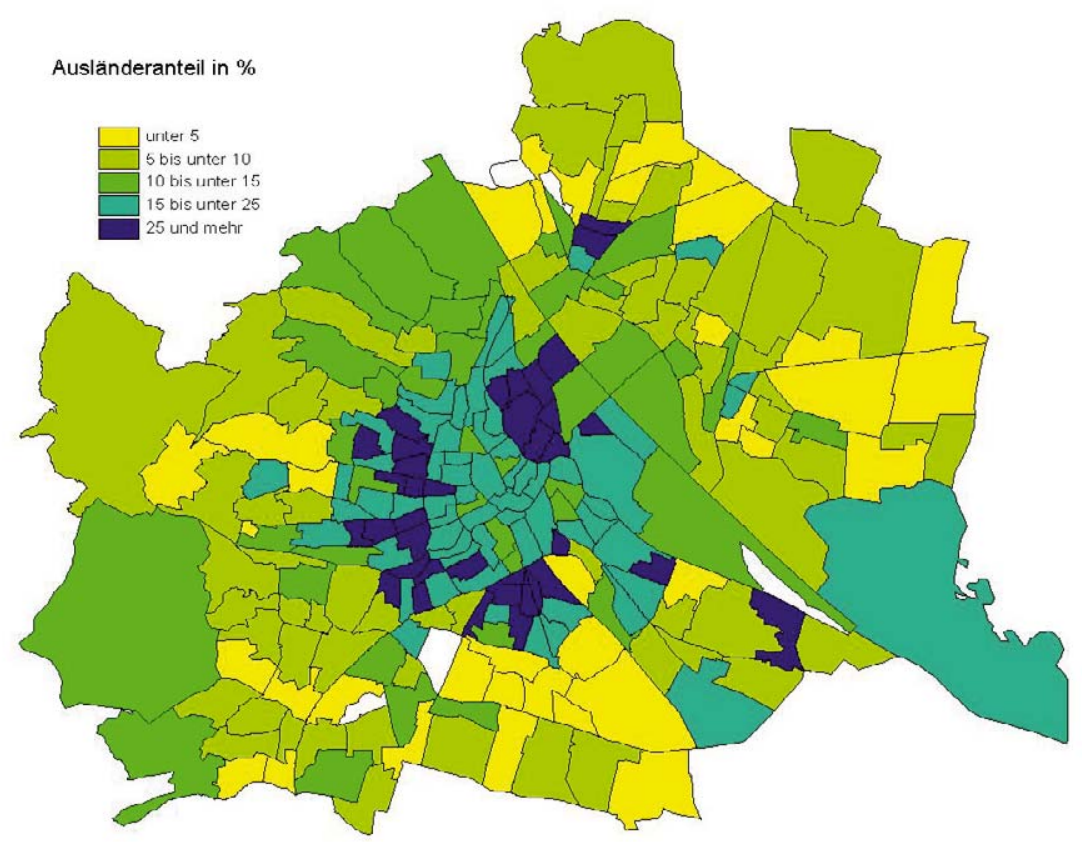

Quelle: Volkszählung 2001, eigene Berechnungen. Kartographie: Ursula Reeger.

Tabelle 5 zeigt die Präsenz der vier zahlenmäßig größten Immigrantengruppen in Wien nach den Kriterien der Staatsbürgerschaft sowie des Geburtsortes für das Jahr 2001. Zusätzlich erfolgt für die ausländischen Staatsbürger noch ein Vergleich mit den Zahlen von 1991. Die Zahl der in Wien legal lebenden Ausländer ist von 1991 auf 2001 um 51.612 Personen angestiegen. Dies entsprach einem Zuwachs um +3,2 Prozentpunkte. Der Ausländeranteil lag im Jahre 2001 somit bei 16\%. Da der Geburtsort erstmals im Rahmen der Volkszählung 2001 erhoben wurde, ist kein Vergleich mit früheren Daten möglich. Faktum ist, dass 2001 fast ein Viertel der Wiener Bevölkerung $(23,6 \%)$ im Ausland geboren worden war.

Zuwanderer aus dem ehemaligen Jugoslawien stellen traditionellerweise - und dies bereits seit den Jahren der Gastarbeiterzuwanderung der 1960er Jahre - die größte Migrantengruppe in der österreichischen Bundeshauptstadt dar. 127.290 im Rahmen des Zensus erfasste Personen und somit mehr als ein Drittel (34,8\%) aller 2001 in Wien lebenden Ausländer waren auf dem Gebiet des ehemaligen Jugoslawien geboren worden. Dies entsprach 8,2\% der Wiener Stadtbevölkerung. Die Absolutzahl exjugoslawischer Staatsbürger stieg in der Dekade 1991-2001 um 26.100 Personen an, womit gleichzeitig die Präsenz dieser ethnonationalen Herkunftsgruppe innerhalb der ausländischen Wohnbevölkerung um 1,3 Prozentpunkte auf 45,7\% wuchs. Die zweitgrößte 
Immigrantengruppe, nämlich Bürger der Türkei, unterlag im Analysezeitraum vor allem aufgrund eines ausgeprägten Trends zur Einbürgerung einem Schrumpfungsprozess. Im Jahre 2001 wurden durch die Volkszählung nur mehr 39.119 türkische Staatsbürger registriert, was einem Minus um 4.757 Personen, oder -10,8\% entsprach. Mit einem Anteil der Türken an allen Ausländern von 15,8\% hatte sich deren Präsenz in der ausländischen Gesamtbevölkerung seit 1991 um 6,5 Prozentpunkte reduziert. Gleichzeitig betrug der Anteil in der Türkei geborener Migranten an allen Ausländern in Wien 2001 bereits nahezu 13\%.

Tabelle 5: Ausländer und im Ausland Geborene nach Herkunftsländern in Wien 1991 und 2001

\begin{tabular}{lrrr}
\hline & Staatsbürgerschaft 1991 & Staatsbürgerschaft 2001 & Geburtsort 2001 \\
\hline Bevölkerung insg. & $\mathbf{1 . 5 3 9 . 8 4 8}$ & $\mathbf{1 . 5 5 0 . 1 2 3}$ & $\mathbf{1 . 5 5 0 . 1 2 3}$ \\
„Ausländer“ insg. & 196.652 & 248.264 & 366.289 \\
Ausländeranteil & 12,8 & 16,0 & 23,6 \\
Exjugoslawien & $\mathbf{8 7 . 3 5 8}$ & $\mathbf{1 1 3 . 4 5 8}$ & $\mathbf{1 2 7 . 2 9 0}$ \\
in \% der Bev. & 5,7 & 7,3 & 8,2 \\
in \% der Ausländer & 44,4 & 45,7 & 34,8 \\
Türkei & $\mathbf{4 3 . 8 7 6}$ & $\mathbf{3 9 . 1 1 9}$ & $\mathbf{4 7 . 3 2 1}$ \\
in \% der Bev. & 2,8 & 2,5 & 3,1 \\
in \% der Ausländer & 22,3 & 15,8 & 12,9 \\
Polen & $\mathbf{1 1 . 0 5 6}$ & $\mathbf{1 3 . 6 4 8}$ & $\mathbf{2 4 . 9 1 7}$ \\
in \% der Bev. & 0,7 & 0,9 & 1,6 \\
in \% der Ausländer & 5,6 & 5,5 & 6,8 \\
Deutschland & $\mathbf{9 . 0 1 7}$ & $\mathbf{1 2 . 7 2 9}$ & $\mathbf{2 6 . 2 3 0}$ \\
in \% der Bev. & 0,6 & 0,8 & 1,7 \\
in \% der Ausländer & 4,6 & 5,1 & 7,2 \\
\hline
\end{tabular}

Quellen: MA 66, Statistik Austria, Volkszählungen 1991 und 2001, eigene Berechnungen.

Polen sind nach wie vor die quantitativ bedeutendste Zuwanderergruppe aus den postkommunistischen Reformländern. Mit fast 25.000 in Polen geborenen Personen stammten 2001 6,8\% aller Ausländer aus diesem ostmitteleuropäischen Land. Im Analysezeitraum war die Zahl der in Wien ansässigen polnischen Staatsbürger um 2.592 Personen $(23,4 \%)$ gestiegen. Dies entsprach zwar einem geringfügigen Anstieg der prozentuellen Präsenz dieser Herkunftsgruppe an der Gesamtbevölkerung, gleichzeitig war jedoch ihr Anteil an allen Ausländern um 0,1 Prozentpunkte zurückgegangen. Ein starker zahlenmäßiger Anstieg kennzeichnet die deutsche Elitemigration. 2001 wurden um 3.712 deutsche Staatsbürger mehr registriert als 1991. Ihr Anteil an der gesamten ausländischen Wohnbevölkerung war um 0,5 Prozentpunkte angestiegen. Die Zahl der 2001 in Wien ansässigen, in Deutschland geborenen Personen lag bei über 26.000, was einem Anteil an allen Ausländern von 7,2\% entsprach (vgl. Tab. 5). 
Tabelle 6: Dissimilaritätsindizes für die zahlenmäßig größten Zuwanderergruppen in Wien 1991 und 2001 (Basis: Staatsbürgerschaft)

\begin{tabular}{llrrrr}
\hline \multirow{2}{*}{1991} & Exjugoslawien & Polen & Türkei & Österreich \\
\hline & Deutschland & 46,8 & 49,7 & 58,0 & 32,3 \\
& Exjugoslawien & - & 33,7 & 27,6 & 44,1 \\
& Polen & & - & 40,2 & 47,6 \\
& Türkei & & & & 54,5 \\
& Deutschland & 46,1 & 42,7 & 55,0 & 31,8 \\
& Exjugoslawien & & 29,5 & 22,8 & 43,9 \\
& Polen & & & 36,5 & 39,4 \\
& Türkei & & & 51,4 \\
\hline
\end{tabular}

Quellen: MA 66, Statistik Austria, Volkszählungen 1991 und 2001, eigene Berechnungen.

Tabelle 6 lässt anhand der Dissimilaritätsindizes (DI) das Ausmaß an sozialräumlicher Wohnsegregation zwischen den vier größten Migrantengruppen erkennen, wobei auch ein Vergleich zwischen den beiden Volkszählungsjahren 1991 und 2001 angestellt wird. Zum Zeitpunkt 1991 war mit einem DI von 32 Wohnsegregation zwischen Deutschen und Österreichern zwar deutlich vorhanden, diese war aber beträchtlich schwächer ausgeprägt als die Segregation der deutschen Elitemigranten gegenüber Exjugoslawen oder Polen. Am stärksten segregierten sich deutsche Zuwanderer mit einem Indexwert von 58 gegenüber türkischen Staatsbürgern. Die sozialräumliche Segregation zwischen Exjugoslawen und Türken war 1991 mit einem DI von 28 verhältnismäßig schwach, trat gegenüber den polnischen Staatsbürgern stärker in Erscheinung und war mit einem Wert von 44 gegenüber den Inländern am deutlichsten. Polen und Türken segregierten sich deutlich stärker voneinander als Polen und Exjugoslawen, mit einem DI von 48 war die Segregation der Polen gegenüber den Österreichern stärker als zwischen den letztgenannten und den Exjugoslawen.

Im Vergleich der beiden Volkszählungsjahre 1991 und 2001 hat sich die sozialräumliche Segregation zwischen den angeführten Migrantengruppen sowie auch jene gegenüber der österreichischen Wohnbevölkerung durchgehend vermindert. Ein sichtbarer Erfolg für die in Wien überaus aktiv betriebene Desegregationspolitik. Im Falle der Deutschen war die Verminderung gegenüber der polnischen Herkunftsgruppe am stärksten ausgeprägt, gegenüber Österreichern und Exjugoslawen am schwächsten, gegenüber den Türken war ein Rückgang auf einen DI von 55 zu verzeichnen. Im Fall der Exjugoslawen hat sich die Wohnsegregation vor allem gegenüber den Türken deutlich vermindert, eine ebenfalls nennenswerte Reduzierung des Dissmilaritätsindex ist gegenüber den Polen eingetreten. Gegenüber der inländischen Wohnbevölkerung hat sich ein schwächerer Rückgang des Dissimilaritätsindex vollzogen. Die verminderten Indexwerte der Polen gegenüber der türkischen (36) sowie der österreichischen (39) Wohnbevölkerung weisen einmal mehr auf eine sich abschwächende Wohnsegre- 
gation hin. Als ein weiterer positiver Trend ist hervorzuheben: Auch die Segregation der türkischen Bevölkerung gegenüber den Inländern hat sich von 1991 bis 2001 verringert, ist aber nach wie vor sehr hoch und wird nur von der Segregation der deutschen Elitemigranten von den türkischen Zuwanderern übertroffen.

Segregation und Konzentration haben also auch in Wien im Verlauf der vergangenen 25 Jahre in zunehmendem Maße zu einer gewissen Ethnifizierung im Bereich des Wohnens geführt. Aus räumlicher Perspektive wesentlich ist, dass ethnische Segregation in Wien nicht so sehr viertelsweise, sondern eher block- und hausweise (,Ausländerhäuser") in Erscheinung tritt.

\subsection{Empirische Befunde der Hauserhebungen}

\subsubsection{Eindrücke von der Hauserhebung aus der Perspektive einer Erhebenden (von Wibke Strahl)}

1030 Wien: Das Wohnhaus präsentiert sich in einem völlig desolaten Zustand. Es wirkt sehr abgewohnt. Der Verputz fällt von der Decke. Überall sieht man das blanke Mauerwerk. Die Türen sind alt und erheblich beschädigt. Sie schließen nicht mehr und sind mit Sicherheitsschlössern versperrt. Es riecht muffig und alt. Blanke Glühlampen hängen ohne Lampenschirme an den Decken. Das Wohnhaus wirkt düster und dunkel, ähnlich einer Notunterkunft. Die WCs auf den Gängen werden benutzt. Es gibt drei Wohnungen pro Stockwerk. Die Wohneinheiten wurden sicherlich noch nicht zusammengelegt. Es sind nicht alle Wohnungen bewohnt. Sechs Wohnungen weisen Sicherheitsschlösser auf und es gibt sechs verschließbare Postkästen (von insgesamt 20, wobei diese großteils erheblich beschädigt sind). Klingeln und Klingelbretter existieren nicht, die Außentür ist nicht verschließbar. Nach Einschätzung des Erhebungsteams wird das Haus ausschließlich von Migranten (ehemaligen Gastarbeitern) bewohnt. Auf den Gängen sind ausschließlich nichtdeutsche Sprachen zu vernehmen. Migranten besuchen einander gegenseitig in den Wohnungen. Sie verständigen sich durch Klopfzeichen und Rufe, da es auch keine Türklingeln gibt. Ein Migrantenkind mit dunklem Teint läuft die Stiegen hinauf. Eine Mutter mit Kind (ebenfalls Migranten) kommen gerade vom Einkaufen (sie tragen „Mondo“-Tüten und Einkaufswagen) zurück und blicken sehr misstrauisch. Sie verstehen meine Fragen in deutscher Sprache kaum. Das Wohnhaus steht vereinzelt auf einer Brachfläche. Einen Innenhof gibt es nicht. Aus den Fenstern hängt Wäsche zum Trocknen. Die Rückseite des Hauses ist nicht verputzt, die Vorderseite hingegen wird gerade mit neuem Verputz ausgestattet.

1050 Wien: Der Hausflur weist einen äußerst desolaten Zustand auf. Der Verputz fehlt an den Wänden teilweise völlig, dort wo er noch vorhanden ist, sind die Wände mit Graffiti vollgeschmiert. Zigarettenstummel liegen im ganzen Haus herum. Die Bassenas werden als Mistkübel verwendet. Die Gänge vor den Eingangstüren sind vollkommen mit Gerümpel (Waschmaschinen etc.) verstellt. Der Hausflur ist völlig 
verschmutzt, aber auch der Innenhof gleicht einer Müllhalde: ein altes Sofa, ein Fernsehapparat, ein Kühlschrank usw. verunzieren den Hof. Neben der Kellertüre befindet sich eine Wohnungseingangstür. Man hört dahinter Migranten sprechen. Als ich im Innenhof fotografierte, wurde ich von einem kleinen (Migranten)mädchen misstrauisch beobachtet; es verschwand jedoch gleich wieder. Im Haus hörte ich Migrantinnen sprechen: Eine klopfte bei einer anderen an die Wohnungstüre. Eine weitere Migrantin mit dunklem Teint kam die Stiege hinauf. Sie wollte oder konnte mir keine Antworten auf hausbezogene Fragen geben. Eine türkische Familie betrat das Haus, als das Erhebungsteam hinausging. Ihre Blicke drückten erhebliches Misstrauen aus.

Am „Schwarzen Brett“ waren keine Angaben über die Verwaltung oder die Besitzverhältnisse vorhanden.

1050 Wien: Das Wohnhaus befindet sich ab dem zweiten Stock in einem desolaten Zustand und ist völlig verschmutzt. Die Wände sind mit Essensresten und mit Aufschriften in nichtdeutschen Sprachen verschmiert. Zigarettenstummel liegen auf der Stiege. Die Bassenas werden als Aschenbecher benutzt. Gegenstände stehen auf den Gängen, ein alter Tisch ist auf der Rückseite beschrieben. Ein Migrant betrat das Haus. Er ging in eine Erdgeschosswohnung und schloss sogleich hinter sich ab. Es herrschte eine eher düstere Stimmung.

1050 Wien: Eigentümer des Hauses ist Herr X. Nach Angaben der ehemaligen Mieterin Frau Y. (ihre Tochter wohnt noch in diesem Haus) geht es dem besagten Herrn X. nur ums Geld, und mit Migranten ,kann man dies ja machen“, es sei aber sehr schwer, eine günstige Wohnung in Wien zu finden. Die betreffende Partei zahlt für $33 \mathrm{~m}^{2} 220$ Euro Miete. Die Wohnungen befinden sich teilweise in einem desolaten Zustand: es regnet herein, kaputte Fenster werden nicht repariert, sondern nur mit Brettern vernagelt. Im Hausflur ist es sehr dunkel. Es ist nur noch ein Innenhoffenster aus Milchglas vorhanden, die anderen Fenster wurden zugemauert. Styroporplatten dienen als Verkleidung der Decke. Im ersten Stock lösen sich diese Platten bereits wieder und hängen herunter. Im Keller gab es einen Wasserrohrbruch, der nicht behoben wurde. Der Keller ist seither völlig nass.

Die Tochter der Informantin Y. hat wegen des zerbrochenen Fensters bereits unzählige Male beim Hauseigentümer angerufen, jedoch immer nur Vertröstungen zu hören bekommen. Das geht jetzt seit einem Jahr so - nun versucht sie eine andere Wohnung zu finden. Zu Gericht brauche man als Mieter gar nicht zu gehen, meint Frau Y., denn jede Hauspartei habe bislang den Prozess gegen Herrn X. verloren: , Er hat da schon so seine Kontakte. “

1050 Wien: Das Wohnhaus ist baulich als äußerst desolat zu klassifizieren. Die Wände sind teilweise ohne Verputz, man blickt auf das blanke Mauerwerk. Viele Wohnungen sind wohl auch nicht mehr bewohnt. Das Fensterglas der Wohnungen ist oftmals eingeschlagen. Türen und Fenster sind undicht, es ist extrem kalt im Haus. Man hört und sieht niemanden. Es ist ruhig, nur ein Migrant verlässt eine Wohnung. Die Frage, ob er hier wohne, verneint er flüchtig. Er spricht kein Deutsch, nur wenig Englisch. Er geht schnell weiter - es scheint, als hätte er Angst. Er betont immer wie- 
der, dass er hier nicht wohne. Auf den Fensterbänken liegen zahlreiche tote Insekten und Zigarettenstummel. Das Haus wirkt verlassen und abgewohnt. Vereinzelt steht Gerümpel auf den Gängen. Das Fensterglas der Hoftüre ist eingeschlagen. Es herrscht eine sehr düstere Stimmung.

1050 Wien: Es handelt sich sozusagen um ein ,alternatives“ Wohnhaus. Im Erdgeschoss befindet sich ein „Kostet-nix-Laden“ mit dem Motto, einen monatlichen Beitrag zu zahlen und allerlei dort herumstehenden Krimskrams mitnehmen zu können - ähnlich einem Flohmarkt. Es gibt weiters Sitzgelegenheiten und Tische wie in einer Bar.

Dank der Unterhaltung mit Herrn Y., einem Österreicher, konnte man einiges über die Bewohnerstruktur des Hauses erfahren: In diesem Haus wohnen vier Österreicher, nämlich drei junge Singles und die ältere Witwe eines Generals. Eine Wohnung wird von einem ungarischen Paar mittleren Alters bewohnt. Ein brasilianischer Künstler nutzt das Dachgeschoss als Atelier und Wohnung. Bis September 2005 hat eine pakistanische Familie in einer kleinen Erdgeschosswohnung gewohnt. Sie bewohnten zu viert ein Zimmer und eine Gangküche. Die Wohnung hatte jedoch feuchte Wände, was sich negativ auf die Gesundheit der Kinder auswirkte. Die Familie ist deshalb ausgezogen, als sie eine andere Bleibe fand. In der anderen Erdgeschosswohnung wohnt Herr X. mit seiner Frau. Er ist Serbe und wohnt schon seit 40 Jahren in diesem Haus. Seine Leidenschaft ist das Sammeln von Gegenständen: Radios, Kleinmöbel usw. Zum Teil repariert er die Dinge, wenn sie defekt oder beschädigt sind. Herr X. und seine Frau haben eine Wohnküche, also ein Zimmer, zur Verfügung, wo sie schlafen, essen und leben. Im kleinen Nachbarraum hat er sich Platz für sein Sammelsurium geschaffen, er wird sozusagen als Lagerraum genutzt. Im Sommer verbringt X. viel Zeit im Hof, er hat sich eine kleine „Bude“ mit Sitzgelegenheit gebaut. Deswegen gibt es im Haus auch öfter Streit, weil sich eine Bewohnerin, die mit dem Sohn der Hausbesitzerin liiert ist, sehr darüber aufregt und sich selbst schon als Hausherrin aufführt.

Die Begegnung mit Herrn X. war seltsam. Auf die Frage des Auskünfte erteilenden Hausbewohners Y., er solle doch bitte von früher erzählen, reagiert er verstört: ,, Nein, ich sage nichts!" Er geht in seine Wohnung zurück, ist jedoch neugierig und kommt kurz darauf wieder heraus. Er machte ein Foto von mir, lächelte und meinte dies sei für seine Sammlung. Seine Frau ist sehr nett, aber sie spricht leider nur Serbokroatisch. Die beiden leben von einer kleinen Rente der Frau, denn X. hat kein Einkommen.

1110 Wien: Ein freundlicher Hausbesorger, Herr X. aus Mazedonien, gab Auskunft. Er lebt schon seit mehr als 15 Jahren in diesem Haus. Er kam aus Westdeutschland und lebte in der Nähe von Köln. Doch als 1989 die Berliner Mauer fiel, sah es schlecht mit Arbeit für ihn aus und er ist nach Wien 11 gezogen. Der damalige Hausbesitzer wohnte gleich vis á vis und hatte ein Geschäft in derselben Gasse. Herr X. durfte in die Erdgeschosswohnung ziehen. Er musste an den Hauseigentümer eine Ablöse von 300.000 Schilling für die Wohnung bezahlen, wobei in dieser nichts vor- 
handen war als das nackte Mauerwerk. Eine Quittung über den erlegten Betrag wurde nicht ausgestellt. Für den Mietvertrag musste er weitere 7.000 Schilling entrichten.

Im Verlauf der Zeit hat er viel Zeit und Geld in diese Wohnung investiert. Er hat sich beispielsweise eine neue Eingangstüre gekauft, als die alte gar nicht mehr geschlossen hat. Des Weiteren hat er sich in seiner Zweizimmerwohnung selbst eine Wasch- und Duschmöglichkeit eingebaut. Doch seit Jahren sind die Wände in seiner Wohnung feucht; überall ist Schimmel, was nicht gerade gesundheitsfördernd ist. Die Hausverwaltung fühlt sich nicht zuständig und auch nach mehrmaligem Kontakt ist keine Besserung erfolgt. Da die Person des Hausbesitzers im Verlauf der vergangenen 15 Jahre dreimal gewechselt hat, wird Herr X. auch sein Geld, welches er in die Wohnung in Form von Sanierungsmaßnahmen investierte, nicht wiedererhalten. Mit dem ersten Eigentümer wurde darüber nichts in schriftlicher Form festgehalten und die Nachfolgenden fühlen sich nicht angesprochen. Deswegen mag er trotz des Schimmels nicht ausziehen, da er auch über keine weiteren finanziellen Mittel verfügt. Er fragte das Erhebungsteam nach einer Gemeindewohnung, aber eine solche war zu jenem Zeitpunkt für Ausländer nicht noch zugänglich.

Die neuen Fenster im Haus mussten die Mieter selbst bezahlen, von der Hausverwaltung kam nur der Auftrag. Auch so interessiert sich niemand für das Haus und seine Bewohner. Das Eingangstor schließt seit Jahren nicht mehr, sodass Obdachlose schon mehrmals ins Haus eingedrungen sind und im Innenhof nächtigen wollten. Der Eingangsbereich wurde nur provisorisch und ohne Zement als Bindemittel gepflastert. Die Pflastersteine wurden einfach in den Untergrund gedrückt. Briefkästen gibt es nur mehr acht an der Zahl für zehn Hausparteien. Die Wasserrohre verlaufen über dem Erdboden und direkt durch die Wohnung von Herrn X. Er vermutet, dass dadurch die Feuchtigkeit in seiner Wohnung zugenommen hat. Damit die Rohre im Winter nicht einfrieren, hat Herr X. sie mit Glaswolle versehen. Im Sommer 2005 sind Dachziegel heruntergefallen. Doch auch dies hat die Hausverwaltung nicht interessiert. Der letzte Neuanstrich des Hausflures ist auch schon vor längerer Zeit erfolgt. Die Farbe blättert zum Teil ab und die Wände sind verschmutzt.

Das Haus besitzt keinen Keller, deswegen steht viel Gerümpel auf den Gängen und im Innenhof herum. Neben Herrn X. wohnen noch neun weitere Serben in diesem Haus. Sie kennen einander alle und besuchen einander auch gegenseitig. Sie bilden eine kleine „Gemeinde“ und sind füreinander da.

Obwohl Herr X. schon mehr als 20 Jahre im deutschsprachigen Raum lebt, spricht er eher mittelmäßiges Deutsch, aber er ist sehr bemüht, Auskunft zu geben. Im Haus wird nur Serbokroatisch gesprochen. Sein erwachsener Sohn und seine Tochter sind ausgezogen, leben aber beide auch im 11. Bezirk.

1110 Wien: Das Wohnhaus wurde im Verlauf der vergangen 20 Jahre saniert. Die Dachgeschosse wurden ausgebaut, vereinzelt gibt es Dachbalkone bzw. -terrassen. Wohnungseingänge wurden neu gestaltet, es gibt sowohl alte als auch neue Eingangstüren etc. Indizien für Sanierungstätigkeiten sind also vorhanden, dennoch wirkt das Haus völlig abgewohnt. Die vier Stiegenhäuser sind völlig verschmutzt. Der Verputz 
ist größtenteils beschädigt oder fehlt teilweise zur Gänze. Die Wände der Stiegenhäuser weisen Risse auf, sind verschmutzt sowie oftmals mit fremdsprachigen Graffiti beschrieben. Zigarettenstummel liegen herum. Die Lampenverkleidungen im Hausflur dienen als Aschenbecher. Gerümpel und Wäscheständer stehen im Innenhof, aber v. a. in den Gängen herum. Man hört viele Einwanderer sprechen. Eine Migrantenfamilie verlässt ihre Wohnung. Die Menschen blicken verstört und misstrauisch, sie verstehen mich aber nicht.

Herr X., ein Migrant aus Exjugoslawien, geht auf mich zu. Er blickt sehr skeptisch, versteht mich aber. Er lebt seit 13 Jahren in diesem Haus. Seit diesem Zeitpunkt kann er Sanierungsarbeiten ausschließen. Auf die Frage nach dem völlig verschmutzten und nicht gepflegten Zustandes des Hauses verweist er aber auf die türkischen Mitbewohner: ,Die Türken wollen nichts mit uns zu tun haben und wir nichts mit den Türken. Sie haben eben eine andere Kultur. " Man lebt nebeneinander her nicht miteinander. Herr X. sucht auch schon seit einem halben Jahr nach einer neuen Wohnung, aber es sei schwierig, denn nur wenige wollen Ausländer als Mieter haben.

1230 Wien: Das Haus wird von zahlreichen Exjugoslawen bewohnt. Frau Y. gab Auskunft über die Situation. Sie wohnt seit 30 Jahren im Erdgeschoss dieses Hauses. Frau Y. gewährte mir auch einen Blick in ihre Wohnung. Sie war winzig klein, bestehend aus einer Wohnküche und einem Schlafzimmer. Es gibt keine Dusche und kein WC. Die Wohnungen im Erdgeschoss sind alle so angelegt. Einige Hausparteien haben sich Duschen in ihre Wohnküchen selbst eingebaut, da ein Wasseranschluss vorhanden war. Frau Y. hat 30 Jahre lang in ein und derselben Firma gearbeitet und nach den Bauarbeitern dort nach Feierabend immer geduscht. Jetzt wäscht sie sich in der Wohnküche am Waschbecken. Ihre beiden Nachbarinnen, auch aus Exjugoslawien stammend, handhaben dies ebenso. Die Schlafzimmer liegen zur Triester Straße hin, aufgrund des Verkehrslärms und -staubes können die Mieter kaum lüften, was einen muffigen Geruch in den Wohnungen zur Folge hat. Hinzu kommt, dass die Fenster teilweise undicht sind.

\subsubsection{Basisinformationen zur komparativen Auswertung des Hausbestands 1981 und 2005}

Von der Erhebung des Jahres 1981 waren sämtliche 750 Hauserhebungsbögen als Originale im Archiv des Instituts für Stadt- und Regionalforschung vorhanden. Die Erhebungsbögen wurden sodann in einem ersten Analyseschritt einer systematischen Sichtung unterzogen, da alle Häuser von unserem Erhebungsteam wieder aufgesucht wurden. Schließlich erwies es sich aber als faktisch nur möglich, 696 Häuser in die Analysen einzubeziehen. Die fehlenden 54 Gebäude konnten aus den folgenden Gründen im Jahre 2005 nicht untersucht werden:

- es lagen im Erhebungsbogen für 1981 mangelhafte Angaben vor (sehr selten);

- die angegebenen Adressen waren de facto nicht auffindbar, d.h. es mussten 1981 Fehler bei der Adresserfassung unterlaufen sein (sehr selten); 
Karte 9: Verortung der Häuser der Erhebung 2005/06 im Wiener Stadtraum ${ }^{24}$

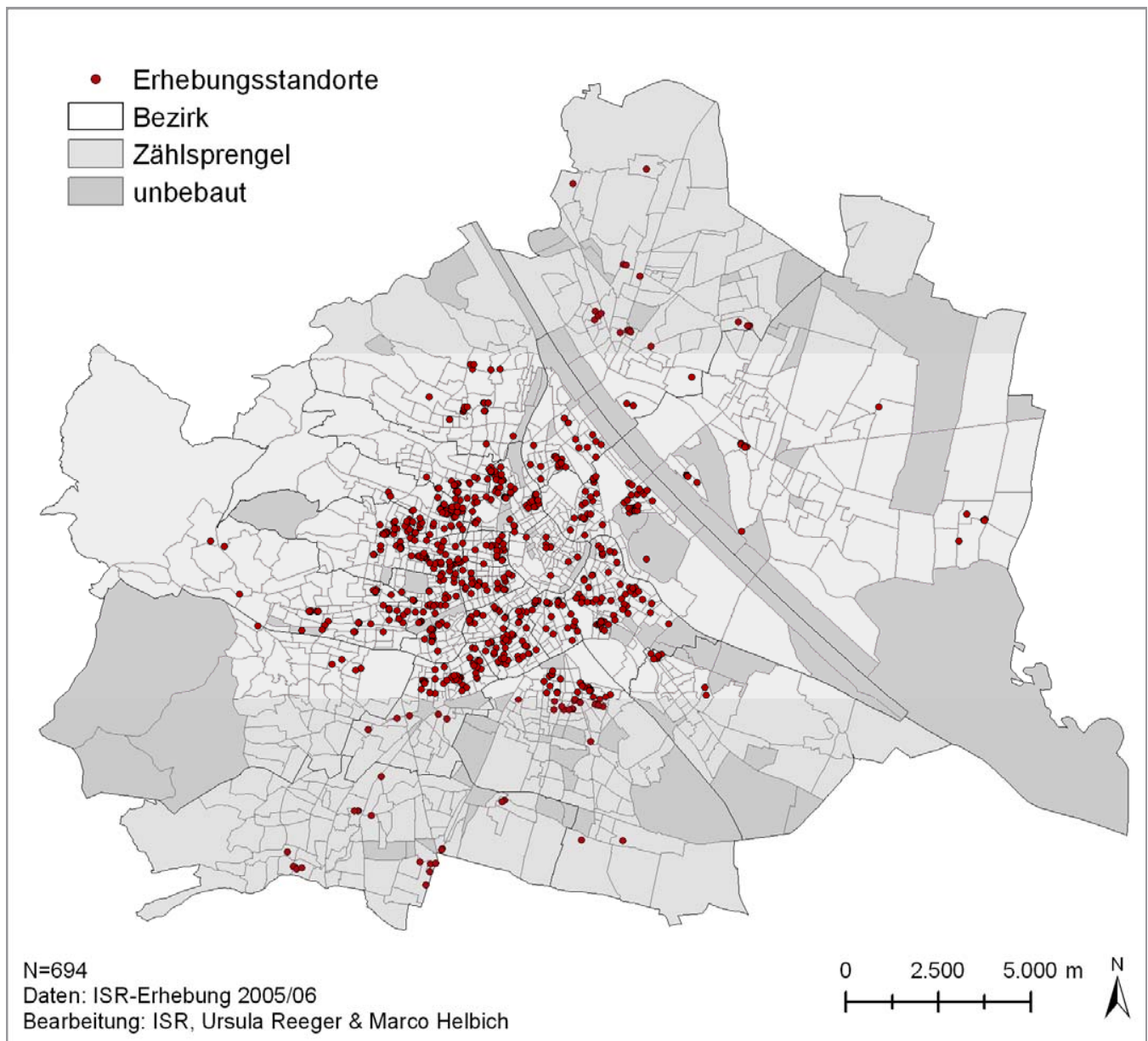

- Hausbewohner verbalisierten beim Versuch der Hauserhebung Drohungen gegenüber unserem Erhebungsteam und/oder untersagten definitiv den Zutritt (öfter);

- es war aus anderen Gründen (Gegensprechanlage) kein Zutritt zu den Häusern möglich (öfter).

Karte 9 zeigt die Verortung sämtlicher im Sample von 2005/06 enthaltenen Häuser im Wiener Stadtraum. Die Basis bildete dabei das Sample von 1981. Einerseits war

24 Bei den Karten auf Hausebene ist zu beachten, dass aus technischen Gründen nicht immer alle Objekte dargestellt werden konnten. Trotzdem bieten sie einen wertvollen Überblick, der die Ergebnisse gut widerspiegelt. 
bereits im Rahmen der Ersterhebung besonderer Wert darauf gelegt worden, Häuser in allen Wiener Gemeindebezirken zu berücksichtigen, andererseits bildeten sich quasi automatisch und bedingt durch die Konzentration der (ex)jugoslawischen Gastarbeiterbevölkerung klumpige Verteilungsmuster. So sind die Bezirke jenseits der Donau, welche als Wohngebiete für Migranten erst in relativ rezenter Zeit interessant wurden, durch verhältnismäßig wenige Häuser in der Erhebung vertreten. Analoges gilt für die Innere Stadt. Relativ schwach präsent sind weiters die Bezirke Simmering und Liesing sowie Döbling und die Brigittenau. In den übrigen Bezirken bilden die im Rahmen der Enquete berücksichtigten Gebäude zumeist Konzentrationsmuster, welche sowohl die „bürgerlichen“ inneren Bezirke mit gründerzeitlichem Baubestand als auch die traditionellen Gastarbeiterbezirke mit gründerzeitlicher Zinskasernenbebauung westlich und südlich des Gürtels umfassen.

Das Sample beinhaltete also Häuser in sämtlichen Wiener Gemeindebezirken, wenngleich die Verteilung auf die unterschiedlichen Bezirke in einem erheblichen Ausmaß variierte und bereits durch die Selektionskriterien der Erhebung des Jahres 1981 (vgl. Lichtenberger 1984: 34 ff.) vorgegeben war. Der Wohndistribution der exjugoslawischen Gastarbeiterbevölkerung im Wiener Stadtraum entsprechend waren und sind die (Gast)arbeiterbezirke im Sample deutlich stärker vertreten als die Cottageviertel, wobei Ottakring mit einem Anteil von 10,6\% (74 Häuser) den Spitzenplatz einnimmt. In der Kategorie der Arbeiterbezirke sind weiters stark repräsentiert: Rudolfsheim-Fünfhaus mit 49, die Leopoldstadt mit 45, Favoriten und Meidling mit jeweils 42 Gebäuden sowie Margareten mit 41. Mit nur 24 deutlich weniger Wohnhäuser wurden im traditionellen Arbeiterbezirk Brigittenau erhoben. Schwach vertreten ist mit einem Anteilswert von 1,3\% (9 Gebäude) der flächen- und einwohnermäßig große Bezirk Simmering. Aber auch in traditionell eher bürgerlichen Gemeindebezirken, wie in Landstraße (51) und am Alsergrund (44), konnten umfangreiche Stichproben gezogen werden. Am schwächsten ist der klassische Oberschichtwohnbezirk Hietzing in unserer Analyse präsent. Aus diesem wurden bloß 5 Häuser $(0,7 \%)$ in die Erhebung einbezogen. Auch die Innere Stadt ist mit der nur bescheidenen Zahl von 7 Gebäuden (1\%) berücksichtigt. Ein Wert, der jedoch der geringen Wohnpräsenz ehemaliger Gastarbeiter im Zentrum Wiens entspricht. Das Stadtgebiet am jenseitigen Donauufer ist mit insgesamt 37 Häusern ebenfalls eher schwach repräsentiert. Dieses Faktum ist allerdings aus der traditionellen residentiellen Konzentrationstendenz der exjugoslawischen Gastarbeiterimmigration der 1960er und 1970er Jahre auf die cisdanubischen Gemeindebezirke abzuleiten.

\subsubsection{Veränderungen hinsichtlich der Gebäudenutzung}

Bezogen auf die Grundgesamtheit von 696 Gebäuden ist weiters anzumerken: In 657 Fällen $(94,4 \%)$ handelte es sich bei der Neuerhebung exakt um dieselben Gebäude, die bereits in den Kontext der Erhebung von 1981 einbezogen worden waren. Im Falle von 30 Gebäuden $(4,3 \%)$ befanden sich zwischenzeitlich errichtete Neubauten 


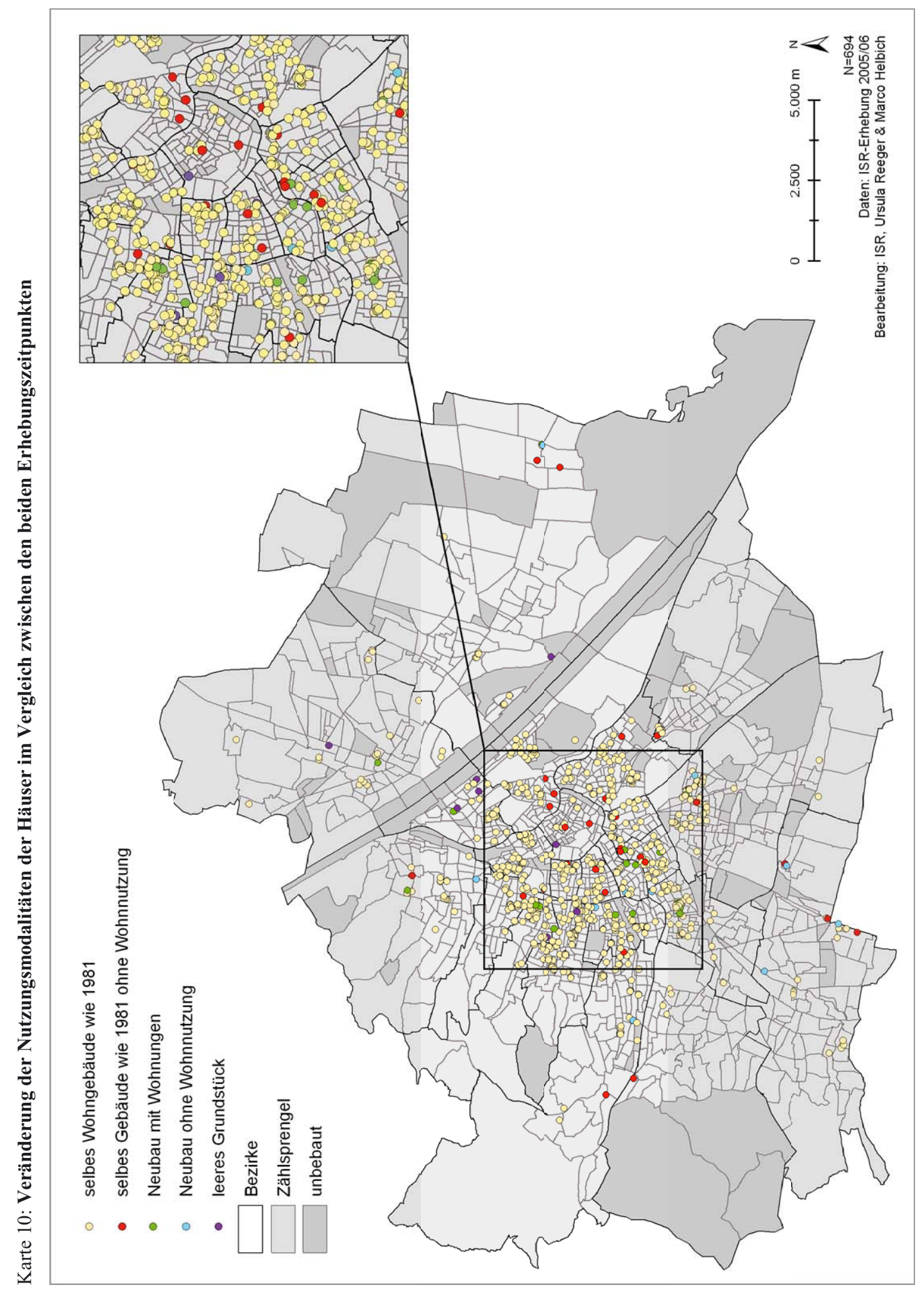


an derselben Stelle und in 9 Fällen waren die Liegenschaften zum Zeitpunkt der Erhebung 2005 unbebaut und/oder ungenutzt. Auf diese letztgenannte Kategorie (leere Parzelle oder Nutzung als Parkplatz) entfiel also ein Anteilswert von 1,3\%. Das eben Gesagte ist deshalb von Relevanz, da auf dieser Grundlage die Diversifikation des Samples in zwei Subsamples basiert:

- Subsample 1: dieselben Gebäude wie in der Erhebung $1981(\mathrm{n} 1=657)$

- Subsample 2: Neubauten, „Baustellen“ etc. (n2=39).

Die Karte 10 dokumentiert, dass die Gebäude, in denen sich eine Veränderung hinsichtlich der Nutzung vollzogen hat, sehr ungleichmäßig über den Wiener Stadtraum verteilt sind. Jene ehemaligen Gastarbeiterwohnhäuser, in denen 2005 keine Wohnnutzung mehr nachweisbar war, konzentrieren sich vor allem auf die Innenstadt und die diese umgebenden inneren Gemeindebezirke (vgl. den Detailausschnitt in der Karte). Neubauten mit Wohnnutzung waren vor allem in den westlichen Gemeindebezirken, zum Teil innerhalb vor allem aber außerhalb des Gürtels, errichtet worden. Die wenigen Neubauten ohne Wohnnutzung sowie die unbebauten Liegenschaften verteilen sich sehr dispers im Stadtraum. Bei einem Großteil der erhobenen Gebäude hat sich allerdings keinerlei Nutzungsänderung vollzogen.

Die anteilsmäßigen Relationen der einzelnen Nutzungsarten zu den beiden Erhebungszeitpunkten weisen eine nur geringe Variationsbreite auf. Sowohl 1981 als auch 2005 überwogen die Nutzungen als reines Wohnhaus sowie als Wohnhaus mit Büros und Geschäftslokalen. Nur 7 (1981: 5) Häuser waren als überwiegende Geschäftsbzw. Bürogebäude zu klassifizieren.

Tabelle 7: Veränderungen der Gebäudenutzung, 1981 und 2005

\begin{tabular}{lrr}
\hline & absolut & in \% \\
\hline gleiche Nutzung Wohnhaus & 204 & 32,6 \\
gleiche Nutzung überwiegend Wohnhaus mit Büros, Geschäften & 211 & 33,7 \\
von überwiegender Wohnnutzung zu reiner Wohnnutzung & 102 & 16,3 \\
vom reinen Wohnhaus zu überwiegend Wohnhaus mit Büros, Gesch. & 90 & 14,4 \\
restliche Fälle & 19 & 3,0 \\
insgesamt & 626 & 100,0 \\
\hline
\end{tabular}

Quelle: eigene Erhebung 2005.

Die komparative Analyse zur Nutzung der erhobenen Gebäude lässt für zwei Drittel der Häuser im Sample eine Stabilität der Nutzungsmodalitäten erkennen (vgl. Tab. 7). Mit 32,6\% sind Häuser vertreten, welche zu beiden Erhebungszeitpunkten als Wohngebäude genutzt waren. Mit 33,7\% ein weiteres rundes Drittel präsentierte sich in beiden Analysejahren als Wohnhaus mit Büros oder Geschäften. Auch im Falle dieses Drittels war also eine Nutzungsstabilität gegeben. Veränderungen hinsichtlich der Nutzung hatten sich bei rund 30\% des erhobenen Baubestandes ergeben: Bei 
$16,3 \%$ hatte innerhalb des Analysezeitraumes eine Verschiebung von überwiegender zu reiner Wohnnutzung stattgefunden, in 14,4\% der Fälle war eine Nutzungsveränderung vom reinen Wohnhaus zur überwiegenden Nutzung als Wohnhaus mit Büros und Geschäftslokalen erfolgt.

\subsubsection{Wohnnutzung: Die Zahl der Wohneinheiten}

Im Hinblick auf die Wohnungszahl je Haus ist das Gros der Gebäude durch weitgehende Stabilität gekennzeichnet, wenngleich sich auch Verschiebungen zwischen den beiden Analysezeitpunkten vollzogen haben. Diese sind zumindest zum Teil einerseits auf die Unmöglichkeit der exakten Verifikation der Wohnungszahl im Haus, aber auch auf die Sanierung und Zusammenlegung von Wohneinheiten zurückzuführen. Jedenfalls lagen in 68\% der erhobenen Gebäude (427) die Abweichungen der Wohnungszahlen in einem geringfügigen Rahmen von $+5 /-5$ Wohnungen.

Im Jahre 1981 war die Klasse „16 bis 22 Wohnungen“ mit 25,4\% am stärksten besetzt, gefolgt von der Kategorie „10 bis 15 Wohnungen“" mit exakt 21\%. In 19,2\% der erhobenen Gebäude befanden sich 23 bis 29 Wohneinheiten. Sehr kleine (unter 10 Wohnungen) sowie relativ große Häuser (mehr als 40 Wohnungen) waren mit jeweils 9,4\% im Ersterhebungssample am schwächsten repräsentiert (vgl. Tab. 8).

Tabelle 8: Zahl der Wohnungen, 1981 und 2005

\begin{tabular}{lrrrr}
\hline & 1981 absolut & 1981 in \% & 2005 absolut & 2005 in \% \\
\hline unter 10 Wohnungen & 59 & 9,4 & 72 & 11,5 \\
10 bis 15 Wohnungen & 131 & 21,0 & 153 & 24,4 \\
16 bis 22 Wohnungen & 159 & 25,4 & 189 & 30,2 \\
23 bis 29 Wohnungen & 120 & 19,2 & 99 & 15,8 \\
30 bis 39 Wohnungen & 97 & 15,5 & 82 & 13,1 \\
40 und mehr Wohnungen & 59 & 9,4 & 31 & 5,0 \\
insgesamt & 625 & 100,0 & 626 & 100,0 \\
\hline
\end{tabular}

Quelle: Erhebungen 1981 und 2005.

Bis zum Jahr 2005 haben sich diesbezüglich deutliche Verschiebungen ergeben. In summa ist die Tendenz zu einem Anstieg bei den Klassen mit geringeren Zahlen an Wohneinheiten pro Haus zu konstatieren, während die Kategorien mit höheren Wohnungszahlen anteilsmäßige Rückgänge zu verbuchen hatten. Die Klasse mit 40 und mehr Wohnungen ist mit bloß 5\% am schwächsten vertreten - wohl eine Folge von Zusammenlegungen sehr kleiner Zimmer-Küche-Wohneinheiten im Verlauf der vergangenen 25 Jahre. Im Gegensatz dazu hat die Kategorie mit bis zu 10 Wohneinheiten leicht zugelegt und ist nun mit 11,5\% in der Stichprobe vorhanden. Die Zuwächse beliefen sich in den Klassen von 10 bis 15 sowie von 16 bis 22 Wohneinheiten auf 3,4 
bzw. 4,8 Prozentpunkte. Der Häuserbestand der Kategorien „23 bis 29 “ und „,30 bis 39 Wohnungen“ verzeichnete Rückgänge im Ausmaß von 3,4 bzw. 2,4 Prozentpunkten.

\subsubsection{Basisparameter des Gebäudezustandes}

Zum Zwecke der Klassifikation der baulichen Marginalität der Häuser wurden im Rahmen der Ersterhebung von 1981 der Erhaltungszustand und der Ausstattungsstandard herangezogen. Als ein Kriterium für eine mit der steigenden Zahl von Gastarbeiterwohnungen im Haus einhergehende bauliche Verslumungstendenz diente die Kategorie „beschädigter Flur“. Der Zustand der Fassade besaß laut Lichtenberger (1984) aufgrund des Wiener „Fassadenkults“ geringere Aussagekraft. Das in Wien fest verankerte Pseudoeigentumsdenken durch die Vererbung von Mietwohnungen sowie die Möglichkeit der Aufnahme von Wohnungsverbesserungskrediten trug zu einer Separierung zwischen Wohnungs- und Hausimage bei. Selbst äußerlich eher heruntergekommene Gebäude beherberg(t)en nicht selten sehr repräsentative Wohneinheiten. Dieses Phänomen wirkte und wirkt extremen Segregationstendenzen entgegen. Dieser Anachronismus zwischen einem teilweise schlechten Erhaltungszustand der Fassade und in solchen Gebäuden befindlichen zuweilen gediegenen Wohnungen besteht nach wie vor. Zugleich sind aber in den 1980er und 1990er Jahren auch Generalsanierungen des Gebäudes mit einer standardmäßigen Aufwertung der Wohneinheiten ein häufiges Phänomen geworden. Bezogen auf die Gesamtzahl der Wohnungen hat sich bei den Exjugoslawen ebenso wie bei den Wienern der Anteil der Bassenawohnungen beträchtlich Ausmaß verringert. Trotz objektiver Verbesserung der Wohnverhältnisse ist aber der Wohnungsstandard der Exjugoslawen, verglichen mit jenem der Wiener Bevölkerung, etwas zurückgeblieben.

\subsubsection{Der Zustand der Fassade}

Die komparative Analyse des äußeren Erscheinungsbildes der Wohnhäuser zu beiden Erhebungszeitpunkten lässt Rückschlüsse auf das Ausmaß an getätigten Investitionen in das Gebäude zu. Einen besonders augenfälligen Faktor repräsentiert der Zustand der Hausfassade, wobei im Rahmen der Ersterhebung von 1981 zwei Klassifikationskategorien vorgegeben wurden: 1 = neuer Verputz, 2 = alter Verputz. Wir haben uns auch 2005 an diesen beiden Kategorien orientiert (vgl. Tab. 9).

Das Gros (44,5\%) der im Sample befindlichen Gebäude wies zu beiden Erhebungszeitpunkten alten Verputz auf. Zählt man jene Häuser hinzu, welche in beiden Jahren mit neuemVerputz ausgestattet waren, so ergibt sich ein knapp über der Hälfte $(51,9 \%)$ aller erhobenen Bauten liegender Anteil, welcher durch Stabilität hinsichtlich des Fassadenzustands gekennzeichnet ist. Eine Aufwertung und optische Verbesserung des Erscheinungsbilds der Fassade ist in 230 Häusern (36,2\%) erfolgt. Demgegenüber war bei mehr als einem Zehntel (76 bzw. 11,9\%) der Gebäude eine eindeutige Verschlechterung des Erhaltungszustands der Fassade zu konstatieren. 
Tabelle 9: Veränderungen des Fassadenerhaltungszustands, 1981 und 2005

\begin{tabular}{lrr}
\hline & absolut & in \% \\
\hline 1981 und 2005 neuer Verputz & 47 & 7,4 \\
1981 und 2005 alter Verputz & 283 & 44,5 \\
Verbesserung 1981 bis 2005 & 230 & 36,2 \\
Verschlechterung 1981 bis 2005 & 76 & 11,9 \\
insgesamt & 636 & 100,0 \\
\hline
\end{tabular}

Quelle: Erhebungen 1981 und 2005.

Die bezirksbezogene Analyse des Fassadenerhaltungszustands führt zu bezirksspezifisch stark divergierenden Resultaten, welche teilweise mit dem Status des Bezirks als „Nobel-“ oder „Arbeiterbezirk“ zusammenhängen dürften. Allerdings ist darauf hinzuweisen, dass es sich hierbei um keinen stringenten Zusammenhang handelt, da auch in zahlreichen Gemeindebezirken, welche letzterer Kategorie hinzuzuzählen sind, seitens der Hausbesitzer ebenso in die Fassadenamelioration investiert wie in „gutbürgerlichen“"Wohnvierteln (vgl. Karte 11).

Karte 11: Veränderung des Fassadenerhaltungszustands, 1981 bis 2005 nach Bezirken

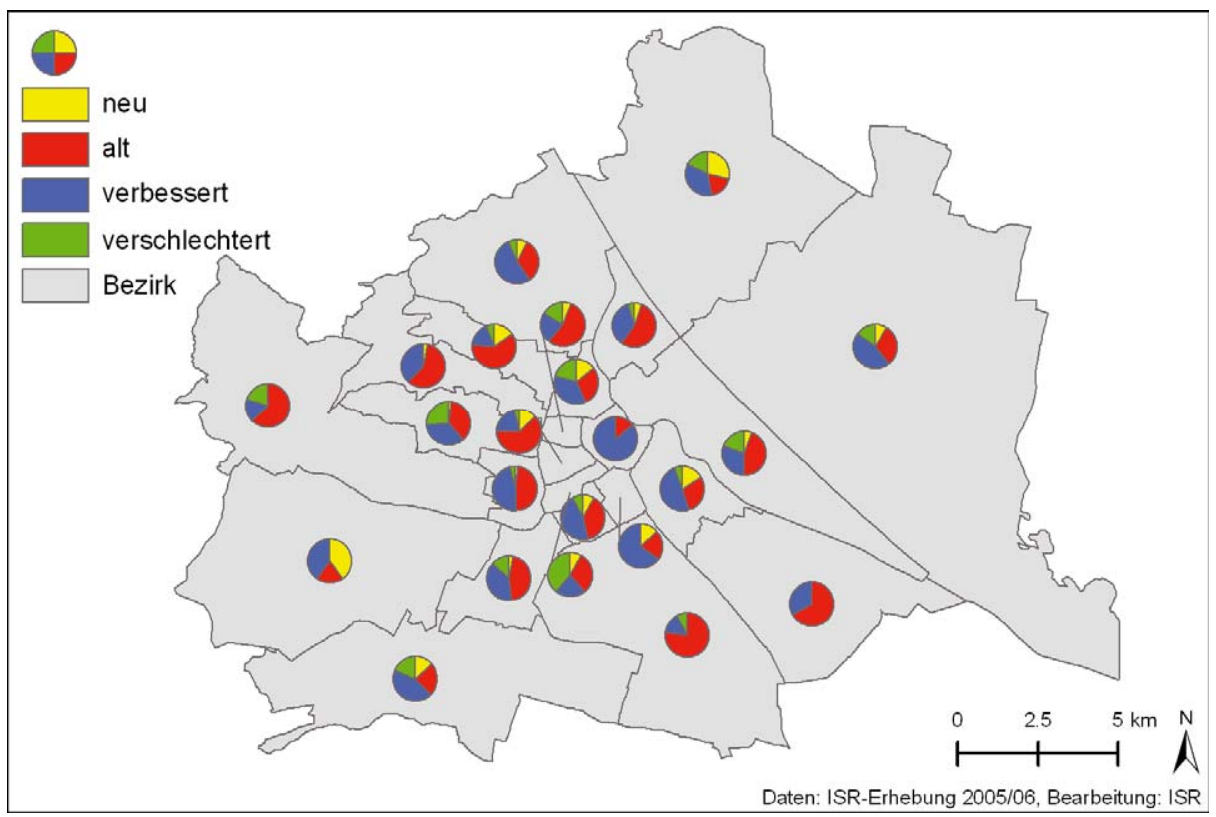

Faktum ist, dass das höchste Ausmaß an Fassadenaufwertungen mit rund $86 \%$ in der Inneren Stadt zu konstatieren war, wobei neuerlich einschränkend angemerkt wer- 
den muss, dass in diesem Bezirk insgesamt nur 7 Gebäude in die Erhebung Eingang gefunden haben. Mit einem Anteil von 65,2\% an Fassadenverbesserungen positioniert sich der 4. Gemeindebezirk an der zweiten Stelle vor Döbling mit 8 Häusern $(53,3 \%)$ in dieser Kategorie und Landstraße, wo an 25 Gebäuden (49\%) Aufwertungen durchgeführt worden waren. Hietzing ist mit einem Anteil von $40 \%$ vertreten. Es sind also vor allem bürgerliche Innen- sowie Cottagebezirke, in welchen das Ausmaß an Fassadenverbesserungen am höchsten war.

Dieses Resultat bedeutet jedoch keineswegs, dass in den traditionellen Gastarbeiterbezirken der Fassadenverfall ungehindert fortgeschritten wäre. Auch hier haben Hauseigentümer Investitionen in die Fassadenerhaltung getätigt, wenngleich das Ausmaß geringer war. In Margareten, Rudolfsheim-Fünfhaus und Donaustadt lagen die Anteile der Fassadenaufwertungen bei jeweils über 46\%, in Liesing bei 43,8\% und in Meidling bei fast 38\%. Die Bezirke 16, 17, 20 und 21 sind durch Anteilswerte verbesserter Fassaden zwischen 35 und 37\% charakterisiert. Mit Abstand am wenigsten wurde in Favoriten in die Fassadensanierung investiert. Hier war bei nur 6 Gebäuden (15\%) eine Verbesserung konstatierbar. Nur unwesentlich höher war der Anteil verschönerter Fassaden in Penzing (16,7\%) sowie in Währing (17,6\%).

Foto 1: Fassade mit neuem Verputz, 1050 Wien

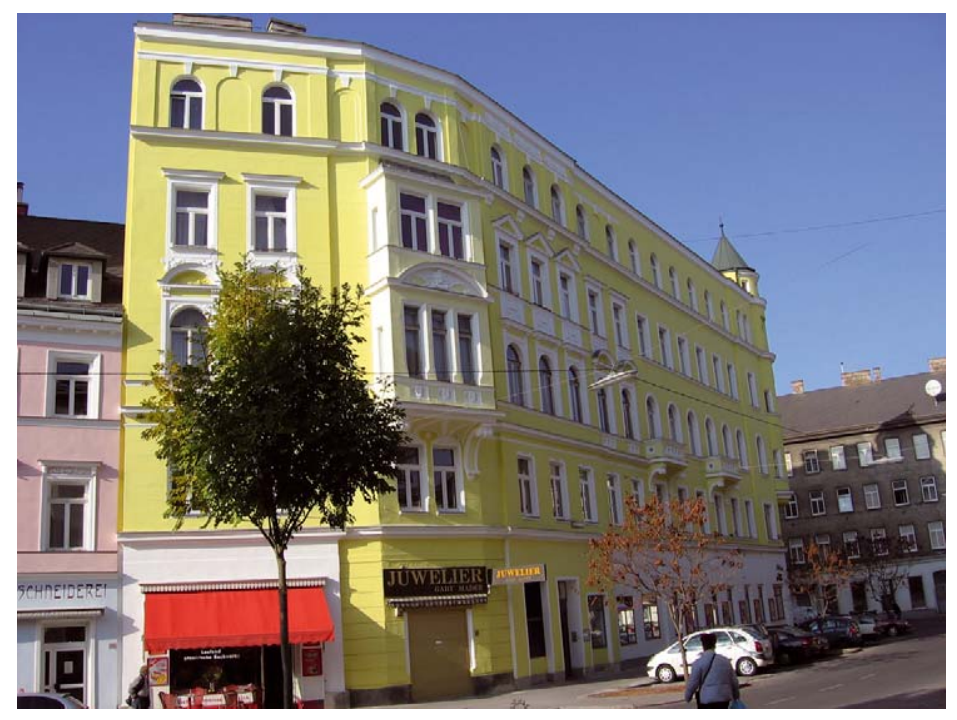

Quelle: eigene Erhebung 2005.

Die Fassadenabwertungen weisen ein davon gänzlich divergentes Verteilungsmuster auf. Das höchste Ausmaß an Fassadenverfall war 2005 in den Gemeindebezirken Mariahilf (38,5\%, jedoch nur 5 Gebäude) und Ottakring (26,2\% und 16 Gebäude) feststellbar. Verschlechterungen im Ausmaß von rund einem Fünftel des bezirksbezo- 
gen erhobenen Baubestandes entfielen auf die Bezirke 2, 9, 14 und 23. Zwischen 10 und $20 \%$ betrug das Ausmaß der Fassadenverschlechterungen in der Leopoldstadt, in der Josefstadt, in Meidling sowie jenseits der Donau in Floridsdorf und Donaustadt. Keinerlei Fassadenverfall war in den Bezirken Innere Stadt, Wieden, Simmering, Hietzing und Hernals erfolgt. Sehr bescheiden fielen die Anteile der Gebäude mit Negativentwicklungen hinsichtlich des Fassadenzustandes in den Bezirken 3, 5, 7, 10, $15,18,19$ und 20 aus.

Der Großteil der erhobenen Häuser war durch keine Veränderungen hinsichtlich des Fassadenzustandes charakterisiert. Sowohl 1981 als auch 2005 mit neuem Verputz versehen waren vor allem die Gebäude in Hietzing ( $40 \%$ allerdings bloß 2 Häuser) und in Floridsdorf (29,4\% oder 5 Häuser). Im Ausmaß von 10 bis $20 \%$ der im Bezirk erhobenen Bauten war neuer Verputz im 3., 4., 7., 9., 18. und 23. Gemeindebezirk nachweisbar. Kein einziges Gebäude, welches sich sowohl 1981 als auch 2005 mit neuem Verputz präsentierte, fand sich im 1., 10., 11. und 14. Bezirk und bloß jeweils eines war im 6., 8., 12., 15., 16., 17., 19. und 22. Bezirk lokalisiert.

\section{Foto 2: Haus mit altem Verputz, 1040 Wien}

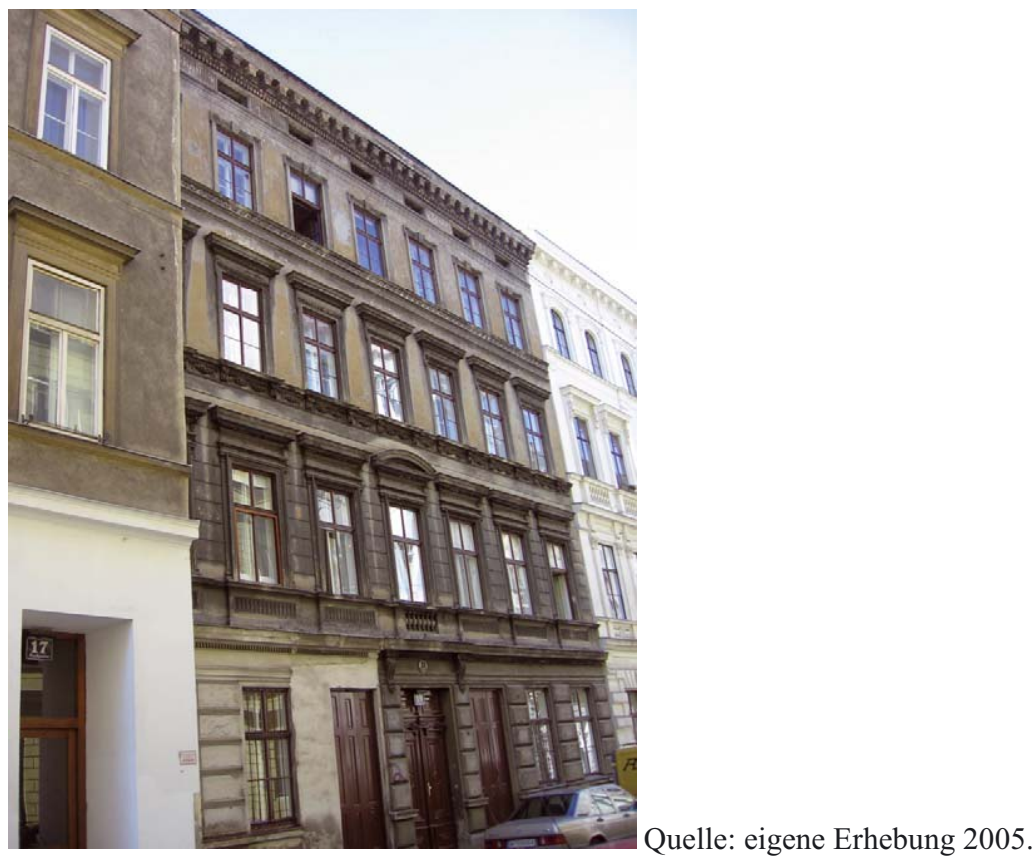

In zahlreichen Wiener Gemeindebezirken war der überwiegende Teil der Gebäude in beiden Erhebungsjahren mit älterem Verputz versehen (vgl. Karte 11). Die höchsten Anteilswerte solcher Gastarbeiterhäuser waren im 10. (31 Häuser oder 77,5\%), im 11. (6 Häuser oder $66,7 \%$ ), im 14. (19 Häuser oder 63,3\%), im 7. (15 Häuser oder 
62,5\%), im 18. (21 Gebäude oder 61,8\%), im 17. (21 Häuser oder 60\%), im 8. (10 Bauten oder 55,6\%) sowie im 20. (11 oder 55\%) Bezirk lokalisiert. Die anteilsmäßig geringste Präsenz an Gebäuden mit altem Verputz entfiel auf die Bezirke Innere Stadt (1 bzw. 14,3\%), Floridsdorf (1 oder 17,6\%) sowie Hietzing (1 oder 20\%).

Zum Zwecke einer weiteren Differenzierung des Erhaltungszustands der Fassade wurde sowohl 1981 als auch 2005 eine Klassifikation nach den drei Kategorien 1) in Ordnung, 2) teilweise beschädigt und 3) stark beschädigt vorgenommen (vgl. Tab. 10).

Im Jahr der Ersterhebung wurden 418 Hausfassaden und somit zwei Drittel als „in Ordnung" befindlich klassifiziert. Teilweise Beschädigungen wurden für 192 Gebäude $(30,5 \%)$ konstatiert. Nur ein sehr geringer Prozentsatz (3\% bzw. 19 Wohngebäude) wurde 1981 als stark devastiert eingestuft. Hinsichtlich dieses Aspekts des Gebäudezustandes hat sich im Rahmen der Neuerhebung eine grundlegende Verschiebung ergeben. Nur mehr 300 Häuser und somit ein deutlich niedrigerer Prozentanteil $(46,1 \%)$ als 1981 konnten als in Ordnung befindlich eingestuft werden. Eine exakt gleiche Zahl an Gebäuden entfiel auf die Kategorie „teilweise beschädigt“. Dies entsprach einem Anstieg der Präsenz der teilweise beschädigten Häuser im Sample um immerhin mehr als 15\% im Vergleich zu 1981. Auch die stark beschädigten Fassaden sind häufiger geworden. Ihr Anteil hat sich mit 7,8\% gegenüber dem Jahr 1981 sogar mehr als verdoppelt und umfasste 200551 Gastarbeiterwohnhäuser. Für 28 Gebäude konnte 1981 keine Klassifikation des Fassadenzustands vorgenommen werden.

Tabelle 10: Fassadenzustand, 1981 und 2005

\begin{tabular}{lrrrrr}
\hline Fassadenzustand & $\begin{array}{r}\text { in } \\
1981\end{array}$ & $\begin{array}{r}\text { Fassadenzustand 2005 } \\
\text { teilweise } \\
\text { beschädigt }\end{array}$ & $\begin{array}{r}\text { stark } \\
\text { beschädigt }\end{array}$ & $\begin{array}{r}\text { insg. } \\
\text { abs. }\end{array}$ & $\begin{array}{r}\text { insg. } \\
\text { in \% }\end{array}$ \\
\hline in Ordnung & 49,6 & 45,5 & 4,8 & 415 & 100,0 \\
teilweise beschädigt & 40,7 & 47,1 & 12,2 & 189 & 100,0 \\
stark beschädigt & 47,4 & 31,6 & 21,1 & 19 & 100,0 \\
insgesamt & 46,9 & 45,6 & 7,5 & 623 & 100,0 \\
\hline
\end{tabular}

Quelle: Erhebungen 1981 und 2005.

Die Kreuztabellierung der drei qualitativen Ausprägungen der Variable „Fassadenzustand" zu beiden Erhebungszeitpunkten erlaubt eine detailliertere Analyse der Entwicklung des visuell wahrnehmbaren Erhaltungszustandes der 623 in diesem Kontext erhobenen Gastarbeiterwohnhäuser, von denen Angaben zu beiden Erhebungszeitpunkten vorhanden waren (vgl. Tab. 10). Von den 415 Häusern, welche sich 1981 durch eine in Ordnung befindliche Fassade auszeichneten, befand sich knapp die Hälfte $(206$ bzw. 49,6\%) nach wie vor in einem äußerlich ordentlichen Zustand. In 189 Fällen (45,5\%) war es zwischenzeitlich zu Teilbeschädigungen gekommen und 20 $(4,8 \%)$ mussten 2005 hinsichtlich ihres Fassadenerhaltungszustandes als stark devastiert klassifiziert werden. 


\subsubsection{Der Zustand des Hausflurs bzw. Eingangsbereichs}

Die Beurteilung dieses Teiles der Wohnhäuser erfolgte bereits 1981 in Analogie zur Fassade in Form von zwei grundlegenden Kategorien: 1 = neuer Verputz und 2 = alter Verputz. Diese Kategorisierung wurde zum Zwecke der optimalen Vergleichbarkeit auch für 2005 beibehalten. (vgl. Tab. 11). Die hohe Zahl an „missing values“ (113 Gebäude oder 17,2\%) erklärt sich für 2005 aus dem Faktum, dass zahlreiche Häuser nicht mehr zugänglich waren und trotz entsprechender Versuche unseres Erhebungsteams seitens der Bewohner auch niemand bereit war, den Zutritt zu ermöglichen.

Tabelle 11: Zustand des Hausflurverputzes, 1981 und 2005

\begin{tabular}{lrr}
\hline & absolut & in \% \\
\hline 1981 und 2005 neuer Verputz & 59 & 10,8 \\
1981 und 2005 alter Verputz & 238 & 43,8 \\
Verbesserung 1981 bis 2005 & 166 & 30,5 \\
Verschlechterung 1981 bis 2005 & 81 & 14,9 \\
insgesamt & 544 & 100,0 \\
\hline
\end{tabular}

Quelle: Erhebungen 1981 und 2005.

Von den 544 Gebäuden, welche in der Zustandsanalyse des Hausflurverputzes Berücksichtigung finden konnten, wies die Mehrheit (43,8\%, 238 Gebäude) sowohl 1981 als auch 2005 im Eingangsbereich einen alten Verputz auf. Zu beiden Analysezeitpunkten im Eingangsbereich neu verputzt präsentierte sich dem Erhebungsteam rund ein Zehntel (10,8\% bzw. 59) der Gebäude. Bei 166 Wohngebäuden (30,5\%) war während der zweieinhalb Dekaden seit der Ersterhebung bezüglich des Verputzes im Eingangssektor eine Verbesserung eingetreten. Eine Verschlechterung musste für 81 Wohngebäude (fast 15\%) konstatiert werden.

Die komparative Analyse des Flurverputzzustands auf der Ebene der Gemeindebezirke dokumentiert bezirksspezifisch differenzierte Entwicklungen. Am deutlichsten manifestiert sich dies in der Subkategorie jener Gebäude, welche 1981 und 2005 neuen Flurverputz aufwiesen. Der Status des Bezirks als Oberschicht- oder Arbeiterbezirk scheint hierbei eine Rolle zu spielen (vgl. Karte 12). Wie verteilt sich also die Subkategorie jener Häuser, deren Eingangsbereich in beiden Erhebungsjahren durch neuen Verputz gekennzeichnet war? Die höchsten Anteilswerte werden durchwegs in den gutbürgerlichen Wohnbezirken erreicht. Mit 42,9\% weist der 1. Bezirk den höchsten Anteil auf, gefolgt von Wieden mit einer Präsenz dieser Zustandsklasse von 34,8\%. Mit nahezu 29\% im 9. und 24\% im 18. Wiener Gemeindebezirk sind es die Häuser in zwei weiteren ,guten“ Wohnbezirken, in denen der Verputz im Hausflur in einem besonders hohen Maß in Ordnung ist. Diesem Befund stehen etliche Bezirke gegenüber, in deren erhobenem Hausbestand die optimale Erhaltung des Hausflurs völlig absent ist. Dies ist zum Beispiel im 11., 12., 17., 21., 22. und 23. Bezirk der Fall; bloß 
in geringen Anteilswerten ist diese Kategorie in den Bezirken 2, 6, 7, 10, 14, 15 und 16 vorhanden.

Karte 12: Vergleich der Veränderungen des Hausflurverputzes, 1981 und 2005 nach Bezirken

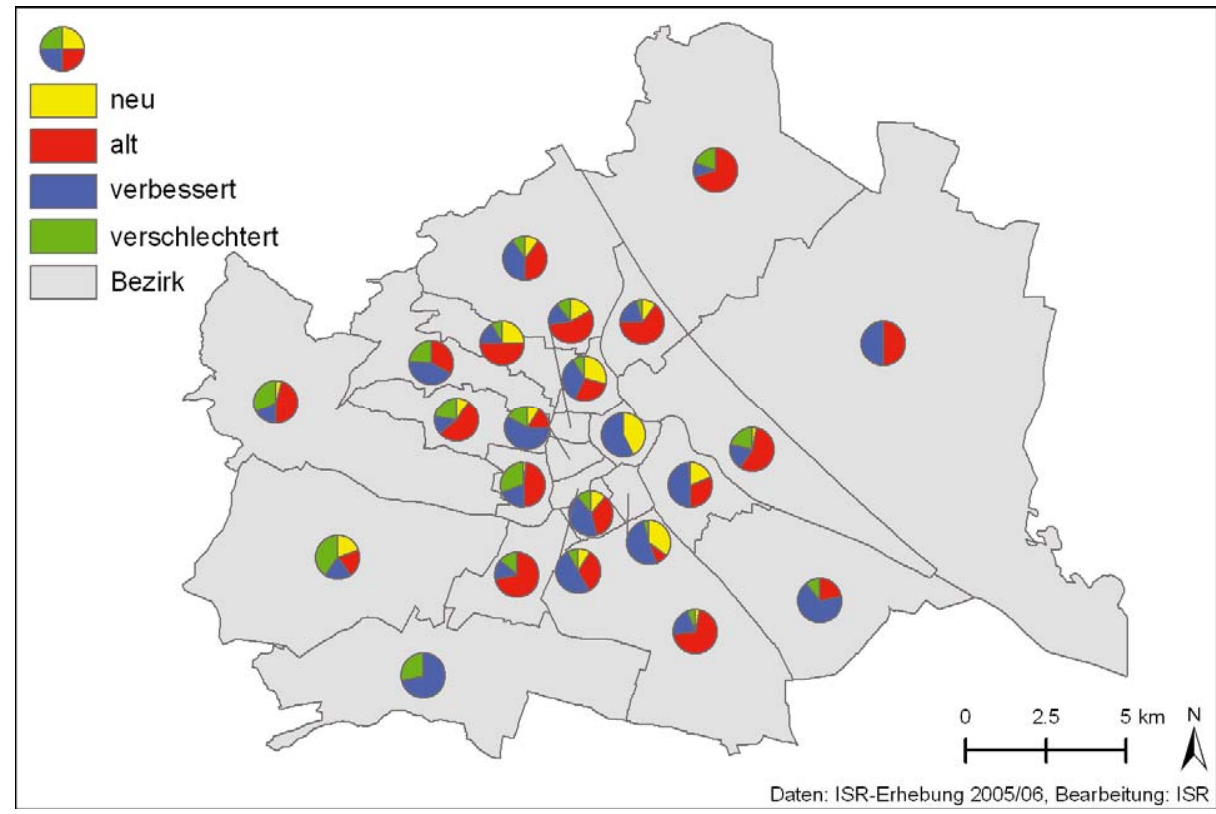

Bezüglich der Subkategorie ,,alter Verputz 1981 und 2005“ manifestiert sich auf Bezirksebene ein konträres Verteilungsmuster. Mit Anteilen von jeweils über $70 \%$ ist für die Bezirke 10, 12 und 21 die höchste Präsenz dieser Subkategorie ausgewiesen. Stark präsent sind Wohngebäude mit altem Verputz im Hausflur auch im 20. (65\%), 8. $(55,6 \%)$, 2. (56,8\%), 18. (52\%) und 22. (50\%) Bezirk. Nur in äußerst geringem Ausmaß oder gar nicht vorhanden war dieser Verputzzustand im 1., 4. und 23. Bezirk.

In einer ganzen Reihe von Gemeindebezirken haben sich Verbesserungen des Erhaltungszustandes des Flurverputzes in einem beträchtlichen Ausmaß vollzogen. Besonders anzuführen sind hier Liesing und Simmering, wo in 71,4\% bzw. 66,7\% der Gebäude eine Verschönerung erfolgte. Mit Anteilen von knapp der Hälfte oder darüber waren Verbesserungen des Eingangsbereichs in den Gemeindebezirken 1, 4, 6, 7 und 22 erfolgt. Nur schwach präsent sind Aufwertungen des Hausflurverputzes in Meidling (14,3\%), Ottakring (12,5\%), Währing (16\%) und Floridsdorf (10\%).

Wie verteilen sich nun jene Häuser, in welchen eine Verschlechterung der Verputzqualität im Flur konstatiert wurde? Die höchste Präsenz dieser Kategorie wird in Hietzing (40\%), Penzing (32,1\%) sowie in Rudolfsheim-Fünfhaus (30,2\%) erreicht. Weitere hohe Anteilswerte entfallen auf die Bezirke Leopoldstadt, Ottakring, Hernals 
(jeweils zwischen 20 und 25\%) und Liesing (28,6\%). Kein einziges Gebäude mit einer Minderung des Zustandes des Hausflurverputzes war im 1. und 22. Bezirk nachweisbar. Äußerst geringe Anteile dieser Kategorie waren für die Bezirke Landstraße $(2,1 \%)$, Brigittenau (5\%), Favoriten (5,9\%) sowie Währing (8\%) und Alsergrund $(8,6 \%)$ festzustellen.

Foto 3: 1981 und 2005 neuer Verputz im Flur, 1140 Wien

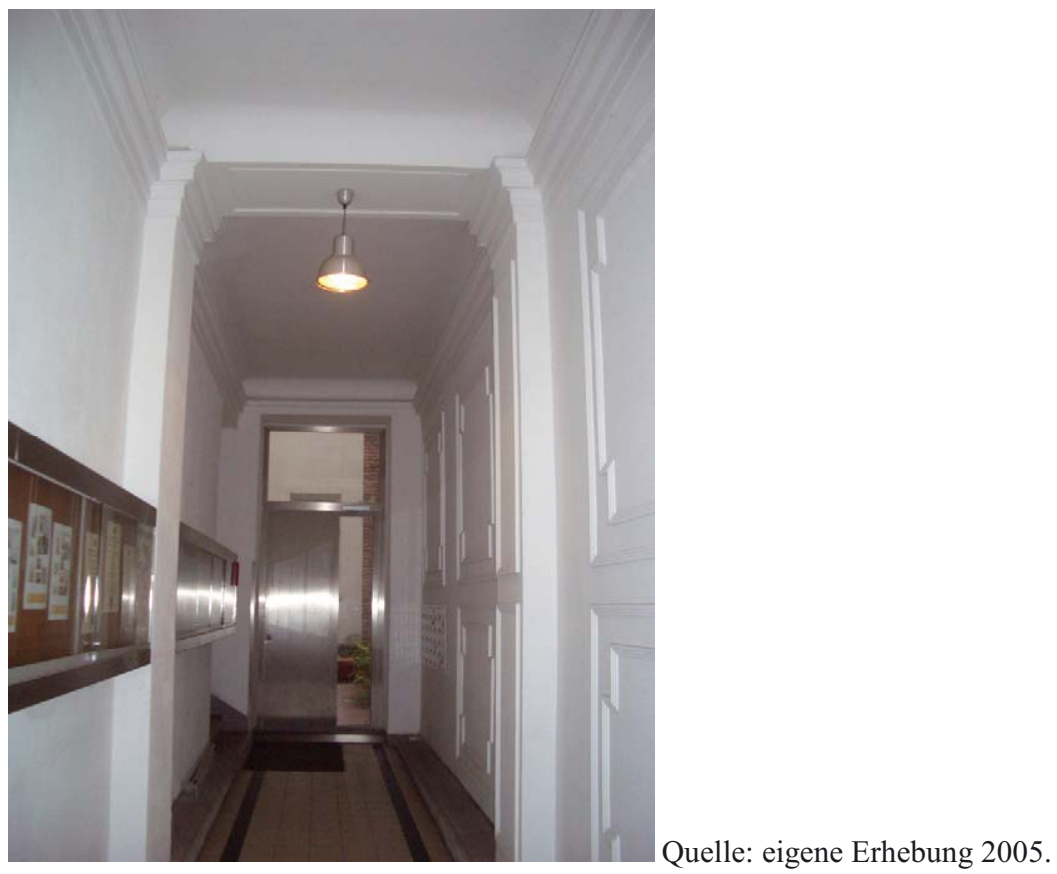

Auch der Zustand des Hausflurs wurde nach den drei Kategorien 1) in Ordnung, 2) teilweise beschädigt und 3) stark beschädigt klassifiziert, wobei die Resultate aussagekräftiger ausfallen als im Falle des Verputzes. Zunächst ein diesbezüglicher Vergleich der Samples zu den beiden Analysezeitpunkten: Im Jahre 1981 konnten 615 Gebäude in die Analyse involviert werden, nur 24 waren auszuklammern. Zum damaligen Zeitpunkt wurden für nahezu die Hälfte des Samples (281 Gebäude bzw. 45,7\%) die Hausflure als in Ordnung befindlich kategorisiert. Ein mit 43,9\% etwas geringerer Prozentsatz (270 Häuser) wies damals partiell beschädigte Eingangsbereiche auf. Von starken Beschädigungen im Flur war rund jedes zehnte Gebäude im Sample (64 Häuser) betroffen.

Der Zustand der Hausflure hat 2005 gegenüber der Ersterhebung eine deutliche Verschlechterung erfahren. 568 Häuser konnten in die Bewertung einbezogen werden, mit 89 war der Anteil der fehlenden Werte fast viermal so hoch wie 1981. Als gänzlich in Ordnung befindlich konnten 2005 nur mehr 213 Häuser klassifiziert werden. Dies entsprach einem Anteil von 37,5\%, wobei dieser Relativwert 8,2 Prozentpunkte 
unter dem Wert von 1981 angesiedelt war. Mit 42,4\% (241 Gebäude) lag die Präsenz partiell beschädigter Hausflure geringfügig (-1,5\%) unter jener des Jahres 1981. Die gravierendste Verschiebung hat sich hinsichtlich der als stark beschädigt zu klassifizierenden Hausflure ergeben. In diese Klasse waren 114 Gastarbeiterwohnhäuser einzuordnen. Deren Anteil lag 2005 also bei über einem Fünftel des gesamten Samples und war somit nahezu doppelt so hoch wie in der Ersterhebung.

Foto 4: 1981 und 2005 alter Verputz, 1140 Wien

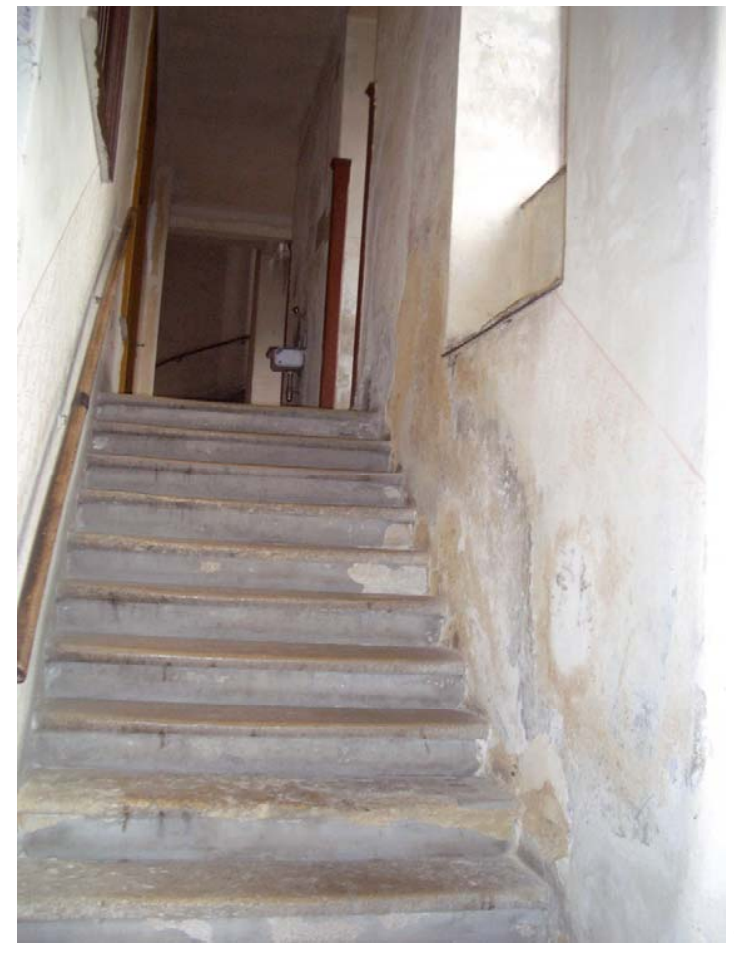

Quelle: eigene Erhebung 2005.

Ein Vergleich der Veränderungen des Erhaltungszustandes der Eingangsbereiche zu beiden Erhebungszeitpunkten wird in Tabelle 12 dokumentiert. Hierbei konnten 539 Häuser einem Vergleich unterzogen werden. Unter den 204 Gebäuden, welche zu Beginn der 1980er Jahre als baulich in Ordnung kategorisiert werden konnten, waren $106(43,6 \%)$ auch im Untersuchungsjahr 2005 in Ordnung. Bei 109 war eine Verschlechterung des Flurzustandes eingetreten. Diese 44,9\% waren 2005 als partiell beschädigt einzustufen. In 18 Fällen (11,5\%) war eine erhebliche Devastierung des Eingangsbereiches zu konstatieren.

Bei den 238 Gastarbeiterwohnhäusern, welche anlässlich der Erstanalyse mit teilweise beschädigtem Flur ausgestattet waren, hatten sich im Falle von 94 (nahezu 40\%) 
keine gravierenden Veränderungen vollzogen. Der Eingang war nach wie vor partiell beschädigt. In 80 Häusern, also bei rund einem Drittel, waren Sanierungsarbeiten vorgenommen worden, sodass die Hausflure 2005 als in Ordnung befindlich eingestuft wurden. Verhältnismäßig stark war die Verschiebung in Richtung der Kategorie der starken Beschädigungen. 64 (26,9\%) der 1981 bloß teilweise beschädigten Hausflure waren 2005 als stark beschädigt zu klassifizieren.

Tabelle 12: Vergleich des Hausflurzustandes, 1981 und 2005

\begin{tabular}{lcccrc}
\hline \multirow{2}{*}{$\begin{array}{l}\text { Hausflurzustand } \\
1981\end{array}$} & $\begin{array}{c}\text { in } \\
\text { Ordnung }\end{array}$ & $\begin{array}{c}\text { teilweise } \\
\text { beschädigt }\end{array}$ & $\begin{array}{c}\text { stark } \\
\text { beschädigt }\end{array}$ & $\begin{array}{c}\text { insg. } \\
\text { abs. }\end{array}$ & $\begin{array}{l}\text { insg. } \\
\text { in \% }\end{array}$ \\
\hline in Ordnung & 43,6 & 44,9 & 11,5 & 243 & 100,0 \\
teilweise beschädigt & 33,6 & 39,5 & 26,9 & 238 & 100,0 \\
stark beschädigt & 31,0 & 48,3 & 20,7 & 58 & 100,0 \\
insgesamt & 37,8 & 42,9 & 19,3 & 539 & 100,0 \\
\hline
\end{tabular}

Quelle: Erhebungen 1981 und 2005.

Foto 5: Prachtvolles gutbürgerliches Wohnhaus mit Jugendstilanklängen, Flur 1981 und 2005 in Ordnung befindlich, 1040 Wien

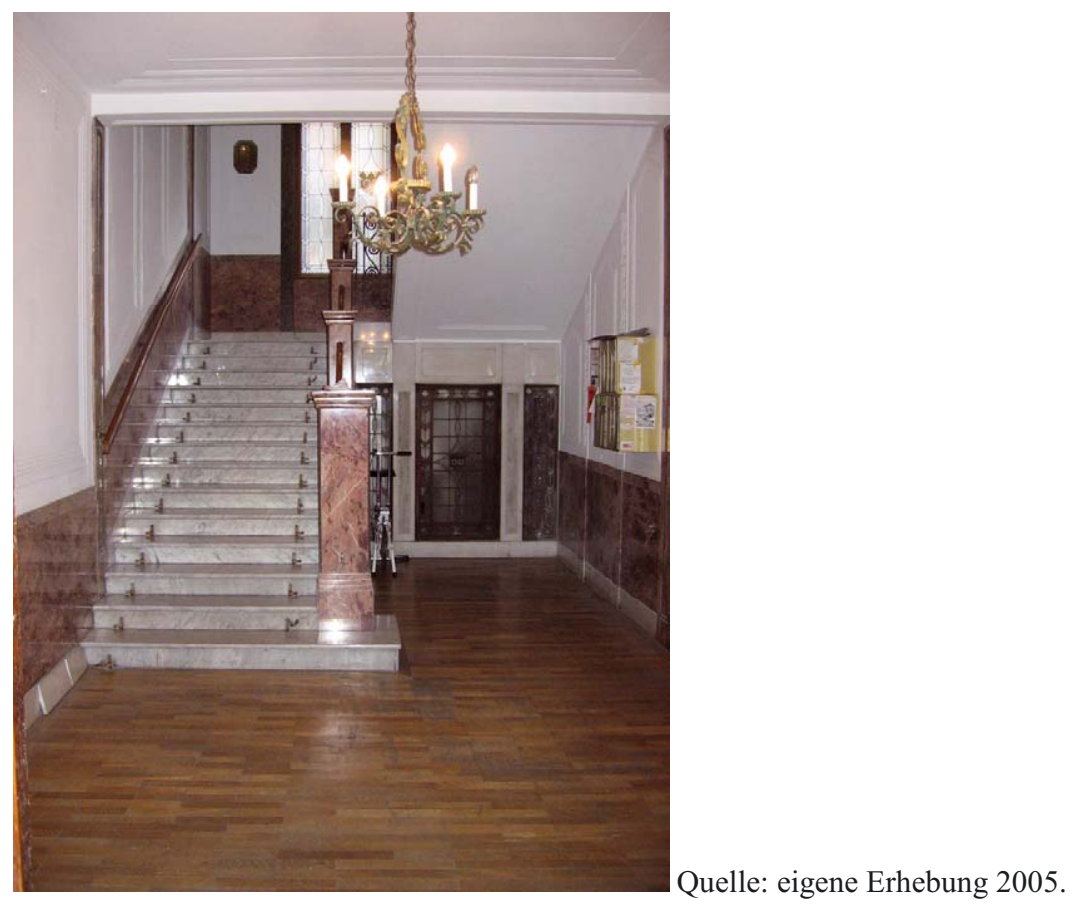


Foto 6: Beschädigungen im Flur 1981 und 2005, 1050 Wien

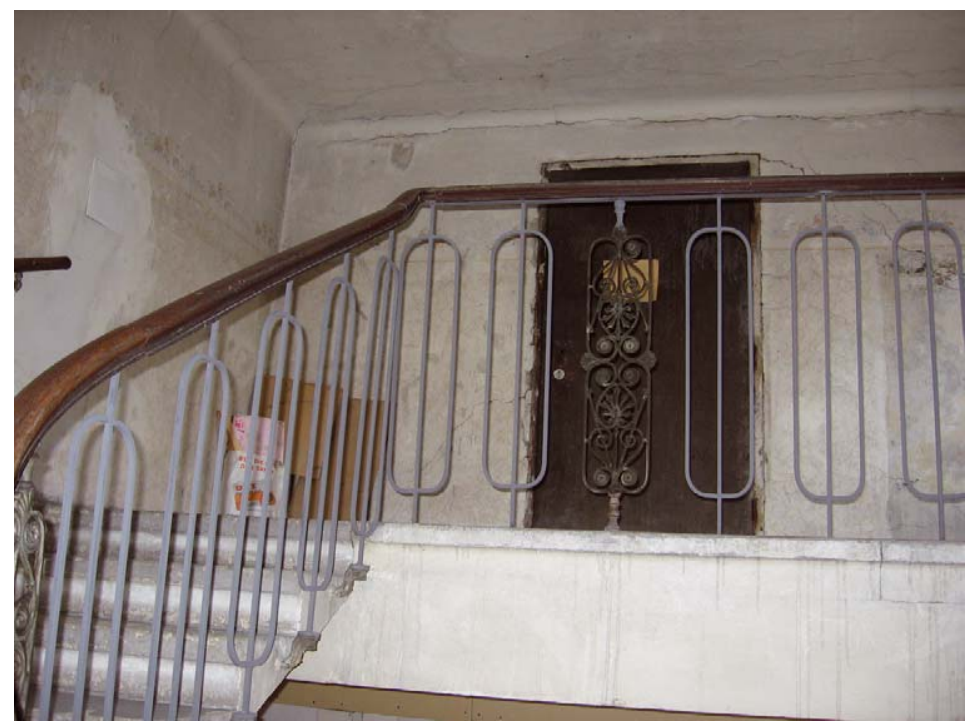

Quelle: eigene Erhebung 2005.

Auch in der Subgruppe der 58 Wohngebäude, deren Flure 1981 starke Beschädigungen aufwiesen, hatten sich Veränderungen ergeben. Bei rund einem Fünftel $(20,7 \%$ bzw. 12 Häuser) war der Flur nach wie vor erheblich devastiert, aber bei fast der Hälfte (28 bzw. 48,3\%) waren Teilsanierungen durchgeführt worden, sodass die Eingänge als nur mehr partiell beschädigt klassifiziert wurden. Bei fast einem Drittel (18 Häuser bzw. 31\%) war eine weitgehende Sanierung in die Wege geleitet worden.

\subsubsection{Der Zustand der Innenhöfe}

Ein weiterer einer Klassifikation leicht zu unterziehender Bereich in den meisten Häusern war der Innenhof. Dieser Bestandteil gründerzeitlicher Wohnbauten präsentiert sich in seinem Erscheinungsbild so unterschiedlich wie die Häuser an sich. Die Gestaltungspalette der Innenhöfe reicht dabei von - bei extrem hohem gründerzeitlichem Bebauungsgrad - gerade einmal ausgesparten engen Lichthöfen über flächenmäßig größere, jedoch weitgehend ungepflegte Höfe, die bestenfalls als Stellplätze für Mülltonnen sowie als ,wilde“ Sperrmülldeponien Verwendung finden, bis zu großzügig geplanten Innenhöfen, die sich aufwendig begrünt und gärtnerisch ansprechend gestaltet präsentieren.

Als ein basales Kriterium zur Bewertung des Innenhofes wurde 1981 der Zustand des Verputzes herangezogen. In die Analyse fanden 478 Gebäude Eingang. Der Anteil der fehlenden Gebäude war mit 27,2\% (179 Häuser) verhältnismäßig hoch, was auf die Unzugänglichkeit von Höfen bzw. vielfach auf deren Nichtvorhandensein zurück- 
zuführen war. Zu beiden Erhebungszeitpunkten mit einem neuen Verputz ausgestattet waren 27 Innenhöfe, also nur 5,6\%. Nahezu zwei Drittel der Höfe (63,6\% bzw. 304) waren in beiden Jahren mit einem älteren Verputz versehen. Die komparative Analyse ergab weiters, dass sich diesbezüglich Verbesserungen bei fast einem Fünftel des untersuchten Gebäudebestands vollzogen haben. Bei 93 Innenhöfen (19,3\%) war eine Sanierung des Innenhofverputzes erfolgt. Abwertungen der Verputzqualität waren für 54 Häuser $(11,3 \%)$ nachweisbar.

Foto 7: „Eigenwillige“ Hinterhofgestaltung: ein buntes Gemisch von Satellitenschüsseln und Wäscheleinen, 1160 Wien

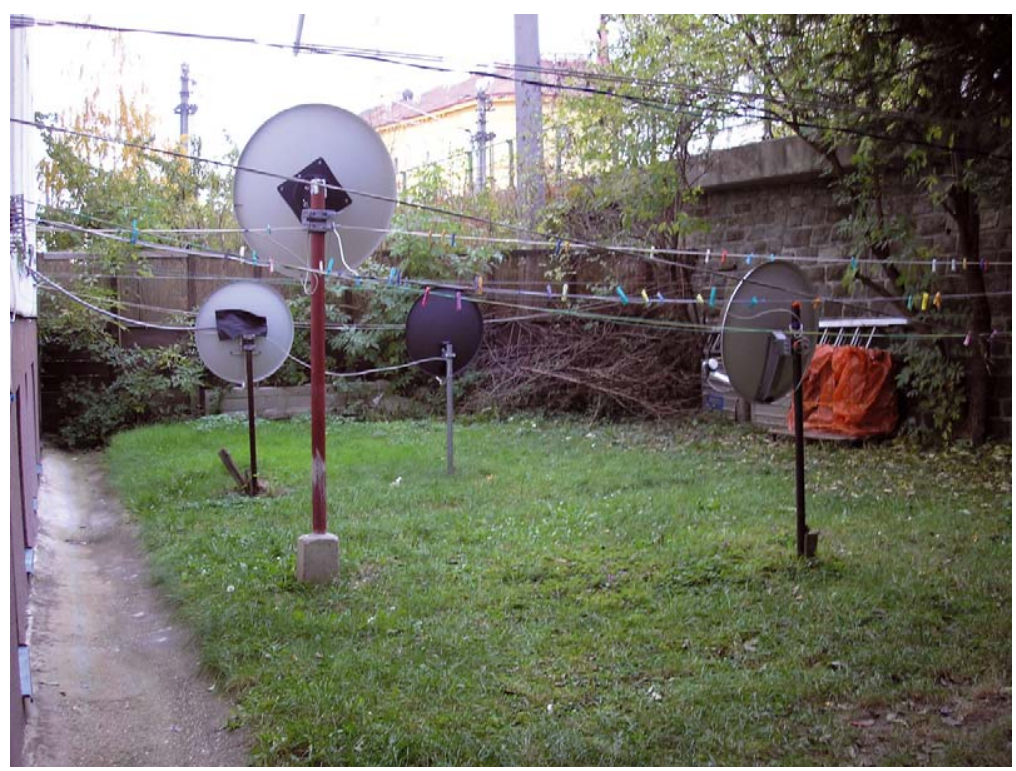

Quelle: eigene Erhebung 2005.

Ein weiteres relevantes Beurteilungskriterium für den baulichen Gesamtzustand der Gebäude manifestiert sich im Zustand des Innenhofes. Hierbei haben sich zu den beiden Erhebungszeitpunkten erheblich voneinander divergierende Resultate ergeben. 1981 konnten 605 Innenhöfe von Gastarbeiterwohnhäusern einer Klassifikation unterzogen werden. Davon wurden 304 (und somit knapp mehr als die Hälfte) als in Ordnung befindlich eingestuft. 230 Innenhöfe und damit ein Anteil von 38\% wiesen leichte Beschädigungen auf und wurden dementsprechend als teilweise devastiert kategorisiert. Der Gruppe der stark beschädigten Innenhöfe mussten 71 Fälle $(11,7 \%)$ zugeordnet werden.

Die Neuerhebung von 2005 konnte nachweisen, dass hinsichtlich des Innenhofzustandes eine wesentliche Abwertung stattgefunden hatte. Infolge des Problems der generell verminderten Zugänglichkeit der Häuser konnten allerdings nur mehr 511 
Höfe in die entsprechende Analyse involviert werden. Mit 146 war die Zahl der nicht einbezogenen Innenhöfe also nahezu dreimal so groß wie 1981. Von den zugänglichen Höfen befanden sich 128 in einem tadellosen Zustand. Dies entsprach einem Prozentanteil von $25 \%$, welcher somit nur halb so hoch ausfiel wie 1981. 66 Häuser (12,9\%) wiesen stark beschädigte Innenhöfe auf. Dieser Anteil war nur um 1,2\% Prozentpunkte höher als 1981. Die wesentlichste Verschiebung hatte sich in der Kategorie der partiell beschädigten Innenhöfe vollzogen. 316 Höfe, mit $61,8 \%$ also nahezu zwei Drittel (!), wiesen teilweise Beschädigungen auf. Damit lag der Zuwachs in dieser Kategorie gegenüber dem Ersterhebungsjahr bei 23,8 Prozentpunkten.

Foto 8: Hof mit Relikten alter vorstädtischer Bebauungsstrukturen, 1110 Wien

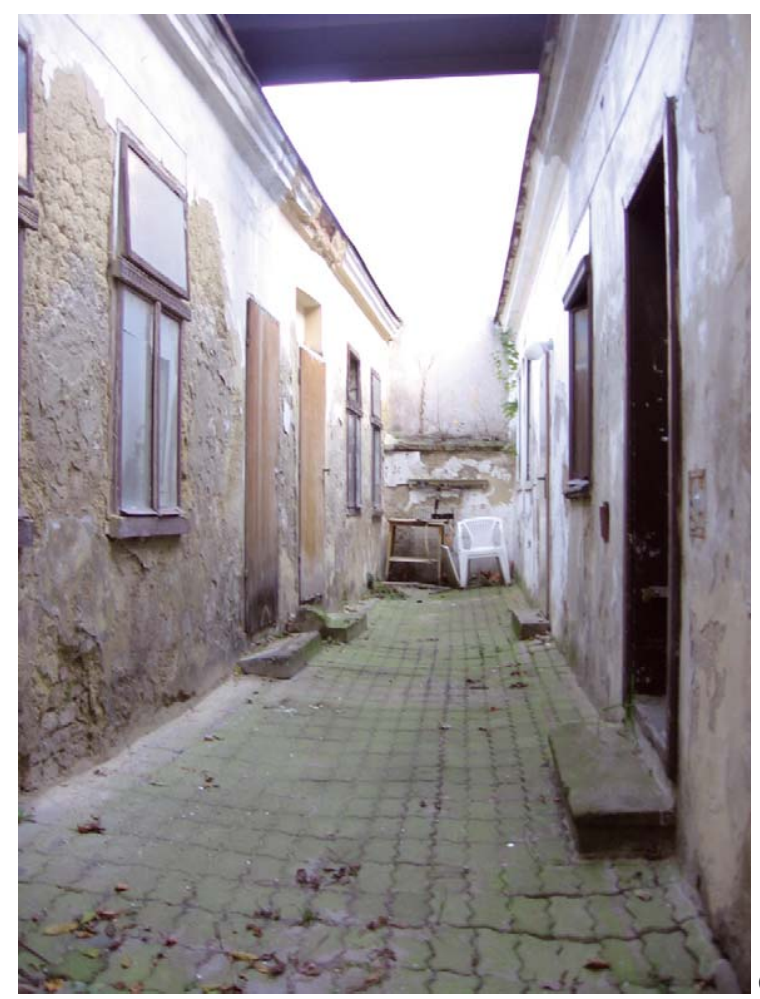

Quelle: eigene Erhebung 2005.

In 477 Fällen konnte ein Vergleich des Innenhofzustandes zu beiden Erhebungszeitpunkten durchgeführt werden. Dieser illustriert eine Reihe von grundlegenden Veränderungen, die sich diesbezüglich im Analyszeitraum vollzogen (vgl. Tab. 13). Von den 234 Innenhöfen, welche sich 1981 in Ordnung befunden hatten, waren nur 67 $(28,6 \%)$ auch 2005 als ordentlich einzustufen. In 143 Fällen $(61,1 \%)$ mussten partielle Beschädigungen konstatiert werden. Die Präsenz stark beschädigter Höfe war mit 23 
(9,8\%) eher gering, der hohe Anteil teilweiser Beschädigungen bekundet aber eine Verschiebung des Innenhofzustandes in Richtung partieller Schäden.

Tabelle 13: Vergleich des Innenhofzustandes, 1981 und 2005

\begin{tabular}{lcccrc}
\hline \multicolumn{7}{c}{ Innenhofzustand 2005 } & & \\
Innenhofzustand & in & teilweise & stark & insg. & insg. \\
1981 & Ordnung & beschädigt & $\begin{array}{r}\text { beschädigt } \\
\text { abs. }\end{array}$ & in \% \\
\hline in Ordnung & 28,6 & 61,1 & 9,8 & 234 & 100,0 \\
teilweise beschädigt & 21,3 & 63,4 & 15,3 & 183 & 100,0 \\
stark beschädigt & 20,0 & 60,0 & 20,0 & 60 & 100,0 \\
insgesamt & 24,7 & 61,8 & 13,2 & 477 & 100,0 \\
\hline
\end{tabular}

Quelle: Erhebungen 1981 und 2005.

Wie haben sich nun die 183 Innenhöfe entwickelt, welche 1981 als teilbeschädigt klassifiziert worden waren? Das Gros dieser Höfe, nämlich $116(63,4 \%)$, war auch im Jahr 2005 als partiell beschädigt einzustufen. Rund ein Fünftel (39 bzw. 21,3\%) befand sich im zweiten Erhebungsjahr in einem ordentlichen Zustand und in 28 Fällen $(15,3 \%)$ war ein fortschreitender Verfallsprozess eingetreten. Diese Höfe waren als stark beschädigt zu klassifizieren. Eine positive Entwicklung hatte sich innerhalb der Subgruppe der 60 ehemals stark beschädigten Innenhöfe vollzogen. Exakt ein Fünftel von ihnen war auch 2005 erheblich devastiert, genau ein weiteres Fünfel befand sich aber in einem ordentlichen Erhaltungszustand und fast zwei Drittel waren zumindest teilweise saniert und so vor weiterem Verfall bewahrt worden. 36 ehemals stark beschädigte Höfe (60\%) waren 2005 also als bloß partiell beschädigt einzustufen (vgl. Tab. 13).

Karte 13 visualisiert die räumliche Verteilung der Gebäude differenziert nach den vier Kategorien des Erhaltungszustandes. Die baulich in Ordnung befindlichen Gastarbeiterwohnhäuser konzentrieren sich vor allem auf die inneren Bezirke, sind aber auch in der nördlichen und südlichen Peripherie der Stadt zu finden. Die Subgruppe mit leichten Beschädigungen weist ein großräumiges Verteilungsmuster auf. Gebäude dieser Erhaltungskategorie finden sich sowohl in den inneren Bezirken als auch in den Gastarbeiterbezirken entlang der Gürtelzone sowie weit in den Westen des Hauptuntersuchungsgebietes hineinreichend. Auch die Gebäude mit Beschädigungen, welche als mittelschwer zu klassifizieren waren, verteilen sich sehr großräumig, wobei diese zwar auch in den Gemeindebezirken innerhalb des Gürtels zu finden sind, noch mehr aber in den traditionellen Arbeiterquartieren entlang und außerhalb der Gürtelzone. Die starke Bauschäden aufweisenden Häuser konzentrieren sich vor allem in den westlichen und südlichen Bezirken, also auf die klassischen Gastarbeiterwohngebiete von Ottakring, Hernals, Rudolfsheim-Fünfhaus, Meidling und Favoriten, finden sich in Form eines klumpigen Verteilungsmusters aber auch in der Leopoldstadt sowie in der Brigittenau. Schwer beschädigte Häuser finden sich seltener in den bürgerlichen Innenbezirken und kaum in den Cottagevierteln der Stadt. 


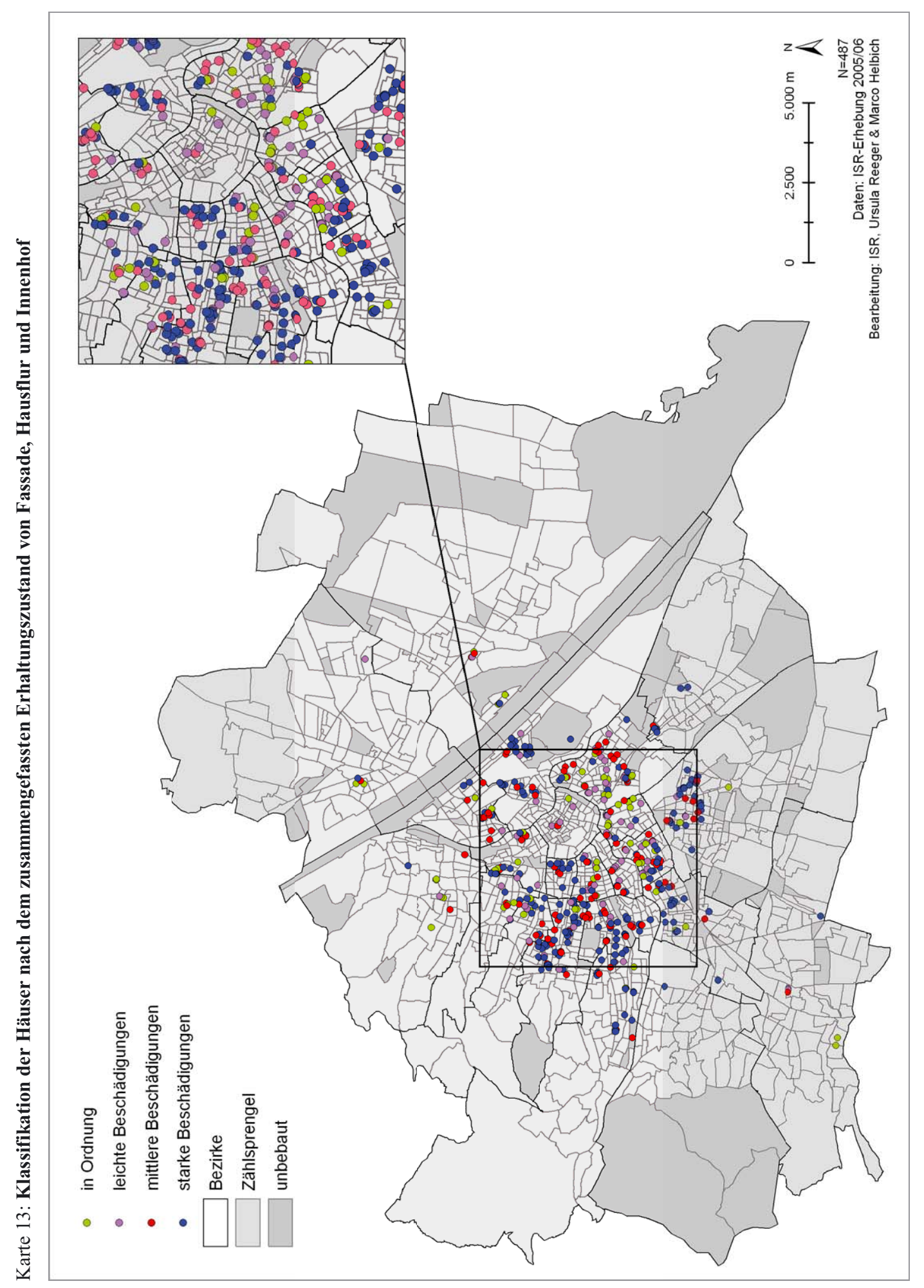




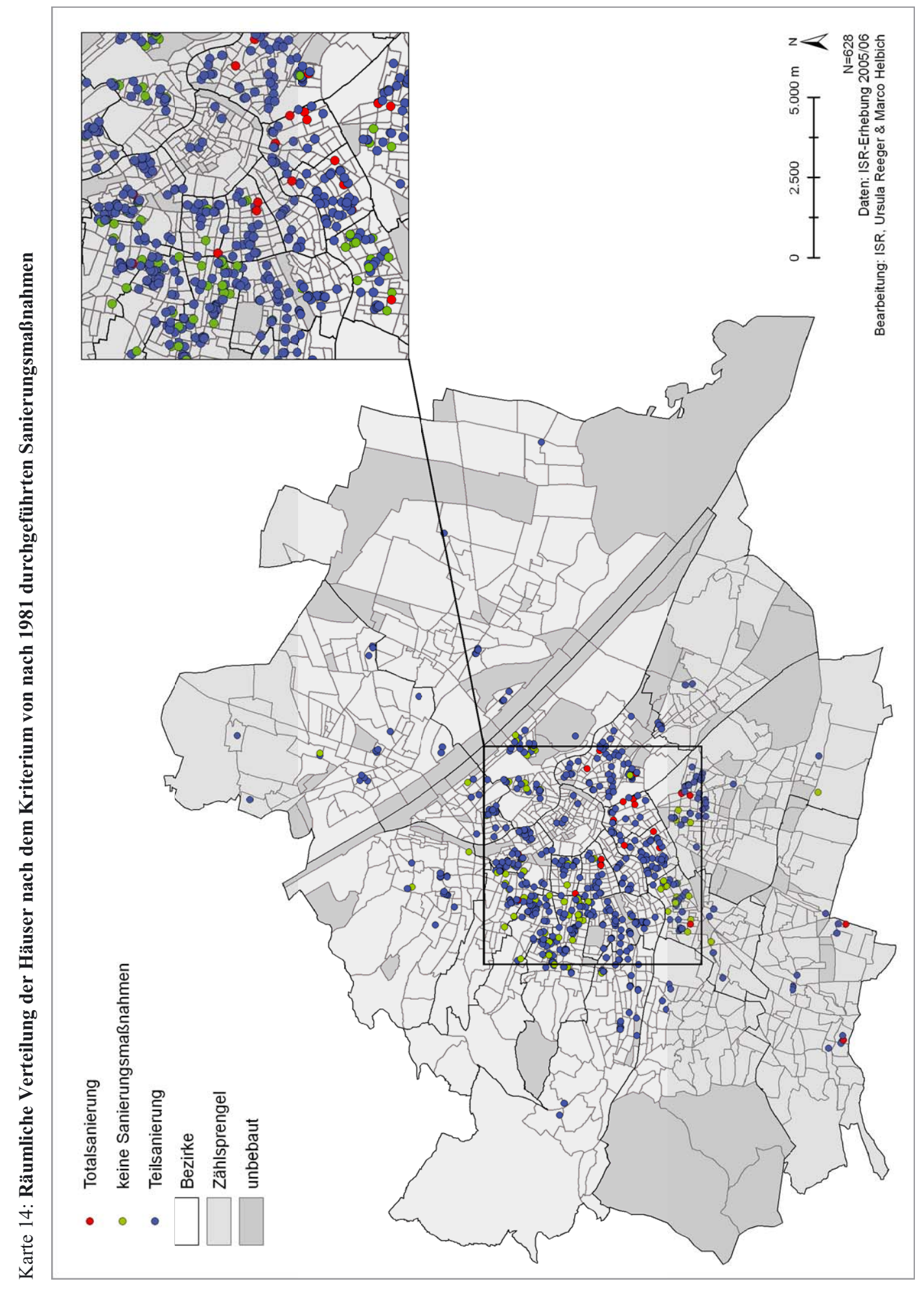


Das Kartogramm 14 veranschaulicht die Verteilung der feststellbaren Sanierungsmaßnahmen am erhobenen Hausbestand. Mit Abstand am häufigsten wurden Teilsanierungen vorgenommen. Diese partiell sanierten Häuser verteilen sich über große Teile des Wiener Stadtraumes und sind sowohl in Cottagevierteln als auch in Arbeiterbezirken sowie jenseits der Donau und im äußersten Süden des Stadtraumes zu finden. Die beiden gegensätzlichen Kategorien der komplett sanierten sowie der völlig unsanierten Gebäude weisen auch ein gegensätzliches räumliches Muster auf. Komplettsanierungen konzentrieren sich in erster Linie auf die bürgerlichen Innenbezirke im Süden und Südwesten (7., 5., 4. und 3.). Im Gegensatz dazu wurden keinerlei Investitionen in eine Sanierung vor allem Häusern zuteil, die in den westlichen und südlichen Arbeiterbezirken (Ottakring, Hernals, Meidling und Favoriten) außerhalb der Gürtelzone lokalisiert sind. Vereinzelt finden sich unsanierte Gebäude zwar auch in den inneren Bezirken, dies jedoch in geringer Zahl.

\subsection{Bewohnerbezogene Analysen}

\subsubsection{Datenbasis}

Da es sich 2005 aus Gründen der Unfinanzierbarkeit als unmöglich erwies, eine Befragung auf Haushalts- bzw. Bewohnerebene durchzuführen, mussten andere empirische Zugänge gewählt werden, welche einigermaßen verlässliche Rückschlüsse auf die Bewohnerstrukturen der erhobenen Gebäude zuließen. Eine naheliegende Quelle stellten die in der Mehrzahl der Häuser vorhandenen und auch bei versperrtem Eingangstor zumeist von außen zugänglichen Klingelbretter dar. Allerdings boten auch diese, wie sich im Rahmen der Erhebung schließlich herausstellte, nicht die Möglichkeit einer Kompletterfassung der Bewohnerstrukturen. Bei fast zwei Dritteln $(66,1 \%)$ der erhobenen Gebäude (460) waren Klingelbretter mit empirisch auswertbaren Namensangaben vorhanden. Unerwartet hoch waren mit 165 (23,7\%) die Zahl und der Anteil jener Wohnhäuser, welche über kein zugängliches Klingelbrett verfügten. In diesen Fällen wurde als empirische Annäherung an die Bewohnerstruktur der Ausweg über die Benutzung des elektronischen Telefonverzeichnisses OTB gewählt. Auf diese Weise konnten die Bewohnerstrukturen zumindest partiell über den Umweg der Fernsprechanschlüsse rekonstruiert werden. Zum OTB als Hilfsmittel wurde auch in jenen 18 Fällen $(1,7 \%)$ gegriffen, in denen zwar ein Klingelbrett vorhanden war, dieses aber keine (entzifferbaren) Namensangaben enthielt.

\subsubsection{Nutzungsmodalitäten und Bewohnerstruktur}

In summa handelte es sich bei 626 der 696 Häuser um Gebäude, welche sich sowohl 1981 als auch 2005 in Wohnnutzung befanden. Leer stehende bzw. zum Erhebungszeitpunkt in Sanierung befindliche Gebäude machten 1,7\% (12 Häuser) aus. Auf dem Areal von 5 weiteren ehemaligen Gastarbeiterhäusern befanden sich Baustellen. 
15 Gebäude (2,2\%) waren zu reinen Bürogebäuden geworden. Etliche andere Adressen der Ersterhebung fielen aus, da die entsprechenden Gebäude den folgenden Nutzungen zugeführt worden waren: Einkaufszentrum/Parkplatz (5), Kloster (2), Schule (2), Spielplatz (2), Spital (1), Hotel (1), Heuriger (1), Studenten- (1) bzw. Arbeiterwohnheim (1).

Die komparative Analyse nach den Kriterien der aktuellen Nutzung des Gebäudes soll an dieser Stelle vorgeschaltet werden. Bei 445 Gebäuden (63,9\%) handelte es sich im Jahr 2005 um dasselbe wie 1981 und die Bewohnerstruktur konnte anhand des Klingelbretts eruiert werden. In 181 Fällen (26\%) war das jeweilige Gebäude ebenfalls identisch, die Bewohnerstruktur musste allerdings auf Basis des OTB erhoben werden. In 31 Fällen (4,5\%) war das Gebäude zwar nach wie vor vorhanden, befand sich jedoch nicht mehr in Wohnnutzung. In 30 Fällen (4,3\%) waren die Gebäude von 1981 zwischenzeitlich durch Neubauten ersetzt worden: Davon befanden sich 19 Gebäude in Wohnnutzung, bei 11 Häusern lag keine Verwendung zu Wohnzwecken vor. Auf dem Areal von neun ehemaligen Gastarbeiterhäusern war inzwischen die Spitzhacke zum Einsatz gekommen und die Gebäude waren abgerissen worden. Leere Liegenschaften machten einen nur geringen Anteil von 1,3\% aus.

\subsubsection{Die Entwicklung der Präsenz (ex)jugoslawischer Haushalte}

Bei der Interpretation der Ergebnisse der nun folgenden Analysen müssen folgende Einschränkungen, welche aus der Konstituierung des Datensatzes resultieren, unbedingt berücksichtigt werden:

- Als Grundlagen fungieren die Informationen aus den Klingelbrettern sowie - bei deren Fehlen - die Telefonbuchangaben.

- Beide Datenquellen sind grundsätzlich problematisch, da auf dieser Basis keine vollständige und hundertprozentig empirisch valide Erfassung der Bewohnerstrukturen möglich ist. Die darauf basierenden Resultate sind also als eine methodisch weitgehend optimierte Annäherung an die faktischen Verhältnisse aufzufassen und spiegeln die Realität nicht 1:1 wider.

- 1981 wurden auf Basis der Meldestatistik der Fremdenpolizei ausschließlich Häuser in die Studie einbezogen, in denen nachweislich zumindest ein jugoslawischer Haushalt vorhanden war. Bei den Häusern im Sample handelte es sich also keineswegs durchwegs um ausgesprochene „Gastarbeiterghettos“, also um solche mit hohen Wohnkonzentrationen ehemaliger jugoslawischer Gastarbeiter. Nicht selten stammte bloß der/die Hauswart(in) aus dem damaligen Jugoslawien.

In einem ersten Schritt wurde anhand der Familiennamen ein Vergleich der Präsenz jugoslawischer Haushalte zu beiden Untersuchungszeitpunkten durchgeführt. In 415 ehemaligen Gastarbeiterwohnhäusern, also in zwei Dritteln, hat sich der Anteil exjugoslawischer Haushalte seit 1981 reduziert. Dieses auf den ersten Blick spektakuläre Ergebnis ist allerdings etwas zu relativieren. In 111 Fällen, also in nahezu einem Viertel der Häuser in dieser Subkategorie, war 1981 bloß ein Haushalt jugoslawischer 
Herkunft. Dieser jeweils einzelne Haushalt war 2005 nicht mehr vorhanden. In diesem Zusammenhang muss auf die Tatsache hingewiesen werden, dass sich im personenbezogenen Sample von 1981 sehr viele Jugoslawen befanden, welche Hausbesorgerfunktionen innehatten und somit Dienstwohnungen bewohnten. Gerade im Bereich der Hausbesorgung und -betreuung haben sich aber in jüngster Zeit Umwälzungen vollzogen. ${ }^{25}$ Mit der Abschaffung des Berufes des Hausbesorgers durch die neuen legistischen Rahmenbedingungen (ersatzlose Abschaffung des Hausbesorgergesetzes 2000) ${ }^{26}$, in vielen Fällen wohl aber auch infolge der Erreichung des Pensionsalters, haben die exjugoslawischen Hausbesorger ihre Dienstwohnungen räumen müssen und sind verzogen. Zahlreiche Hausbesorgerwohnungen wurden in marktgängige Mietwohnungen umgewandelt und die Hausbetreuung von Reinigungsfirmen oder auch von Personen anderer ethnonationaler Herkunft übernommen. In 14,3\% (89) der untersuchten Gebäude ist die Zahl exjugoslawischer Haushalte konstant geblieben. Ein Ansteigen der exjugoslawischen Wohnpräsenz war in 117 Häusern (18,8\%) zu verzeichnen.

Bezüglich der Zahlen der zum Zeitpunkt der Ersterhebung im Haus vorhandenen Gastarbeiterhaushalte manifestierte sich eine erhebliche Bandbreite, wobei die Grundlage für 1981 die Zahl der Gastarbeiterwohnungen im Haus bildete. In 207 Gebäuden, also in exakt einem Drittel der analysierten Häuser, war 1981 nur jeweils ein (ex)jugoslawischer Haushalt ansässig. Hierbei handelte es sich in vielen Fällen um Hausbesorgerwohnungen. Zählt man jene Gebäude (177 bzw. 28,3\%) hinzu, in denen zwei oder höchstens drei Wohnungen von (Ex)jugoslawen belegt waren, so muss man feststellen, dass nahezu zwei Drittel der Wohnhäuser höchstens drei Gastarbeiterwohnungen aufwiesen, also von „echten“ Wohnkonzentrationen (ex)jugoslawischer Gastarbeiter in diesen Häusern keine Rede sein konnte. Vier bzw. fünf Gastarbeiterhaushalte waren in 78 Gebäuden (12,6\%) ansässig. In weiteren 94 Gebäuden, diese entsprachen einem Anteil von 15\%, lag die Zahl der von Gastarbeitern bewohnten Wohneinheiten zwischen sechs und zehn. Zwischen 11 und 20 Gastarbeiterwohnungen waren 1981 für 55 Gebäude (15,6\%) nachweisbar. In einzelnen Fällen (5) waren auch hohe Zahlen von (ex)jugoslawischen Wohneinheiten vorhanden. Diese lagen in einer Bandbreite von 36 bis 55 Wohnungen. Hierbei ist davon auszugehen, dass es sich um

25 Unter den 626 Häusern befanden sich 144, in welchen Hauswartklingeln vorhanden waren. In den Häusern ohne Klingelbretter ist unbekannt, ob ein Hauswart vorhanden ist. Interessant ist, dass immerhin ein Drittel der Häuser noch über einen Hauswart verfügt. 110 „Hauswartklingeln“ waren ohne Namensangabe, in 20 Fällen war ein serbokroatischer Name angegeben, 5 fielen unter die Kategorie „sonstige“.

26 Mit 8.6.2000 beschloss die Regierung die ersatzlose Abschaffung des Hausbesorgergesetzes und damit das Ende dieses traditionellen Berufs. In Wien betrug die Reduktion dieses Berufsstandes, dem im Jahr 2000 noch 19.000 Personen angehörten, bis 2004 bereits 4.000 Personen, bundesweit waren im selben Zeitraum 10.000 Stellen verloren gegangen (vgl. diverse Beiträge auf http://www.wienweb.at $/$ content $/$ aspx?id $=8819 \&$ at $=228=$ channel $=$ 2\&typ0). 
keine Manifestationen extremer Ghettoisierungsprozesse handelte, sondern um firmeneigene Arbeiterquartiere.

Die Verteilungskarte nach dem Kriterium des Anteils der auf Migrantenhaushalte hindeutenden Familiennamen im Haus dokumentiert den grundsätzlichen Trend, dass mit steigender Distanz zum Stadtzentrum die Anteile der Migrantenhaushalte zunehmen (vgl. Karte 15). Während im Zentrum sowie in den an den ersten Bezirk angelagerten Bezirken Wohnhäuser mit Anteilen von bis zu 20\% bzw. von 20 bis $40 \%$ ausländischer Namen dominieren, bilden in den Gastarbeiterbezirken der Gürtelzone im Westen und Süden des Kernuntersuchungsgebietes die Häuser mit 60 bis $80 \%$ sowie mit mehr als $80 \%$,ausländischen“ Familiennamen klumpige Verteilungsmuster. Dazwischen eingestreut finden sich vereinzelt auch Gebäude, in welchen sich zum Zeitpunkt der Neuerhebung 2005/06 keine Hauspartei mit Migrationshintergrund nachweisen ließ. Diese Häuser (vgl. die blauen Punkte in der Karte), in denen die 1981 noch vorhandenen Gastarbeiterhaushalte in Form eines Sukzessionsprozesses durch andere Hausparteien (Inländer oder Migranten) abgelöst wurden oder in denen die Hausbesorgerfunktion wegfiel, finden sich in erster Linie in Landstraße und auf der Wieden sowie an der urbanen Peripherie - in Floridsdorf und Donaustadt sowie in den westlichen und südlichen Randbezirken.

In mehr als einem Drittel (35,8\%) der ehemaligen Gastarbeiterhäuser (221) war 2005 kein einziger exjugoslawischer Haushalt mehr wohnhaft. In 130 Gebäuden (20,8\%) konnte jeweils ein Haushalt nachgewiesen werden. In einem Fünftel (125) der Gebäude wurden zwei oder drei Wohnungen von Exjugoslawen bewohnt. In einem Zehntel (63 Häuser) der insgesamt 624 untersuchten Wohnbauten belief sich die Zahl exjugoslawischer Haushalte auf vier bis fünf. In 40 Gebäuden waren sechs oder sieben Wohnungen mit exjugoslawischen Haushalten belegt. Häuser mit einer stärkeren Präsenz exjugoslawischer Bewohner bildeten insgesamt nur einen geringen Teil des Samples von 2005. In 21 Gebäuden waren zwischen 11 und 20 Haushalte aus Exjugoslawien nachweisbar. Drei Fälle mit extrem hohen Konzentrationen exjugoslawischer Bewohner (22, 24 und 46 Haushalte) deuten auf die inzwischen selten gewordene Existenz von firmeneigenen Quartieren hin.

Die Basis für die Erstellung von Karte 16 wurde mittels der Auszählung der Familiennamen der Hausparteien und der Selektion „(ex)jugoslawischer“ Familiennamen geschaffen. Als solche wurden sowohl Namen serbokroatischer als auch jene albanischer (kosovarischer) Herkunft klassifiziert. Häuser, für welche zum Zeitpunkt der Neuerhebung keine Hauspartei jugoslawischer Provenienz anhand ihres Familiennamens identifiziert werden konnte (blaue Punkte), bilden einen Dichtering in den inneren Bezirken - vom Alsergrund im Norden bis nach Wieden und Landstraße im Süden reichend. An diesen Ring angelagert finden sich auch viele Häuser, in welchen die Anteile serbokroatischer bzw. kosovarischer Familiennamen Anteile von 15\% oder höchstens 25\% nicht übersteigen. Mit steigender Distanz zum ersten Bezirk nehmen jene Wohnhäuser zu, in denen die Familiennamen der Hausbewohner auf hohe Anteile an Bewohnern mit exjugoslawischem Migrationshintergrund schließen lassen. In den 


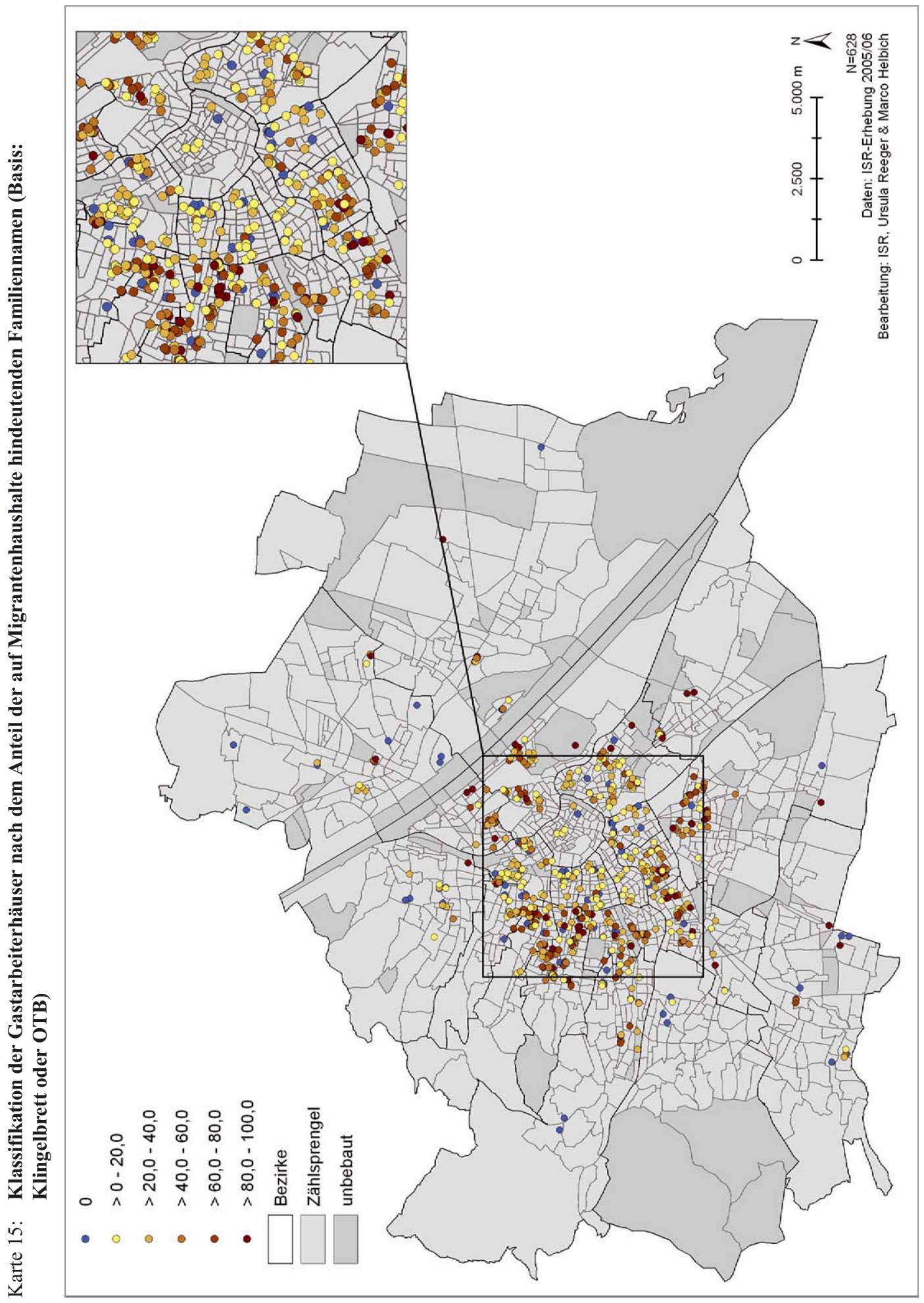




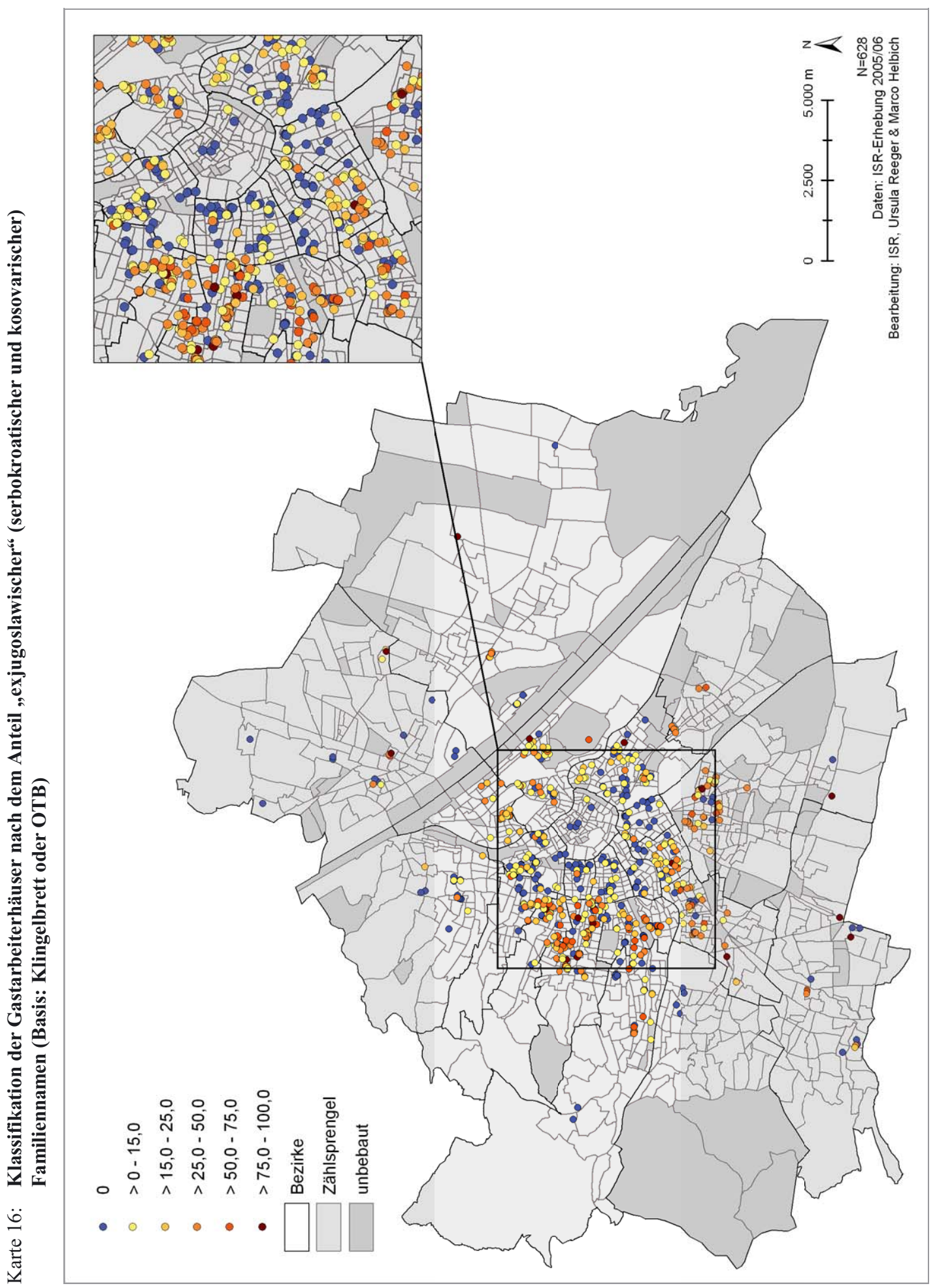




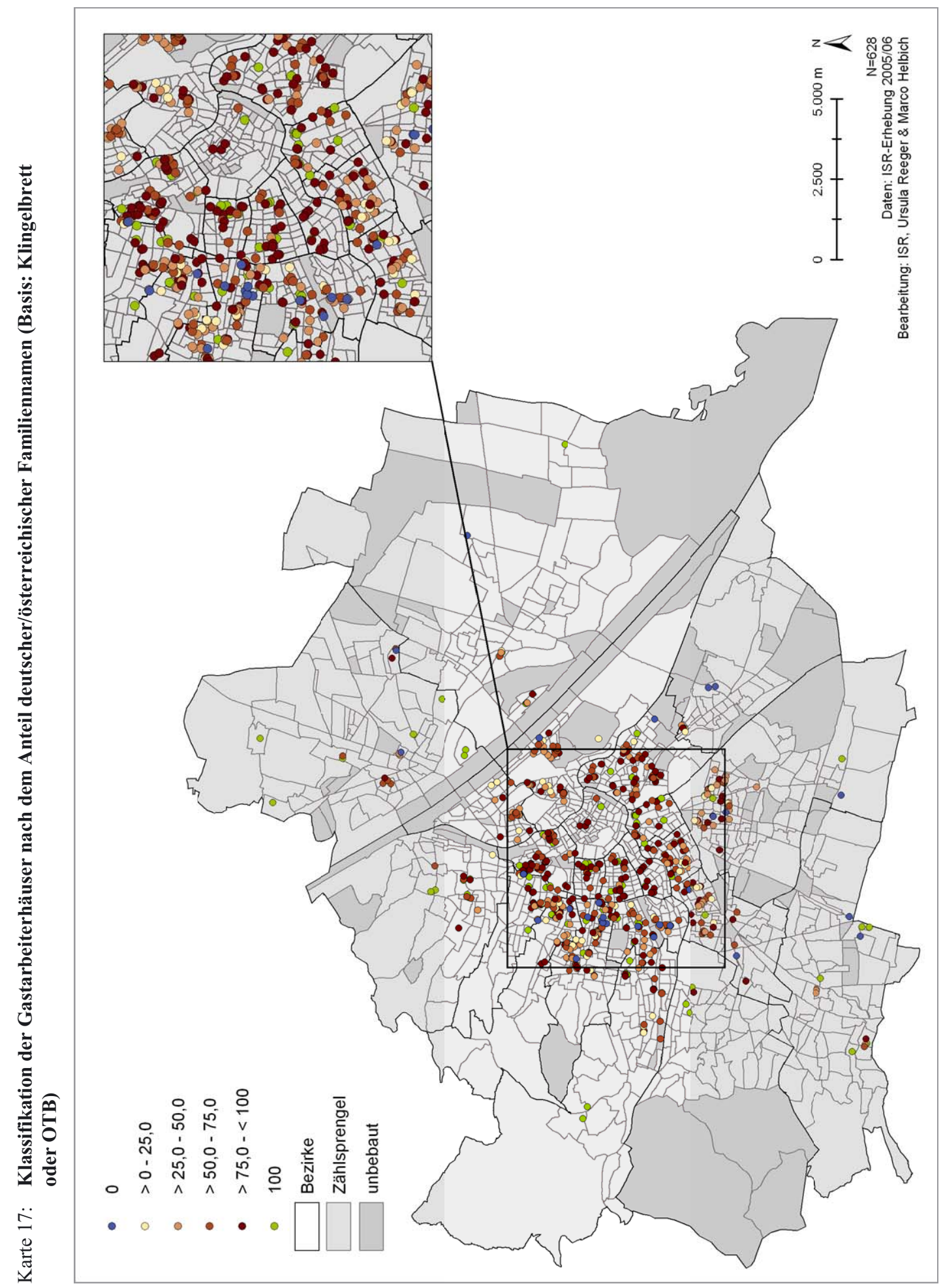




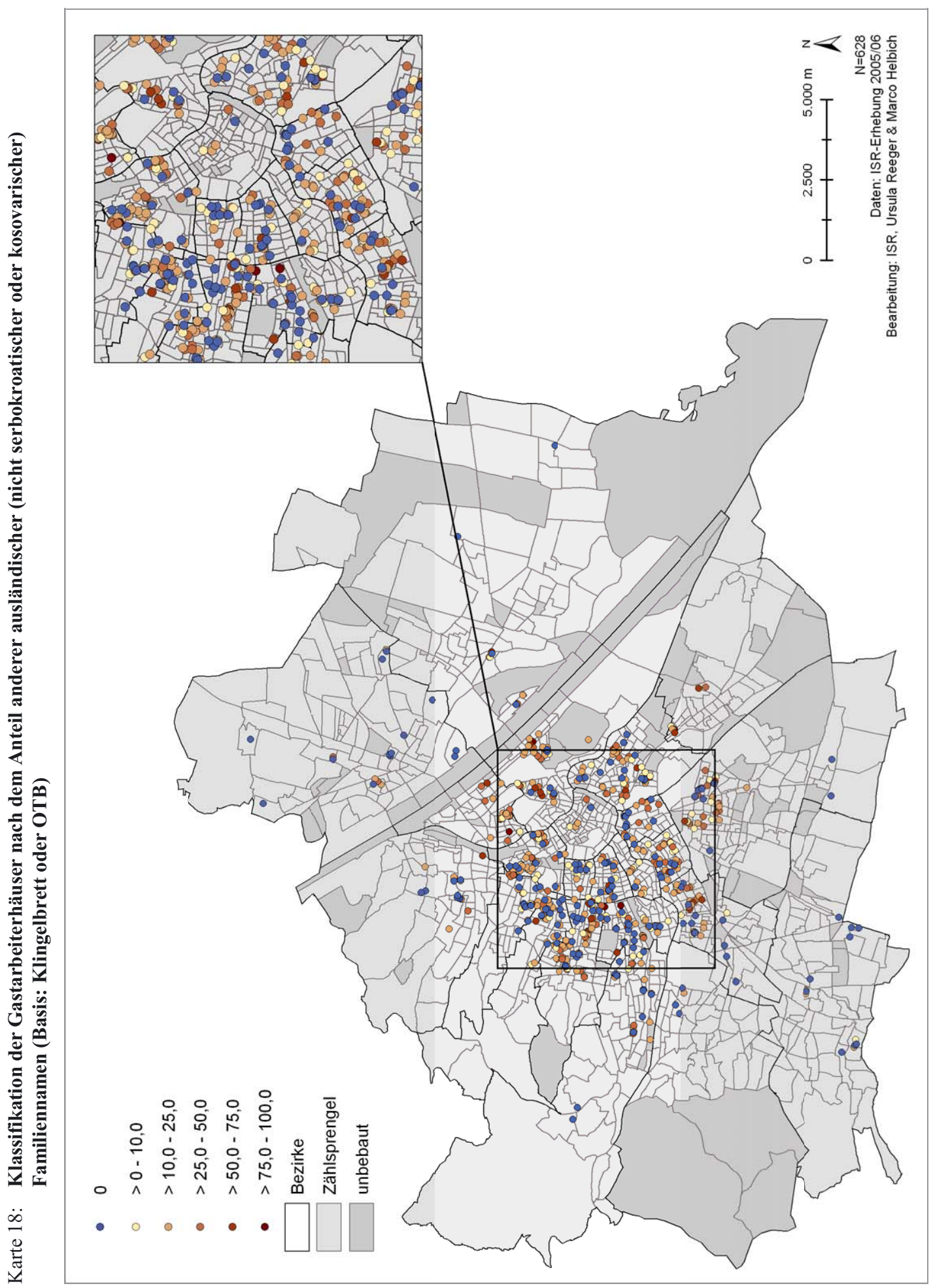


meisten liegen die Anteile exjugoslawischer Hausparteien bei 25 bis 50\% oder sogar bei 50 bis 75\%. Diese Häuser bilden klumpige Verteilungsmuster im 17., 16., 15., 12. und 5. Bezirk und treten gehäuft auch in Favoriten auf. Gebäude mit extrem hohen mononationalen Konzentrationen (mehr als 75\%) exjugoslawischer Bewohner treten nur sehr vereinzelt auf. Sie verteilen sich weiters ohne feststellbare Konzentrationen äußerst dispers über das Stadtgebiet - einmal mehr ein Indiz für die in Wien typischen hausweisen Segregationsprozesse.

Die Karte 17 bildet hinsichtlich der räumlichen Verteilungsmuster einen Gegensatz zur vorangegangenen Karte 16. Die Gebäude mit den höchsten Anteilen von Familiennamen, die auf österreichische Hausparteien schließen lassen, verteilen sich vor allem auf die Innenbezirke und bilden quasi ein ringförmiges Verteilungsmuster um die Innenstadt herum. In den Bezirken Alsergrund, Josefstadt, Neubau, Mariahilf, Margareten, Wieden und Landstraße sowie teilweise in der Leopoldstadt und in der Brigittenau liegt die Präsenz inländischer Hausparteien in vielen Häusern bei 50 bis $75 \%$ bzw. sogar bei mehr als $75 \%$. Innerhalb dieses Rings der inneren Bezirke ist auch das Gros jener Untersuchungsgebäude lokalisiert, in denen die auswertbaren Familiennamen den Schluss auf eine rein inländische Bewohnerschaft zuließen. Diese Häuser sind vereinzelt auch an der westlichen und südlichen Peripherie sowie jenseits der Donau vorzufinden. Das Verteilungsmuster der reinen „Ausländerhäuser“, also jener mit keiner einzigen, einen österreichischen Familiennamen tragenden Hauspartei, steht in einem krassen Gegensatz dazu. Diese Subkategorie ist vor allem westlich des Gürtels in den traditionellen Migrantenbezirken (17., 16. 15.), aber auch in Meidling, Margareten und Favoriten zu finden. Hier sind auch besonders viele Häuser mit geringen Anteilen österreichischer Bewohner (25 bis 50\%) lokalisiert. Die Karte 18 gibt Auskunft über die räumliche Verteilung jener Häuser, die durch unterschiedliche Anteile von Bewohnern mit nichtjugoslawischem Migrationshintergrund charakterisiert sind. Die Häuser, in denen kein einziger Name auf eine Hauspartei mit nichtjugoslawischem Migrationshintergrund schließen ließ, verteilen sich sehr dispers über den gesamten Stadtraum, bilden aber sowohl in den Innen- als auch in den Arbeiterbezirken einige klumpige Verteilungsmuster. In den Ring innerer Gemeindebezirke eingestreut findet sich das Gros jener Wohngebäude, in denen niedrige Anteile (bis 10 bzw. bis $25 \%$ ) von Migranten nichtjugoslawischer Herkunft wohnhaft sind. Vereinzelt sind solche Häuser aber auch in Gastarbeiterbezirken zu finden. Die Häuser mit einer hohen Präsenz (ab 50\%) von nichtjugoslawischen Bewohnern sind stärker auf die Gürtelzone und die Arbeiterbezirke außerhalb des Gürtels konzentriert. Der Großteil dieser „Ausländerhäuser“ ist in Ottakring, Hernals, Rudolfsheim-Fünfhaus, in Margareten und Favoriten lokalisiert. Etliche dieser Wohnbauten liegen aber auch in der Brigittenau, in der Leopoldstadt, in Wieden und im dritten Wiener Gemeindebezirk.

Zum Zwecke der Erleichterung der nachfolgenden Analysen wurde eine Recodierung hinsichtlich der Zahl der im Hause wohnhaften exjugoslawischen Gastarbeiter vorgenommen. Für 1981 resultiert daraus, dass in einem Drittel der Häuser $(33,4 \%)$ bloß ein Gastarbeiterhaushalt ansässig war. In 255 Gebäuden (40,8\%) waren zwei bis 
fünf von Exjugoslawen bewohnte Wohnungen lokalisiert und in einem Viertel $(25,8 \%)$ der Häuser lebten sechs oder mehr Haushalte aus der Balkanrepublik.

Während der zweieinhalb Dekaden bis 2005 haben sich hierbei grundlegende Veränderungen vollzogen. Für die Erhebung 2005 wurde als zusätzliche Kategorie jene mit keiner exjugoslawischen Hauspartei $(35,4 \%)$ eingeführt. In einem Fünftel der Häuser war ein exjugoslawischer Haushalt vorzufinden, in 188 Gebäuden (30,1\%) waren es zwei bis fünf und in 85 Häusern $(13,6 \%)$ lebten sechs oder mehr Haushalte exjugoslawischer Provenienz.

Wie haben sich die Bewohnerstrukturen im Analysezeitraum also entwickelt? Faktisch ist nur in einem kleinen Teil der Häuser (89 bzw. 14,3\%) die Zahl der von Exjugoslawen bewohnten Wohnungen stabil geblieben. 305 Gebäude und somit 49\% des Samples hatten eine (zum Teil wesentliche) Reduktion in Bezug auf die Wohnnutzung durch exjugoslawische Haushalte zu verzeichnen. Zählt man noch jene Subkategorie hinzu, in denen der einzige exjugoslawische Haushalt von 1981 im Erhebungsjahr 2005 nicht mehr vorhanden war, so gelangt man zu dem Resultat, dass sich in 416 Wohnhäusern (66,4\%), ein Rückgang der exjugoslawischen Wohnbevölkerung vollzogen hat. Ein Teil der frei gewordenen Wohneinheiten ist durch Wohnungszusammenlegungen verloren gegangen, weiters haben in diesen Gebäuden Prozesse der Wohnsukzession durch andere Nutzergruppen stattgefunden. Dabei handelt es sich vor allem um Migranten türkischer oder arabischer Herkunft, zum Teil auch um Süd(Inder, Pakistani) oder Ostasiaten (zumeist Chinesen). Die vormaligen Gastarbeiterhäuser weisen gegenwärtig überhaupt ein ungleich vielfältigeres Bewohnergemisch auf als 1981. Da 2005 keine Wohnungserhebung durchgeführt wurde, kann nicht mit Bestimmtheit gesagt werden, in welchem Ausmaß 1981 von jugoslawischen Haushalten bewohnte Wohnungen nun von anderen ethnonationalen Zuwanderergruppen genutzt werden. ${ }^{27}$ Auf der Gebäudeebene (und durch die anhand der Klingelbretter gesammelten Daten belegbar) kann aber ausgesagt werden, dass im untersuchten Hausbestand inzwischen auch viele Ost-West-Migranten (Polen, Ungarn, Slowaken) wohnhaft sind. Ein Anstieg der Präsenz der exjugoslawischen Migranten im Haus war in 117 Gebäuden $(18,8 \%)$ zu verzeichnen.

Vergleicht man die entsprechenden Werte der Jahre 1981 und 2005 im Detail, so fällt zunächst die große Zahl an Gebäuden (221 oder 35,4\%) auf, in denen 2005 kein einziger exjugoslawischer Haushalt mehr ansässig war. Eine Entwicklung, die in einem Konnex mit dem Rückgang der Hausbesorgerfunktion in zahlreichen Wiener Wohnhäusern zu sehen ist. Deutlich zurückgegangen ist damit auch die Zahl jener

27 Was geschah mit den von den ehemaligen Gastarbeitern aufgegebenen Wohnungen? Nach Lichtenberger (1984: 292) bestanden drei Möglichkeiten: 1) es konnte ein Abbruch des Gebäudes erfolgen; 2) es kam zur Sukzession, d.h. zur Übernahme dieser Wohnungen durch andere Migrantengruppen (z.B. Asiaten, Afrikaner, Osteuropäer); 3) auch inländische Interessenten (z.B. Studenten, Alleinerziehende) für ehemalige Gastarbeiterwohnungen waren vorhanden. 
Baulichkeiten, in denen eine Wohnung von Exjugoslawen bewohnt war: von 207 auf bloß noch 130, also von 33,2\% auf 20,8\%. Galt 1981 noch, dass in 177 Häusern $(28,4 \%)$ zwei oder drei Wohneinheiten von Gastarbeitern bewohnt waren, so war deren Zahl 2005 auf 125 (20,1\%) abgesunken. In summa zeigt also die Präsenz exjugoslawischer Haushalte in den untersuchten Wohnhäusern einen deutlich rückläufigen Trend. 1981 lag in 89,2\% der Gebäude der Anteil jugoslawischer Haushalte bei einer Zahl von höchstens zehn. In mehr als einem Zehntel waren mehr als zehn jugoslawische Hausparteien ansässig. 2005 galt dies bloß noch für 3,8\% und in 96,2\% der Gebäude waren höchstens zehn exjugoslawische Haushalte vorhanden.

Karte 19: Veränderung der Zahl exjugoslawischer Haushalte auf Hausebene nach Bezirken 2005

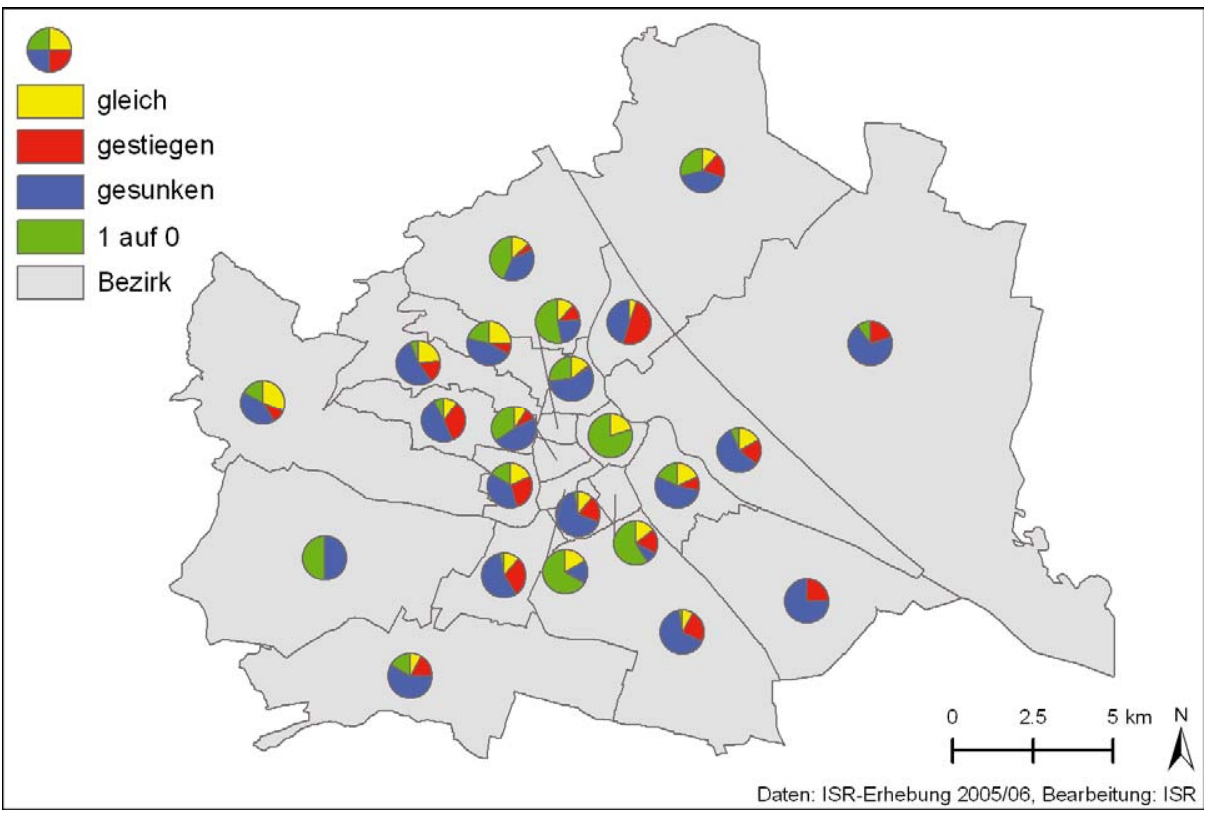

Im Folgenden sollen die Veränderungen der Zahlen exjugoslawischer Haushalte einer Detailanalyse auf Bezirksebene unterzogen werden (vgl. Karte 19). Jeweils bezogen auf die Gesamtzahl der erhobenen Häuser im entsprechenden Gemeindebezirk ist der höchste Anteil jener Häuser, in denen zwischen 1981 und 2005 ein Anstieg der Zahl exjugoslawischer Haushalte erfolgte, mit 50\% in der Brigittenau zu verorten. An zweiter Stelle, wenngleich mit deutlichem Abstand, lag Ottakring mit 24 Häusern (33,3\%), gefolgt von den Bezirken Meidling (29,7\%), Rudolfsheim-Fünfhaus (27,3\%) und Simmering (25\%). Im 1., 6., und 13. Bezirk war es in keinem einzigen Haus zu einem Anstieg der Gastarbeiterpräsenz gekommen, im 7., 9., 18. und 20. Bezirk lag der Anteil der Häuser mit Anstiegen bei unter 10\%. Die markantesten Prozentsätze 
von Häusern mit Rückgängen der exjugoslawischen Bevölkerung waren in Simmering (75\%) und Donaustadt (70\%) sowie ex aequo in Favoriten und Margareten $(65,8 \%)$ zu verzeichnen. Weitere Bezirke, in denen auf die Häuser mit Rückgängen exjugoslawischer Bewohner Anteile von bis zu 50\% entfielen, waren der 2., 3., 12., 13. 17. und 23. Gemeindebezirk. Eine spezielle Kategorie bilden auch hier jene Gebäude, in denen der einzige Gastarbeiterhaushalt des Jahres 1981 zum Zeitpunkt der Zweiterhebung nicht mehr vorhanden war. Die ausgeprägteste Präsenz dieser Kategorie war mit $80 \%$ in der Inneren Stadt zu verzeichnen, wobei es sich absolut aber nur um vier Gebäude handelte. Weitere Bezirke, in denen die Reduktion von einem auf keinen exjugoslawischen Haushalt im Haus eine starke Verbreitung aufwies, waren Mariahilf $(66,7 \%)$, Wieden $(59,1 \%)$, die Josefstadt $(52,1 \%)$ sowie Hietzing $(50 \%)$. Die höchste Präsenz von Wohnbauten mit gleichbleibenden Zahlen exjugoslawischer Wohnnutzung war für Penzing (31\%), Hernals (22,9\%) und Währing (24,2\%) zu konstatieren.

Stellt man nun die Bezirke, in denen es zu ausgeprägten Rückgängen bei der exjugoslawischen Bevölkerung kam, jenen gegenüber, in deren Gebäudebestand sich Anstiege vollzogen oder wo eine Konstanz vorliegt, so lassen sich folgende Regelhaftigkeiten erkennen:

- Jene Wohnhäuser, in denen seit 1981 Anstiege der exjugoslawischen Hausparteien erfolgten, sind vor allem in einigen Gastarbeiterbezirken der Gürtelzone sowie in Simmering zu verorten und kaum in den bürgerlichen Wohnbezirken.

- Inhomogener präsentiert sich die Verteilung der Gebäude mit Rückgängen der Gastarbeiterwohnungen. Es sind vor allem Arbeiterbezirke, in denen sich markante Reduktionen ergaben, wobei Simmering die Spitzenposition einnimmt. Starke Reduktionen vollzogen sich auch in Favoriten und Margareten sowie im 22. Bezirk, der nicht zu den Gastarbeiterbezirken zu zählen ist. Ausgeprägte Rückgänge waren darüber hinaus auch in den gutbürgerlichen Bezirken 3 und 13 und sowie im 23. zu verzeichnen.

- Welche Bezirke weisen besonders hohe Anteile jener Gebäude auf, in denen der einzige exjugoslawische Haushalt von 1981 abwanderte? Das räumliche Muster ist ziemlich klar: Von diesem Phänomen waren vor allem gutbürgerliche Innenbezirke sowie der Cottagebezirk Hietzing betroffen.

\subsubsection{Exjugoslawische und andere Migrantenhaushalte}

Für die nun folgenden Ausführungen zur Bewohnerstruktur der Häuser wurde die Zahl der eruierbaren Familiennamen als Grundgesamtheit herangezogen. Wir gingen somit von der Hypothese aus, dass die am Klingelbrett bzw. im OTB vorhandenen Namen ein Spiegelbild der gesamten Bewohnerschaft eines Hauses darstellen. Die Korrelationsanalyse nach Pearson auf der Basis der Variablen (1) Anteil jugoslawischer Namen an allen privaten Namen 2005 und (2) Anteil ausländischer Namen außer jugoslawische - an allen privaten Namen 2005 ergab zunächst keinen signifikanten Zusammenhang (Korrelationskoeffizient von -0,001 auf einem zweiseitigen 
Signifikanzniveau von 0,989) zwischen Exjugoslawen und Migranten anderer ethnonationaler Provenienz. Vorsichtig formuliert könnte man also davon die folgende Schlussfolgerung ableiten: Exjugoslawen leben weder sehr häufig noch überhaupt nicht mit anderen Ausländern zusammen.

In 91 von 626 Gebäuden (14,5\%) waren ausschließlich Namen vorzufinden, die auf keinen Migrationshintergrund der betreffenden Hausparteien hinwiesen. Auf der anderen Seite waren in 29 Häusern $(4,6 \%)$ nur Familiennamen vorhanden, die auf Migranten schließen ließen, bzw. lagen in 13,9\% die Anteile höchstwahrscheinlicher Familiennamen von Migranten bei drei Vierteln und darüber. Mit 22,7\% war die Klasse „25-49,9\%“ am stärksten besetzt, gefolgt von der Klasse ,50-74,9\%“ mit einem Anteilswert von $19 \%$.

\subsubsection{Baulicher Zustand und Zahl der exjugoslawischen Haushalte}

Zwar dürfte in Wien - von Einzelfällen abgesehen - die Ära der extrem devastierten und standardmäßig prekären Gastarbeiterquartiere vorbei sein, dennoch war im Kontext der Analyse des umfangreichen Fotomaterials augenscheinlich, dass der Erhaltungszustand vieler Gastarbeiterwohnhäuser nicht optimal war. Es stellte sich also die Frage nach einem möglichen Zusammenhang zwischen dem Gebäudezustand und der Anwesenheit von jugoslawischen Haushalten im Haus.

Der Gebäudezustand der Häuser wurde in Orientierung an den Kategorien der Hauserhebungsbögen von 1981 für die Fassade, den Hausflur und den Innenhof erhoben. Die Klassifikation des Zustandes erfolgte nach den drei Kategorien „,in Ordnung", teilweise beschädigt“ und „stark beschädigt“ bzw. rekodiert nach ,in Ordnung“ und „beschädigt“. Ein Haus, bei dem alle drei Bereiche als in Ordnung befindlich klassifiziert wurden, erhielt dann den Wert 3, Häuser, die in allen Bereichen Beschädigungen aufwiesen, den Wert 6. Das Sample von $1981(\mathrm{n}=544)$ teilte sich damit folgendermaßen auf: 157 Häuser (28,9\%) konnten als völlig in Ordnung kategorisiert werden, während 111 Gebäude $(20,4 \%)$ in allen drei Bereichen Beschädigungen aufwiesen. Die Mischkategorien 4 und 5 waren mit 127 (23,3\%) bzw. 149 Fällen (27,4\%) besetzt.

2005 waren es nur noch 486 Gebäude, für die eine entsprechende Klassifikation erstellt werden konnte. Die mit 140 hohe Zahl an fehlenden Baulichkeiten begründet sich einmal mehr aus deren Unzugänglichkeit. ${ }^{28}$ Der bauliche Erhaltungszustand der Häuser hat sich insgesamt verschlechtert: Bloß 61 Gebäude $(12,6 \%)$ waren als in Ordnung befindlich zu bewerten. Dies entsprach einem nicht einmal halb so hohen Prozentanteil wie 1981. 218 Baulichkeiten wiesen in allen drei Kategorien Beschädi-

28 Möglicherweise hat sich hier auch ein Bias eingeschlichen, indem vor allem die in einem guten Zustand befindlichen Wohnhäuser zwischenzeitlich mit Gegensprechanlagen ausgestattet wurden und somit aus der Neuerhebung herausfielen. 
gungen auf - ein Anteil von 44,9\% und ein Anstieg dieser Kategorie um nahezu 25 Prozentpunkte gegenüber 1981 !

Ließen sich nun Zusammenhänge zwischen der Zahl der im Haus ansässigen Gastarbeiterhaushalte und dem baulichen Erhaltungszustand nachweisen? Zunächst sei diese Frage für das Jahr 1981 beantwortet: Von den insgesamt 147 Häusern, in denen ein jugoslawischer Haushalt ansässig war, befanden sich 80 (43\%) bezüglich Fassade, Flur und Hof in einem guten baulichen Zustand. Jeweils ein Fünftel war den Mischkategorien 4 und 5 zuzuordnen. Bloß 31 Häuser (16,7\%) mussten in allen drei Kategorien als beschädigt eingestuft werden (vgl. Tab. 14).

Tabelle 14: Zahl der Gastarbeiterhaushalte und Zustand von Fassade, Flur und Innenhof, 1981

\begin{tabular}{lcccccc}
\hline $\begin{array}{l}\text { Zahl der Gast- } \\
\text { arbeiterhaushalte }\end{array}$ & $\begin{array}{c}3 \text { (alles in } \\
\text { Ordnung) }\end{array}$ & 4 & 5 & $\begin{array}{c}6 \text { (alles } \\
\text { beschädigt) }\end{array}$ & $\begin{array}{c}\text { insg. } \\
\text { abs. }\end{array}$ & $\begin{array}{c}\text { insg. in } \\
\%\end{array}$ \\
\hline 1 & 43,0 & 20,4 & 19,9 & 16,7 & 186 & 100,0 \\
2 bis 5 & 27,6 & 26,3 & 29,0 & 17,1 & 217 & 100,0 \\
6 und mehr & 12,1 & 22,7 & 34,8 & 30,5 & 141 & 100,0 \\
insgesamt & 28,9 & 23,3 & 27,4 & 20,4 & 544 & 100,0 \\
\hline
\end{tabular}

Quelle: Erhebung 1981.

Wie sieht es bei zwei bis fünf jugoslawischen Haushalten im Gebäude aus? In diesem Fall nehmen die Absolutzahl und der Anteilswert der baulich vollkommen in Ordnung befindlichen Gebäude deutlich ab: Von 217 Gebäuden befanden sich bloß 60 $(27,6 \%)$ in einem ordentlichen Zustand. Mit einem Relativwert von 17,1\% (37 Häuser) war die Kategorie der beschädigten Wohnbauten zwar nur geringfügig stärker besetzt als bei den Gebäuden mit nur einem Gastarbeiterhaushalt, die krassesten Unterschiede manifestieren sich allerdings in den Mischkategorien. Bei sechs und mehr jugoslawischen Haushalten im Haus zeigt sich eine deutliche Verschiebung in Richtung einer ausgeprägteren Sanierungsbedürftigkeit. Unter den 141 Häusern dieser Subgruppe befanden sich bloß $17(12,1 \%)$ mit einer tadellosen Bausubstanz, 43 (30,5\%) waren als beschädigt einzustufen und 49 (34,8\%) präsentierten sich als partiell sanierungsbedürftig. Das heißt, mehr als 65\% der Gebäude, in denen 1981 mindestens sechs oder mehr Wohnungen von (damals noch) jugoslawischen Haushalten bewohnt waren, wiesen erhebliche bauliche Mängel auf.

Welche Veränderungen haben sich bis 2005 bezüglich des Konnexes zwischen der Zahl exjugoslawischer Haushalte im Haus und dem Bauzustand vollzogen? Zunächst zur Kategorie der Häuser ohne Gastarbeiterhaushalte: In dieser Gruppe, der $147 \mathrm{Ge}$ bäude zuzurechnen waren, zeigt sich eine relativ gleichmäßige Verteilung über die vier Klassen baulichen Erhaltungszustands. Mit 29,3\% ist zwar die Kategorie der schwersten Beschädigungen am stärksten besetzt, andererseits sind aber auch 22,4\% dieser Gebäude völlig in Ordnung (vgl. Tab. 15). 
Tabelle 15: Zahl der Gastarbeiterhaushalte (Indikator: Familiennamen) und Zustand von Fassade, Flur und Innenhof, 2005

\begin{tabular}{lrrrrrr}
\hline $\begin{array}{l}\text { Zahl der Gast- } \\
\text { arbeiterhaushalte }\end{array}$ & $\begin{array}{r}\text { 3 (alles in } \\
\text { Ordnung) }\end{array}$ & 4 & 5 & $\begin{array}{r}6 \text { (alles } \\
\text { beschäd.) }\end{array}$ & $\begin{array}{r}\text { insg. } \\
\text { abs. }\end{array}$ & $\begin{array}{r}\text { insg. } \\
\text { in \% }\end{array}$ \\
\hline 0 & 22,4 & 24,5 & 23,8 & 29,3 & 147 & 100,0 \\
1 & 17,7 & 14,6 & 27,1 & 40,6 & 96 & 100,0 \\
2 bis 5 & 4,9 & 16,5 & 25,0 & 53,7 & 164 & 100,0 \\
6 und mehr & 2,6 & 6,5 & 28,6 & 62,3 & 77 & 100,0 \\
insgesamt & 12,4 & 16,9 & 25,6 & 45,0 & 484 & 100,0 \\
\hline
\end{tabular}

Quelle: eigene Erhebung 2005.

Bei einem Anstieg der Präsenz exjugoslawischer Haushalte im Gebäude manifestiert sich ein Trend der Verschlechterung des baulichen Erhaltungszustandes. Dieser Zusammenhang ist anhand der folgenden Analysen zu untermauern: 96 Gebäude wiesen einen Gastarbeiterhaushalt auf. Von diesen befanden sich $39(40,6 \%)$ in einem sanierungsbedürftigen Zustand und bloß 17 (17,7\%) waren frei von baulichen Mängeln. In der Subkategorie der 164 Häuser mit zwei bis fünf Haushalten aus dem ehemaligen Jugoslawien verstärkt sich dieser Trend. Nur mehr 8 Gebäude (4,9\%) sind baulich völlig in Ordnung, während mehr als die Hälfte (53,7\% bzw. 88 Bauten) der schlechtesten Erhaltungskategorie hinzuzurechnen ist. Bei 41,5\% weisen Fassade, Flur oder Hof zumindest partielle Beschädigungen auf. Wie sieht es nun bei sechs oder mehr Gastarbeiterhaushalten im Gebäude aus? Faktum ist, dass unter den 77 Häusern dieser Subkategorie bloß 2 (2,6\%) einen tadellosen Bauzustand aufweisen, während $48(62,8 \%)$ als sanierungsbedürftig zu klassifizieren sind. Rund 35\% sind hinsichtlich ihres Zustandes einer der beiden Mischkategorien zuzuordnen.

\subsubsection{Baulicher Zustand und Bewohnerstruktur: Wohnen Migranten tatsächlich in schlechterer Bausubstanz?}

Im Folgenden soll anhand von Matrizenanalysen und Chi-Quadrat-Tests die Frage beantwortet werden, ob auch ein Zusammenhang zwischen dem baulichen Erhaltungszustand der Häuser im Sample und dem Anteil der Bewohner mit Migrationshintergrund nachweisbar ist.

Bereits die bivariate Analyse lässt auf Basis des Zustands der Fassaden auf einen Konnex schließen: Die höchsten Anteile (10,1\% und 16,1\%) stark devastierter Fassaden finden sich in jenen beiden Kategorien von Gebäuden mit den höchsten Anteilen (50-74,9\% und 75-100\%) von Familiennamen, die auf Bewohner mit Migrationshintergrund schließen lassen. In diesen beiden Kategorien sind auch die Anteile teilweise beschädigter Fassaden am höchsten (54,6 bzw. 57,5\%). 
Foto 9: Haus der schlechtesten Zustandskategorie, Innenansicht mit Bassena, 1160 Wien

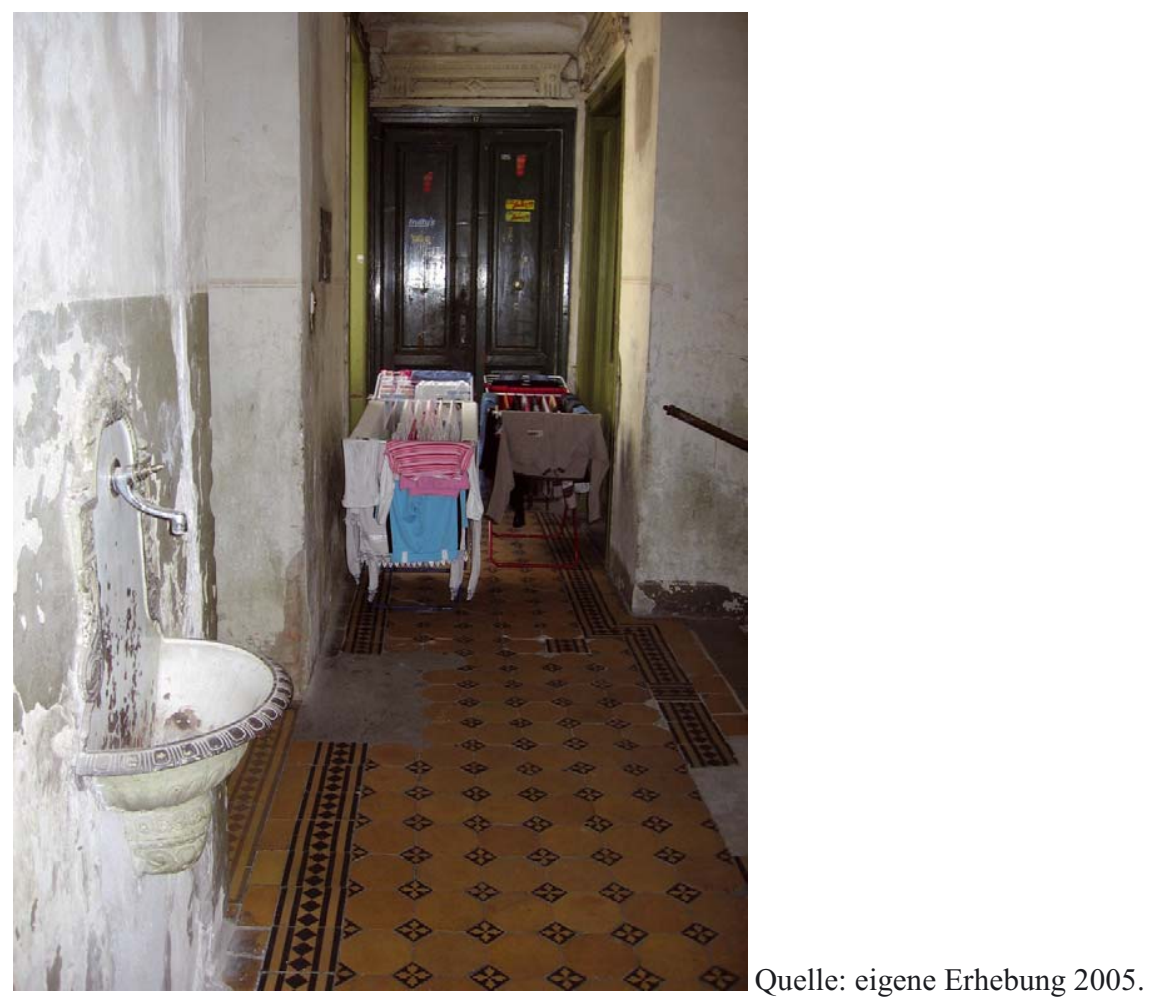

Konträr dazu präsentiert sich der bauliche Erhaltungszustand jener Gebäude mit den geringsten Anteilen an Bewohnern mit Migrationshintergrund. Die stärkste Präsenz in Ordnung befindlicher Fassaden (58,9\%) liegt in Häusern mit 0,1 bis 14,9\% ausländischen Familiennamen vor. In dieser Kategorie sind auch die stark beschädigter Fassaden mit nur 4,7\% am seltensten.

Nicht ganz so konsistent fallen die Verteilungen in den anderen Bewohnerklassen aus, sodass sich die Durchführung eines Chi-Quadrat-Tests als opportun erweist. Der Wert für Chi-Quadrat (nach Pearson) von 34,722 dokumentiert einen signifikanten Konnex zwischen der Zahl Bewohner mit Migrationshintergrund und dem baulichen Zustand der Fassade.

Ist ein analoger Zusammenhang hinsichtlich des Zustands des Hausflurs nachzuweisen? Bereits die Kreuztabellenanalyse legt die Schlussfolgerung nahe, dass ein solcher Konnex bestehen könnte. Die Kategorie mit dem höchsten Anteil ausländischer Familiennamen (75-100\%) weist zugleich die höchste Präsenz (50\%) stark beschädigter sowie den geringsten Anteil $(11,5 \%)$ in Ordnung befindlicher Hausflure auf. Konträr dazu entfällt auf jene Häuser, in denen kein einziger Migrantenname auf 
dem Klingelbrett aufscheint, mit 59,7\% der höchste Anteil an in Ordnung befindlichen Hausfluren. In dieser Kategorie zeigen auch bloß 11,3\% der klassifizierten Hausflure starke bauliche Schäden. Der Trend ist also eindeutig nachweisbar: Je höher der Migrantenanteil im Haus, desto schlechter der Zustand der Hausflure. Die Anteile stark beschädigter Flure steigen von 11,3\% bei keinem Migranten im Haus auf 19,2\% bei $25-49,9 \%$ Migranten, weiter auf $22,8 \%$ bei $50-74,9 \%$ Zuwanderern und schließlich auf $50 \%$ bei $75-100 \%$ Immigranten. Simultan dazu sinken die Anteile völlig in Ordnung befindlicher Flure von fast $60 \%$ bei rein österreichischer Bewohnerschaft auf 44,4\% bei 15-24,9\% ausländischen Namen und weiter auf ein Drittel $(33,1 \%)$ bei 25 $49,9 \%$ Migranten und schließlich auf $11,5 \%$ in Gebäuden mit $75-100 \%$ Zuwanderern.

Neuerlich dokumentiert der Chi-Quadrat-Test auf der Basis von 552 gültigen Fällen und mit einem Wert von 93,814 für Qui-Quadrat nach Pearson einen signifikanten Zusammenhang.

Hinsichtlich des baulichen Erhaltungszustandes der jeweiligen Innenhöfe (soweit vorhanden) ist ein analoger Trend zu konstatieren wie bezüglich der Fassaden und des Hausflures, wobei sich dieser im Rahmen der Matrizenanalyse nicht ganz „sauber“ manifestiert. In den beiden Gebäudeklassen mit den geringsten Anteilen an Migrantenfamilien belaufen sich die Anteile stark beschädigter Innenhöfe auf 5,6\% sowie 3,6\% - sie sind also erheblich niedriger als bei höherer Präsenz zugewanderter Bewohner im betreffenden Haus. Mit einem Anteilswert von 27,6\% stark devastierter Höfe wird der Spitzenwert in der Kategorie von 75 bis $100 \%$ Zuwanderern erreicht. In den drei Klassen mit Migrantenanteilen zwischen 15 und 74,9\% präsentieren sich die Anteile verwahrloster Innenhöfe als nahezu ident. Etwas deutlicher manifestiert sich der Zusammenhang zwischen Hofzustand und Bewohnerstruktur bei den baulich in Ordnung befindlichen Innenhöfen. Der niedrigste Anteil wird hier mit bloß 10,5\% in jenen Gebäuden erreicht, in welchen 75 bis 100\% der Familiennamen auf einen Migrationshintergrund der Bewohner hindeuten. Konträr dazu sind bei keinem ausländischen Namen im Haus 31,5\% der Innenhöfe baulich in Ordnung, bei 0,1 bis 14,9\% Migrantenfamiliennamen sogar fast $37 \%$.

Der auf der Basis von 498 gültigen Fällen durchgeführte Chi-Quadrat-Test belegt mit einem Wert für Chi-Quadrat von 35,798 neuerlich die Signifikanz des Zusammenhanges auch für den Bauzustand der Innenhöfe.

Resümierend ist zu konstatieren, dass alle drei Zusammenhänge signifikant ausfallen. Damit ist die in der Kapitelüberschrift gestellte Frage mit einem eindeutigen „Ja“ zu beantworten. Es besteht also eine Korrelation zwischen dem Anteil im Haus ansässiger Parteien mit Migrationshintergrund und dem Zustand von Fassade, Flur und Innenhof. Je höher der Anteil von Hausparteien mit Migrationshintergrund, desto desolater präsentierte sich unserem Erhebungsteam in der Regel der bauliche Zustand dieser drei Bereiche. 


\subsubsection{Sanierungsmaßnahmen}

Aufgrund des nachgewiesenen Konnexes zwischen der Bewohnerstruktur und dem Erhaltungszustand der Gebäude lag die Schlussfolgerung nahe, dass auch ein Konnex zu den getätigten baulichen Sanierungsmaßnahmen bestehen könnte. In vielen Häusern haben umfangreiche Sanierungsmaßnahmen stattgefunden. Diese reichen vom Austausch der Fenster über den Neuanstrich von Fassade, Aufgängen etc. zur Innensanierung des Leitungssystems bis hin zum Dachbodenausbau.

Rezente Totalsanierungen sind mit einem Anteil von 3\% (19 Häuser) selten vorzufinden. In 76 Häusern $(12,1 \%)$ haben in letzter Zeit keinerlei sichtbare Sanierungen stattgefunden. An der überwiegenden Mehrzahl der erhobenen Wohngebäude (531 bzw. 84,8\%) wurden zumindest Teilsanierungen durchgeführt.

Mittels eines Mittelwertvergleichs treten bestehende Zusammenhänge zwischen der Bewohnerstruktur und baulichen Erhaltungsmaßnahmen hervor. Zunächst zur Kategorie der Totalsanierung: Mit einem Wert von 77,203 wird für die Komplettsanierung das höchste arithmetische Mittel für den Anteil österreichischer Namen an allen privaten Namen erreicht, während mit 5,681 der geringste Wert für den Anteil exjugoslawischer Namen an allen privaten Namen 2005 ausgewiesen ist. Die Kategorien des Anteils aller ausländischer Namen sowie aller ausländischen Namen exklusive der serbokroatischen sind mit 22,797 und 17,116 präsent.

Den Gegensatz dazu bilden die völlig absenten Sanierungsmaßnahmen. Zwar sind diese mit 51,783 ebenfalls in der Kategorie des Anteils der österreichischen Namen an allen Namen am höchsten (dies liegt an der Überrepräsentation von Häusern mit solcher Bewohnerstruktur im Sample und der Mittelwert ist in diesem Fall bei weitem niedriger als bei den Komplettsanierungen), knapp dahinter folgt mit einem arithmetischen Mittel von 48,217 aber die Kategorie des Anteils aller ausländischen Namen. Auch die Mittelwerte für den Anteil exjugoslawischer Namen $(27,262)$ und für alle ausländischen, aber nichtjugoslawischen Namen $(20,955)$ sind relativ hoch.

Unter den 531 Häusern mit Teilsanierungen waren wiederum vor allem solche mit vorwiegend österreichischer Bewohnerschaft $(65,478)$ vertreten. Der Mittelwert von 34,522 für die Klasse des Anteils aller ausländischer Namen weist in Häusern mit hohen nichtjugoslawischen Bewohneranteilen auf eine zwar schwächere, aber im Vergleich zur Totalsanierung auf eine verhältnismäßig regere Teilsanierungstätigkeit hin. Geringfügig darunter liegt der Zusammenhang des Ausmaßes partieller Sanierungen laut Mittelwert (16,571) mit dem Anteil aller nichtjugoslawischen ausländischen Familiennamen.

\subsubsection{Klassifikation nach Raumtypen - eine sozialräumliche Analyse}

Aufgrund der aus vorangegangenen Projekten gewonnenen Erfahrungen wurde auf der Basis der beiden diesbezüglich relevantesten Variaben aus der amtlichen Statistik, nämlich „Ausländeranteil, 1991 und 2001“ und „Bildungsstatus, 1991 und 2001“ eine 
Klassifikation von vier Raumtypen erstellt und sodann deren Verteilung für den gesamten Wiener Stadtraum festgestellt. ${ }^{29}$

Die vier Raumtypen sind folgendermaßen charakterisiert:

- Typ 1: Die Entwicklung von Ausländeranteil und Bildungsstatus erfolgte zwischen 1991 und 2001 unterdurchschnittlich (Lokalisation: vom öffentlichen Wohnbau dominierte Gebiete im Süden Wiens und Transdanubien).

- Typ 2: Entwicklung des Ausländeranteils zwischen 1991 und 2001 unterdurchschnittlich, Bildungsstatus überdurchschnittlich (Lokalisation: innere Bezirke und westlicher Stadtrand);

- Typ 3: Ausländeranteil überdurchschnittlich, Bildungsstatus unterdurchschnittlich (Lokalisation: Ring außerhalb des Gürtels, alte Arbeiterbezirke bzw. heutige Zuwandererwohngebiete);

- Typ 4: Ausländeranteil überdurchschnittlich, Bildungsstatus überdurchschnittlich (Lokalisation: „Nobelwohngebiete“ von Döbling und bürgerliche innere Bezirke).

Tabelle 16: Verteilung der Häuser nach dem baulichen Zustand von Fassade, Flur und Innenhof auf die vier Raumtypen, 2005

\begin{tabular}{lrrrrr}
\hline Zustand von Fassade, Flur und Hof & \multicolumn{7}{c}{ Raumtypen } \\
2005 summiert & 1 & 2 & 3 & 4 & ins. \\
\hline 3 (alles in Ordnung) & 8,6 & 21,8 & 8,1 & 13,6 & 12,6 \\
4 & 19,8 & 21,8 & 9,1 & 25,0 & 16,9 \\
5 & 22,2 & 28,6 & 22,2 & 33,0 & 25,7 \\
6 (Beschädigungen in allen Bereichen) & 49,4 & 27,7 & 60,6 & 28,4 & 44,9 \\
insgesamt abs. & 81 & 119 & 198 & 88 & 486 \\
insgesamt in \% & 100,0 & 100,0 & 100,0 & 100,0 & 100,0 \\
\hline
\end{tabular}

Quelle: eigene Erhebung 2005.

$35,9 \%$ der in der Erhebung berücksichtigten Gebäude sind dem Raumtypus 3 zuzuordnen, befinden sich also in den ehemaligen „working class districts“ außerhalb des Gürtels. 26,8\% der Häuser sind in Raumtypus 2 lokalisiert, welcher die Wiener Innenbezirke sowie den westlichen Stadtrand umfasst. Hierbei handelt es sich um traditionell bürgerliche Wohnbezirke mit einem überdurchschnittlichen Bildungs- und sozioökonomischen Status der Wohnbevölkerung, in denen die Anteile der Bevölkerung mit Migrationshintergrund unter dem Wiener Durchschnittswert angesiedelt sind. Exakt 19\% der erhobenen Baulichkeiten befinden sich in Raumtypus 4, der durch überdurchschnittliche Ausländeranteile in Kombination mit einem über durchschnittli-

29 Vgl. die Beiträge der Autoren im Rahmen des Forschungsschwerpunkts „Fremdenfeindlichkeit" des bm:bwk. 
chen Bildungsstatus der Bewohner charakterisiert wird. Dieser Raumtypus prägt insbesondere die klassischen Cottage- und Nobelbezirke, wie Döbling, Währing und Hietzing, tritt aber auch in den Innenbezirken auf. Mit 18,2\% nur geringfügig schwächer vertreten ist Raumtypus 1, in welchem die Entwicklung von Ausländeranteil und Bildungsstatus zwischen den Volkszählungsjahren 1991 und 2001 unterdurchschnittlich verlief. Diese Raumkategorie prägt vor allem die Bezirke jenseits der Donau sowie den Süden Wiens mit seinen flächenmäßig ausgedehnten Neubaugebieten, in welche Migranten in einem geringeren Maße und vor allem stärker erst seit den 1990er Jahren eingesickert sind.

Der Erhaltungszustand der untersuchten Häuser weist je nach Raumtypus charakteristische Variationen auf (vgl. Tab. 16). Raumtypus 2 weist mit 21,8\% den höchsten Anteil an Gebäuden der besten Zustandskategorie 3 auf. In den Nobelbezirken (Raumtypus 4) konnten 13,6\% der erhobenen Häuser der besten Erhaltungskategorie zugeordnet werden. Mit jeweils über $8 \%$ ist diese Zustandsklasse in den Raumtypen 1 und 3 , also sowohl in den Neubaugebieten als auch in den traditionellen Gastarbeiterbezirken, am schwächsten repräsentiert. Die höchste Präsenz der schlechtesten Erhaltungszustandsklasse (6) entfällt mit 60,6\% auf Raumtypus 3, also die klassischen Ausländerbezirke. Mit 49,4\% Gebäuden der Zustandskategorie 6 sind starke Beschädigungen der Bausubstanz der untersuchten Häuser auch in Raumtypus 1, also im Süden Wiens und jenseits der Donau, in einem hohen Ausmaß nachweisbar. In den Raumklassen 2 und 4 belaufen sich die Anteile der schlechtesten Zustandskategorie auf Werte von jeweils um die 28\%. Summiert man die Anteile der beiden schlechtesten Erhaltungskategorien 5 und 6 auf, so tritt Raumtypus 3 als jener mit der höchsten Präsenz $(82,8 \%)$ von in schlechtem Bauzustand befindlichen Gebäuden hervor. An zweiter Stelle folgt Raumtypus 1 mit 71,6\%. Die Innenbezirke sowie der westliche Stadtrand (Raumtypus 2) weisen mit 56,3\% den niedrigsten Anteil von Gebäuden der Erhaltungsklassen 5 und 6 auf.

\section{Zusammenfassung}

Im Rahmen unseres Forschungsvorhabens wurde die Verteilung der Migrantenbevölkerung aus dem ehemaligen Jugoslawien im Wiener Stadtraum im Vergleich zwischen den Jahren 1981 und 2005 analysiert. Von der Erhebung des Jahres 1981 unter E. Lichtenberger waren 750 Hauserhebungsbögen im Archiv des Instituts für Stadtund Regionalforschung vorhanden. Aus Gründen der Vergleichbarkeit erwies es sich 2005 als möglich, 696 Häuser in die Analysen einzubeziehen. Das Sample umfasste damals Wohnhäuser, in denen 1981 ein oder mehrere jugoslawische Gastarbeiterhaushalte ansässig waren, verteilt über sämtliche Wiener Gemeindebezirke. Die Stichprobenziehung der Ersterhebung erfolgte auf der Grundlage von Meldedaten der Fremdenpolizei. Der Wohndistribution der exjugoslawischen Gastarbeiterbevölkerung im 